NBER WORKING PAPER SERIES

\title{
THE LIQUIDITY SENSITIVITY OF HEALTHCARE CONSUMPTION: EVIDENCE FROM SOCIAL SECURITY PAYMENTS
}

\author{
Tal Gross \\ Timothy Layton \\ Daniel Prinz \\ Working Paper 27977 \\ http://www.nber.org/papers/w27977 \\ NATIONAL BUREAU OF ECONOMIC RESEARCH \\ 1050 Massachusetts Avenue \\ Cambridge, MA 02138 \\ October 2020
}

We are grateful to Anikó Bíró, Amitabh Chandra, Rena Conti, Salama Freed, Andrew GoodmanBacon, Jon Gruber, Ben Handel, Anupam Jena, Michael McWilliams, Tom Mroz, Joe Newhouse, Matt Notowidigdo, Analisa Packham, Maria Polyakova, Elena Prager, Mark Shepard, Liyang Sun, Amanda Starc, Justin Sydnor, Boris Vabson, and seminar participants at Duke Fuqua, the Federal Reserve Bank of Boston, Harvard Medical School, the University of Hong Kong, the Whistler Health Economics Summit, the BU-Harvard-MIT Health Economics Seminar, Georgia State University, APPAM, ASHEcon, the Notre Dame Health Economics Conference, the Annual Health Economics Conference at the University of California, San Francisco, the Annual Southeastern Health Economics Study Group at the University of Tennessee, Knoxville, the Hungarian Economic Association Annual Conference, the Midwest Health Economics Conference at the University of Wisconsin, Madison, and the International Online Public Finance Seminar for useful feedback. Julia Yates provided superb research assistance. Research reported in this publication was supported by the National Institute on Aging of the National Institutes of Health under Award Number P30AG012810 through the National Bureau of Economic Research Center for Aging and Health Research. The content is solely the responsibility of the authors and does not necessarily represent the official views of the National Institutes of Health. The views expressed herein are those of the authors and do not necessarily reflect the views of the National Bureau of Economic Research.

At least one co-author has disclosed a financial relationship of potential relevance for this research. Further information is available online at http://www.nber.org/papers/w27977.ack

NBER working papers are circulated for discussion and comment purposes. They have not been peer-reviewed or been subject to the review by the NBER Board of Directors that accompanies official NBER publications.

(C) 2020 by Tal Gross, Timothy Layton, and Daniel Prinz. All rights reserved. Short sections of text, not to exceed two paragraphs, may be quoted without explicit permission provided that full credit, including (C) notice, is given to the source. 
The Liquidity Sensitivity of Healthcare Consumption: Evidence from Social Security Payments

Tal Gross, Timothy Layton, and Daniel Prinz

NBER Working Paper No. 27977

October 2020

JEL No. G5,H0,I1,I13

\begin{abstract}
Some consumers lack the cash needed to pay for medical care. As a result, they either delay care until they can pay for it or they forgo the care altogether. To test for such a possibility, we study the distribution of monthly Social Security checks among Medicare Part D enrollees. When Social Security checks are distributed, prescription fills increase by 6-12 percent. In that sense, drug consumption of low-income Medicare recipients is "liquidity sensitive." We then study recipients who transition onto a program that eliminates copayments. When those recipients do not face copayments, their drug consumption becomes less liquidity sensitive. That finding implies that, beyond risk protection, generous insurance also provides recipients with the ability to consume healthcare when they need it rather than when they have cash. Further, we find that recipients whose drug consumption is most liquidity sensitive exhibit price elasticities of demand that are twice the size of the average elasticity, suggesting that more-generous insurance causes recipients both to re-time prescription filling and also to start filling prescriptions that they otherwise would not fill. We present a stylized model that uses this finding to call into question the conventional interpretation of demand-response to price as solely inefficient moral hazard.
\end{abstract}

Tal Gross

Questrom School of Business

595 Commonwealth Ave.

Boston, MA 02215

and NBER

talgross@bu.edu

Timothy Layton

Harvard Medical School

Department of Health Care Policy

180 Longwood Avenue

Boston, MA 02115

and NBER

layton@hcp.med.harvard.edu
Daniel Prinz

National Bureau of Economic Research

1050 Massachusetts Avenue

Cambridge, MA 02138

dprinz@g.harvard.edu 
There exists broad agreement among economists that health insurance ought to involve some form of cost sharing: copayments, coinsurance rates, or deductibles. Theory suggests that cost sharing can limit moral hazard (Zeckhauser, 1970), and empirical evidence confirms that cost sharing reduces spending (Manning et al., 1987; Aron-Dine et al., 2013; Shigeoka, 2014; Brot-Goldberg et al., 2017). Indeed, motivated by that evidence, high-deductible health insurance plans have become increasingly common in the United States. Over only ten years, the share of firms offering such plans increased from 4 percent to nearly 30 percent (Kaiser Family Foundation, 2018). Among lower-income Americans, even some state Medicaid programs have introduced cost-sharing mechanisms for some services or prescription drugs (Kaiser Family Foundation, 2019).

Those cost-sharing mechanisms may introduce a particular challenge for lowincome consumers. A large literature suggests that many low-income households wait to consume until their income arrives. Olafsson and Pagel (2018), for instance, find that low-income consumers purchase 70 percent more goods on days when they receive their paychecks. That finding is consistent with many other studies: consumption responds to both predictable and unanticipated changes in income. ${ }^{1}$ One might call such a pattern "liquidity sensitivity:" consumers often delay many of their purchases until their income arrives.

Liquidity sensitivity may be especially problematic in the context of healthcare. In healthcare, consumers are advised to purchase treatments at a time determined by medical necessity, not determined by the arrival of their income. And yet, a third of Americans report that in the past year they "skipped filling a prescription due to its cost" (Goetz, 2018). That pattern is not entirely driven by the uninsured. Among Americans who report being in poor health but are covered by health insurance, 16 percent report that in the past year they "delayed medical care due to cost." ${ }^{2}$

There exist, however, no empirical studies that provide credible evidence of liquidity sensitivity in healthcare. And yet, such evidence could lead to substantial implications for policy. If consumers often delay welfare-enhancing healthcare until their income arrives, then such behavior alone would suggest that insurance contracts should be more generous than they should be in the absence of such behavior. The optimal insurance contract is typically viewed as one trading off risk protection

\footnotetext{
${ }^{1}$ See the work of Parker (1999), Souleles (1999), Stephens (2003), Johnson et al. (2006), Agarwal et al. (2007), Parker et al. (2013), Agarwal and Qian (2014), Gross and Tobacman (2014), Baugh and Wang (2018), and Gross et al. (2020).

${ }^{2}$ Authors' calculations based on the 2017 National Health Interview Survey.
} 
against moral hazard (Zeckhauser, 1970). That formulation may be incomplete for liquidity-sensitive households. In the presence of liquidity sensitivity, an additional benefit of generous insurance coverage must be considered: more-generous coverage allows consumers to avoid having to delay their healthcare until the receipt of their income. With generous coverage, recipients can consume healthcare when they need it, rather than waiting for their income to arrive. ${ }^{3}$

In this paper, we provide empirical evidence of liquidity sensitivity in healthcare consumption. ${ }^{4}$ Specifically, we estimate how the prescription fills of Medicare recipients are affected by income receipt. To do so, we study the distribution of Social Security checks. Since 1997, Social Security recipients have received their monthly checks on a pre-determined schedule based on the day of the month that they were born. This system allows researchers to compare Social Security recipients who just received their check to recipients who are quasi-randomly assigned to receive their checks a week or two later. ${ }^{5}$ We compare the prescription-drug purchases of each Medicare recipient around the day they receive their checks to the healthcare consumption of two control groups. First, we study similar Medicare recipients who receive their checks on a different date. Second, we study Medicare recipients who are enrolled in a program that fully subsidizes their copayments. These comparisons allow us to isolate the effect of receiving Social Security checks on the consumption of Medicare-covered drugs.

The results, first and foremost, reject the hypothesis that the receipt of income has no effect on healthcare consumption. Prescription drug fills for low-income Medicare Part D recipients who face small copayments of only $\$ 2-\$ 5$ increase by over 10 percent on the day they receive their Social Security checks. We observe that effect overall, for all drugs, and also for drugs for which short-term non-adherence can have important health consequences: blood thinners, insulin, anti-psychotics, and antiseizure medications. We also observe this effect for a recipient's first fill of a drug, not just for refills, implying that recipients are not only delaying purchases but also consumption. By constrast, when recipients enroll in a different part of the program that provides zero out-of-pocket prices, their fills exhibit no such increase on the day

\footnotetext{
${ }^{3}$ Ericson and Sydnor (2018) and Malani and Jaffe (2018) develop theoretical models of this.

${ }^{4}$ We use the phrase "liquidity sensitivity" throughout the paper, rather than referring to liquidity constraints. We do so because the results indicate that drug consumption is "sensitive" to liquidity, but they do not prove the existence of a binding constraint. Section 4 discusses the possible mechanisms driving the results.

${ }^{5}$ Stephens (2003), Evans and Moore (2011), Leary and Wang (2016), and Baugh and Wang (2018) use the distribution of Social Security checks to study outcomes other than healthcare consumption.
} 
they receive their checks. Further, a particular feature of the Social Security checkdistribution schedule provides an additional source of variation: two-thirds of checks arrive 28 days after the previous check, and the remaining one-third of checks arrive 35 days after the previous check. Among recipients facing positive copayments, we find a larger increase in prescriptions filled when checks arrive after 35 days rather than after 28 days. We also find a clear gradient in the size of the effect by income: Medicare recipients who live in the lowest-income ZIP Codes increase their prescription fills when they receive their Social Security checks by roughly five times more than those living in the highest-income ZIP Codes.

We then assess the extent to which more-generous insurance coverage lessens liquidity sensitivity. To do so, we study transitions in which Medicare recipients move onto more-generous forms of prescription-drug coverage via the Low Income Subsidy (LIS) program. We study recipients who move from facing full or subsidized copayments that average around $\$ 7-8$ per prescription fill to facing no copayment at all. We use those transitions both to estimate recipients' price elasticity of demand for prescriptions and to study how more-generous coverage affects liquidity sensitivity.

That exercise suggests that higher copayments lead to greater liquidity sensitivity. Medicare recipients are more likely to fill prescriptions on the day they receive their Social Security checks when they face copayments versus when they do not. These findings suggest an additional benefit of full insurance for low-income recipients. The traditional view is that full insurance reduces the risk that consumers face by reducing the difference in their wealth across healthy and sick states of the world. This result suggests another benefit: full insurance eliminates liquidity sensitivity.

Finally, we use the transition to more-generous coverage to estimate a price elasticity of demand. Low-income recipients are price sensitive: they exhibit an overall price elasticity of demand of -0.064 . We then stratify recipients by the extent to which their drug consumption prior to transitioning to more-generous coverage exhibited sensitivity to liquidity. In particular, we divide recipients into groups based on the share of their Wednesday fills that occur on their Social Security payday. We show that this measure is a good proxy for a recipient's liquidity sensitivity. We find that the most liquidity-sensitive recipients exhibit a demand-response to more-generous coverage that is twice as large as the demand-response exhibited by other recipients. This is true for overall drug consumption and for consumption of high-value drugs that physicians believe are especially important for patient health.

These results indicate that liquidity-sensitive recipients do not solely respond to 
more-generous coverage by smoothing their consumption over time - they also respond to more-generous coverage by consuming more drugs. They increase their drug consumption in response to more-generous coverage by much more than other recipients with similar incomes but whose consumption does not exhibit liquidity sensitivity. Such a pattern is consistent with a model in which liquidity sensitivity acts as a friction that prevents consumers from purchasing drugs that they value more than the price, driving a wedge between their demand curve for drugs and their valuation of those drugs. That model implies that the conventional interpretation of a demand-response to more-generous insurance is incomplete. Typically, economists interpret a demand response as evidence of moral hazard, that is, inefficient overconsumption. Instead, this model suggests that more-generous insurance has two opposing effects for liquidity-sensitive recipients. First, more-generous coverage relaxes the liquidity-related friction that otherwise causes consumers to under-consume drugs. Second, more-generous coverage lowers the price of drugs below the cost of the drug, potentially causing consumers to "over-consume" drugs.

Those two effects must be compared in order to assess the optimal generosity of coverage. To illustrate this trade-off, we use our estimates to construct two marketlevel demand curves for prescription drugs. The first is the actual, realized demand curve in the market. The second is a "frictionless" demand curve that describes demand for prescription drugs were the liquidity-sensitive recipients not to face liquidityrelated frictions. Using those demand curves, we estimate the deadweight loss due to more-generous coverage under the conventional model and, alternatively, a model incorporating liquidity sensitivity. That exercise requires strong assumptions about homogeneity of preferences between liquidity-sensitive and liquidity-insensitive recipients and a lack of other frictions faced by the insensitive recipients. Nevertheless, it suggests that liquidity-related frictions partially offset the deadweight loss due to moral hazard.

This paper contributes to research that documents the relationship between the timing of income and consumption. Previous studies have demonstrated that consumers often change their behavior after income shocks, even when those income shocks are anticipated. Some studies have exploited the distribution of Social Security checks, as we do. Stephens (2003), for instance, documents that the distribution of Social Security checks affects total consumption, while Leary and Wang (2016) and Baugh and Wang (2018) focus on financial outcomes, such as the takeup of payday loans. Evans and Moore (2011) demonstrate that the distribution of Social Security 
checks increases short-run mortality. Other studies explore how the arrival of paychecks and government benefits affect food consumption (Shapiro, 2005; Beatty et al., 2019), retailers' responses (Hastings and Washington, 2010; Cheng and Beatty, 2016; Goldin et al., 2019), hospitalizations (Dobkin and Puller, 2007), crime (Foley, 2011), financial decision-making (Carvalho et al., 2016), and aggregate economic activity (Berniell, 2019). Still other studies focus on income shocks that are less anticipated, such as tax rebates and fiscal-stimulus payments. Such studies also uncover significant effects of income receipt on consumption and financial outcomes (Gross and Souleles, 2002; Johnson et al., 2006; Stephens, 2006; Agarwal et al., 2007; Bertrand and Morse, 2009; Agarwal and Qian, 2014; Baugh et al., 2014; Kaplan and Violante, 2014; Carvalho et al., 2016; Baker and Yannelis, 2017; Zhang, 2017; Vellekoop, 2018; Gelman et al., 2019).

This paper is also related to a growing literature on the optimal design of health insurance in particular and social insurance more generally. Most closely related to this paper, Ericson and Sydnor (2018) and Malani and Jaffe (2018) explore theoretical models of health insurance and liquidity constraints. Baicker et al. (2015) discuss optimal cost-sharing mechanisms when healthcare consumption is shaped by behavioral biases, similar to the liquidity-related frictions we document. A related issue is the "access motive" for health insurance: the idea that health insurance not only protects against financial risks but also makes otherwise-unaffordable healthcare accessible (de Meza, 1983; Nyman, 1999). Finally, our paper contributes to a growing literature on health insurance and consumer financial outcomes such as bankruptcy (Mahoney, 2015; Dobkin et al., 2018) and debt (Barcellos and Jacobson, 2015; Mazumder and Miller, 2016; Hu et al., 2018; Goldsmith-Pinkham et al., 2020), as well as recent work on demand for health insurance among low-income households (Finkelstein et al., 2019). These studies grapple with how the traditional economic model of insurance ought to incorporate new findings from the consumption literature and behavioral economics.

As described in Section 4.1, below, the behavior this paper documents may be driven by either straightforward liquidity constraints or, alternatively, behavioral biases. To the extent that the results are driven by the latter, then this paper is related to a growing literature on behavioral biases and health insurance. Much of the research focuses on plan choice and switching costs (Abaluck and Gruber, 2011; Ketcham et al., 2012; Handel, 2013; Polyakova, 2016). Several related studies also explore the demand for drugs under Medicare Part D more generally (Einav et al., 
2015, 2018) and general demand responses to cost sharing (Chandra et al., 2010; Brot-Goldberg et al., 2017). This paper's results illustrate a mechanism that may be at play in many of those studies. Consumers often make decisions that seem selfdefeating. For instance, they cut back on both high-value and low-value healthcare and some forgo insurance coverage altogether. One specific friction at play in generating these results may be liquidity sensitivity. Indeed, Section 4.3, below, shows that liquidity sensitivity drives a small, but non-trivial fraction of this type of behavior.

Beyond health insurance, as Chetty and Finkelstein (2013) highlight, most of the previous studies on liquidity and social insurance focus on unemployment insurance (Hansen and Imrohoroglu, 1992; Gruber, 1997; Card et al., 2007; Chetty, 2008; Centeno and Novo, 2009; LaLumia, 2013). This paper explores how those issues should be considered in the context of health insurance and provides evidence that they are empirically important.

The remainder of the paper proceeds as follows. Section 1 provides background on the Social Security benefit schedule, the Medicare Part D program, and the data we use. We then present our empirical results in two pieces. First, Section 2 describes how the distribution of Social Security checks affects overall prescription drug purchases. Second, Section 3 describes how Medicare recipients who have their copayments eliminated change the pattern in which they fill their prescriptions. Finally, Section 4 describes the implications of the results for the optimal structure of health insurance and Section 5 concludes.

\section{Background and Data}

This section provides background on the setting we study and the data we use. We first review how Social Security checks are distributed. We then describe Medicare Part D and the utilization data we study.

\subsection{The Distribution of Social Security Checks}

Since 1997, Social Security benefits have been distributed to recipients according to a schedule that is based on recipients' dates of birth. Recipients with birthdays on the $1^{\text {st }}$ through the $10^{\text {th }}$ of the month receive their checks on the second Wednesday of each month; recipients with birthdays on the $11^{\text {th }}$ through $20^{\text {th }}$ of the month receive their checks on the third Wednesday of each month; and recipients with birthdays on the $21^{\text {st }}$ through $31^{\text {st }}$ of the month receive their checks on the fourth Wednesday of 
each month. The only deviations occur when federal holidays fall on Wednesdays. In those rare cases, payments are made one day early.

Two-thirds of checks arrive 28 days after the previous check, but one-third of checks arrive 35 days after the previous check. ${ }^{6}$ Checks would always arrive after 28 days were all months to have precisely 28 days. The irregular structure of the calendar leads to occasional five-week gaps between the second, third, or fourth Wednesday of one month and the corresponding Wednesday of the next month. For example, in 2019 recipients received their paychecks after five weeks in February, June, August, and November. ${ }^{7}$

Since March of 2013, all Social Security recipients have been required to receive their benefits electronically, via direct deposit. Even before that law went into effect, most recipients relied on direct deposit. In early 2012, 94 percent of Social Security checks were distributed via direct deposit (O'Carroll, 2012). The funds thus flow electronically from the Social Security Administration to recipients' banks. Banks then make the funds available to recipients on their scheduled paydays. However, there exists one complication. Some banks provide recipients with the funds the day before their official payday. ${ }^{8}$ As a result, below, we find some response to Social Security paychecks the day before payments are supposed to be distributed.

\subsection{Medicare Part D}

To study prescription drug consumption, we use data on a 20-percent sample of recipients enrolled in Medicare Part D, a federal program which provides insurance for prescription drugs to elderly and disabled Americans. In Medicare Part D, recipients choose among private plans, but the federal government provides subsidies for premiums and cost sharing depending on recipients' income.

We rely on several datasets for our analysis: the Medicare recipient Summary File (100 percent), the Medicare Part D Drug Event File (20 percent), and the Medicare Inpatient (100 percent), Outpatient (100 percent), MedPAR (100 percent), and Carrier (20 percent) claims data. Those datasets cover the years 2006 through 2015. We observe recipients' exact dates of birth in the Summary File which allows us to

\footnotetext{
${ }^{6}$ Supplemental Security Income (SSI) payments are made on the first of the month; those who are eligible for both Social Security and SSI and those who were receiving benefits prior to May 1997 are paid on the third of the month.

${ }^{7}$ Appendix Figure A1 presents the flyer, distributed by the SSA, that publicized the 2019 checkdistribution schedule.

${ }^{8}$ We verified this phenomenon in discussions with experts at the Consumer Financial Protection Bureau.
} 
define the three Social Security payday groups described above. We also observe each recipient's geographic location (state, county, and ZIP Code), as well as whether they enroll in Medicare Parts A, B, C, and D. Importantly, we observe, for each month, whether they receive premium and copayment subsidies via the Medicare Part D Low Income Subsidy (LIS) program.

The LIS program subsidizes premiums and copayments to varying degrees. We divide recipients into three main categories. First, there are recipients who face no copayments. That group consists of individuals enrolled both in Medicare and Medicaid. These individuals receive full premium subsidies and are not required to pay a copayment when filling a prescription. We call this group the "no-copay group." Second, there are recipients who face subsidized copayments. These recipients are sufficiently low income to qualify for subsidized copayments, but not Medicaid. This group actually consists of two separate categories. Some recipients are sufficiently low income to face heavily subsidized copayments: about $\$ 2$ for generic drugs and about $\$ 5$ for branded drugs. Other recipients have slightly higher incomes and so receive smaller subsidies. For simplicity, we combine all recipients receiving partial copayment subsidies into one group we refer to as the "subsidized-copay" group. ${ }^{9}$ Finally, third, there are all other recipients not enrolled in the LIS program, who face full copayments. We call this last group the "full-copay group." 10

Table 1 presents summary statistics for these three groups. The no-copay group fills slightly more prescriptions than the groups paying copayments. That difference may reflect a demand response to the lower out-of-pocket prices. But, of course, the difference could be driven by differences in health status across these groups, other differences in recipients' characteristics, or some combination of factors. The difference in out-of-pocket prices across the groups paying some copayments is clear in the table, with the average annual out-of-pocket spending equal to approximately $\$ 183$ in the subsidized-copay group, and $\$ 551$ in the full-copay group.

Two other patterns in Table 1 are noteworthy. First, we observe substantially more people in the full-copay group versus the other groups: over 3.7 million people in 2015 in the full-copay group, versus well under a million in the other two groups, combined. In the empirical results, below, this leads to much narrower confidence

\footnotetext{
${ }^{9}$ Appendix $\mathrm{C}$ presents the main results for those two sub-groups separately.

${ }^{10}$ There exists an additional group of recipients who pay zero copays and zero premiums. This group consists of Medicaid-Medicare-enrolled individuals who are institutionalized. For this group, copays are fully paid by the Medicare program. We exclude from the sample recipients in this group, since they are institutionalized and thus have limited discretion over the timing of their prescription-drug fills.
} 
intervals for estimates based on the full-copay group than for estimates based on the other groups.

Second, note that the average copayment faced by those in the subsidized-copay group is remarkably low: an average of $\$ 4.45$ per script. The $99^{\text {th }}$ percentile of the out-of-pocket-cost distribution is only $\$ 25.67$, and more than 90 percent of fills cost less than $\$ 9$. The small magnitude of the out-of-pocket costs these recipients face is important in interpreting some of the results below. Even though these recipients face relatively small out-of-pocket costs, some still seem to wait until their payday to fill their prescriptions. 
Table 1. Summary Statistics

\begin{tabular}{lccc}
\hline & $\begin{array}{c}\text { No } \\
\text { Copay }\end{array}$ & $\begin{array}{c}\text { Subsidized } \\
\text { Copay }\end{array}$ & $\begin{array}{c}\text { Full } \\
\text { Copay }\end{array}$ \\
\hline $\begin{array}{l}\text { Number of beneficiaries } \\
\text { in 20\% sample in 2006 }\end{array}$ & 213,080 & 20,305 & 479,900 \\
$\begin{array}{l}\text { Number of beneficiaries } \\
\text { in 20\% sample in 2015 }\end{array}$ & 678,447 & 143,779 & $3,788,347$ \\
$\begin{array}{l}\text { Mean total scripts } \\
\text { per year }\end{array}$ & 52.48 & 44.08 & 29.11 \\
$\begin{array}{l}\text { Mean out-of-pocket } \\
\text { spending per year }\end{array}$ & $\$ 0$ & $\$ 183.38$ & $\$ 550.67$ \\
$\begin{array}{l}\text { Mean out-of-pocket } \\
\text { spending per script }\end{array}$ & $\$ 0$ & $\$ 4.45$ & $\$ 20.19$ \\
$\begin{array}{l}\text { Mean share filling } \\
\text { a script each day }\end{array}$ & 0.064 & 0.058 & 0.048 \\
$\begin{array}{l}\text { Share male } \\
\text { Average age }\end{array}$ & 0.367 & 0.392 & 0.447 \\
$\begin{array}{l}\text { Average number of } \\
\text { chronic conditions }\end{array}$ & 70.35 & 70.31 & 70.71 \\
\begin{tabular}{l} 
Share white \\
\hline
\end{tabular} & 0.578 & 0.693 & 0.883 \\
\hline
\end{tabular}

This table presents summary statistics for the copay groups used in the analysis below. For more details, see Section 1.

\section{Overall Liquidity Effects for Prescription Drugs}

This section explores how the distribution of monthly Social Security checks affects Medicare-covered prescription-drug purchases. We first examine the total number of scripts filled on Social Security paydays. We then examine how the effect varies for different types of drugs and demographic groups. 


\subsection{Unadjusted Means}

We first study the effect of Social Security checks on prescription drug fills in the raw data. We assign each prescription-drug fill to "event time," that is, to days relative to the nearest date upon which the recipient receives their Social Security check. For each event day, we then calculate the logarithm of total scripts filled for those who receive their checks on the second Wednesday of each month. We subtract from that value the corresponding log-count for the same day for those who receive their checks on the fourth Wednesday of each month. Finally, we calculate the average of that difference for each event day. This calculation has the advantage of differencing out day-of-the-week-specific effects. ${ }^{11}$

Figure 1 presents the average differences by event day for the no-copay group and the subsidized-copay group. ${ }^{12}$ The diamond-shaped markers plot the results of this exercise for the subsidized-copay group. That plot suggests no major differences until the day before Social Security checks are distributed, when the number of scripts begins to increase for those approaching payday. ${ }^{13}$ The largest differential increase occurs on the day deposits are made. The number of scripts increases by roughly 11 percent on that day. The series then returns back to baseline within several days.

As a point of comparison, the figure presents the same exercise for the no-copay group. The circular-shaped markers in Figure 1 plot the re-centered time series for those recipients. For that group, there is no differential change in prescriptions filled when checks are distributed. Importantly, these recipients still receive Social Security checks on the same schedule - the key difference is that they are not required to pay copayments.

\footnotetext{
${ }^{11}$ Day-of-week effects are large: the number of scripts filled on Sunday is 11 percent lower than the number of scripts filled on Wednesday.

${ }^{12}$ Appendix Figure A4 presents the same analysis when the outcome is the share of recipients filling a script. Appendix Figure A5 presents the same analysis for the full-copay group. Appendix Figure A11 presents the same analysis separately for 28-day wait and 35-day wait periods.

${ }^{13}$ The effects we observe on the day prior to the check-disbursement date are consistent with discussions we had with experts at the Consumer Financial Protection Bureau, who indicated that many banks make these funds available to recipients on the day prior to the actual deposit date.
} 
Figure 1. The Effect of Social Security Checks on Total Scripts: Re-Centered Time Series

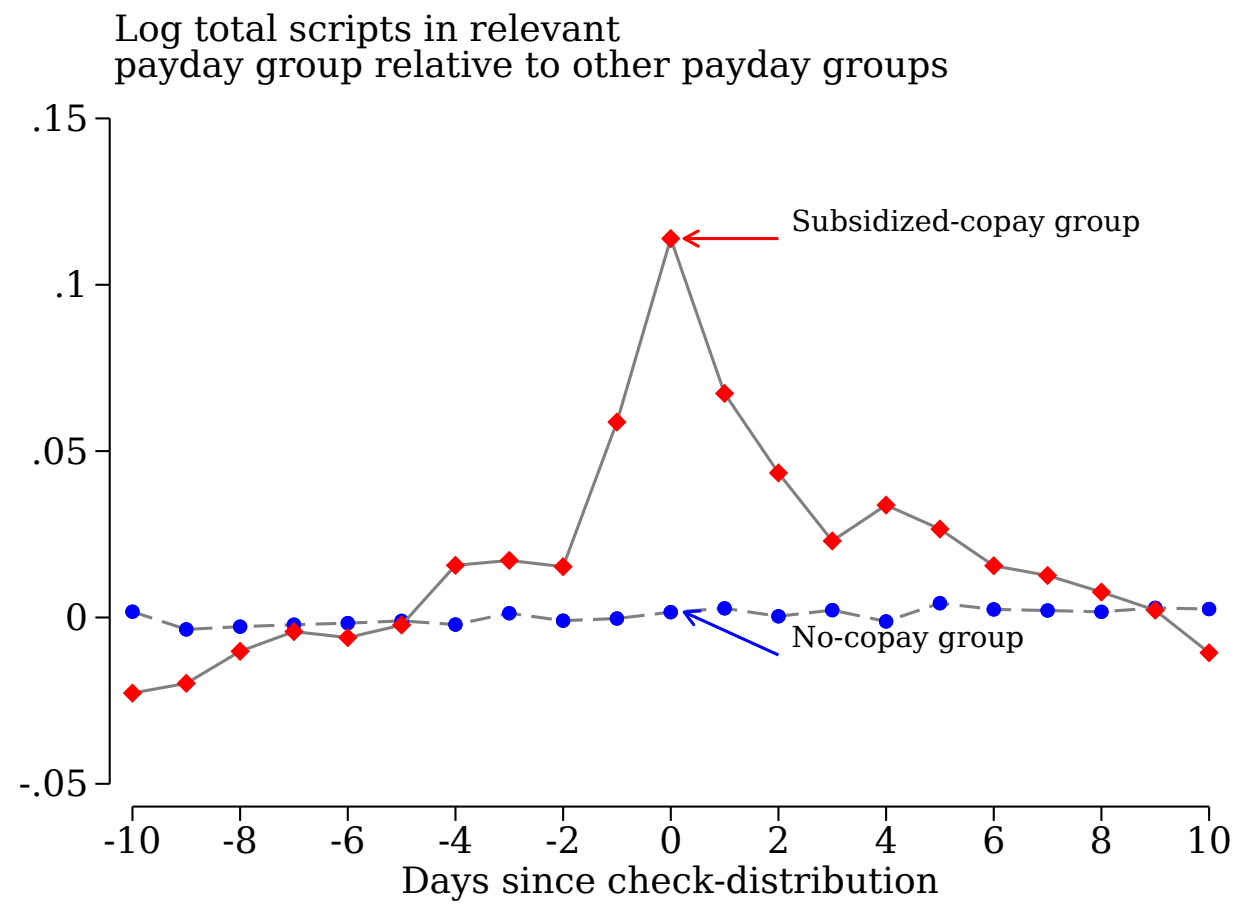

This figure plots mean differences in the logarithm of the number of prescriptions filled for the no-copay group and the subsidized-copay group. For each copay group and event day, we calculate the difference in these outcomes across recipients who are nearest to receiving a check and those who are two weeks from their check. For more details, see Section 2.1.

Appendix Figure A5 presents the same analysis for Medicare recipients who face full copayments. The figure demonstrates the same pattern over time for the fullcopayment group, but the magnitude of the increase in prescription fills is roughly half the magnitude as that in Figure 1 for the subsidized-copay group. For the fullcopayment group, total scripts increase by roughly 6 percent on the check-disbursement date.

\subsection{Regression Approach}

We next develop a regression specification. To do so, we rely on the non-parametric results in Figure 1 to guide us in choosing the appropriate model. That figure suggests that Social Security checks only affect prescription fills over a short, three-day period. We thus specify an event-study model that evaluates the effects of Social Security checks within five days of the distribution of the checks.

The regression compares utilization across 31 birthday groups, with each group 
defined by the day of month of the Medicare recipient's birthday. ${ }^{14}$ Denote the drug consumption on calendar-day $t$ by birthday group $g \in\{1,2, \ldots, 31\}$ as $Y_{t g}$. We assign each birthday group an event time for each calendar day, with event time, $\tau$, ranging from -5 to 5 , relative to the group's nearest check date. We then estimate the event-study regression:

$$
Y_{t g}=\alpha_{t}+\alpha_{g}+\sum_{\tau=-5}^{5} \beta_{\tau} \cdot I_{t g}^{\tau}+\varepsilon_{t g}
$$

Here, $I_{t g}^{\tau}$ is an indicator function equal to one if calendar-day $t$ is $\tau$ days away from the date of Social Security check receipt for those in birthday group $g$. In addition, $\alpha_{t}$ and $\alpha_{g}$ are full sets of calendar-day and birthday group fixed effects, respectively.

This regression amounts to a standard event-study specification tracking the consumption of birthday groups over time. To account for auto-correlation, we cluster the standard errors at the level of the birthday group. The objects of interest from this regression are the $\beta_{\tau}$ 's: coefficients that trace out the effect of Social Security checks on behavior just before and just after the checks arrive, using birthday groups with different check-disbursement dates to difference out any day-of-week, day-of-month, and day-of-year effects.

Figure 2 presents estimates of the $\beta_{\tau}$ 's for the subsidized-copayment group when the outcome of interest is the logarithm of the number of scripts filled. ${ }^{15}$ The point estimates suggest a statistically significant effect of Social Security checks. The number of prescriptions filled begins increasing on day -1 , hits a maximum on payday, and then declines. The magnitude of the day-zero estimate, $\beta_{0}$, suggests an 11-percent increase in scripts.

\footnotetext{
${ }^{14}$ The day of the month in which each recipient was born is the level of variation: the SSA matched those 31 groups to dates on which to distribute checks. And so we cluster the standard errors on those 31 groups (Abadie et al., 2017).

${ }^{15}$ Appendix Figure A7 presents the same analysis when the outcome is the logarithm of the number of recipients filling a script. Appendix Figure A8 presents the same event-study figure for the fullcopayment group. Appendix Figure A9 presents a version of the event-study figure that extends more days past the check-distribution dates.
} 
Figure 2. The Effect of Social Security Checks on Total Scripts: Event-Study Estimates

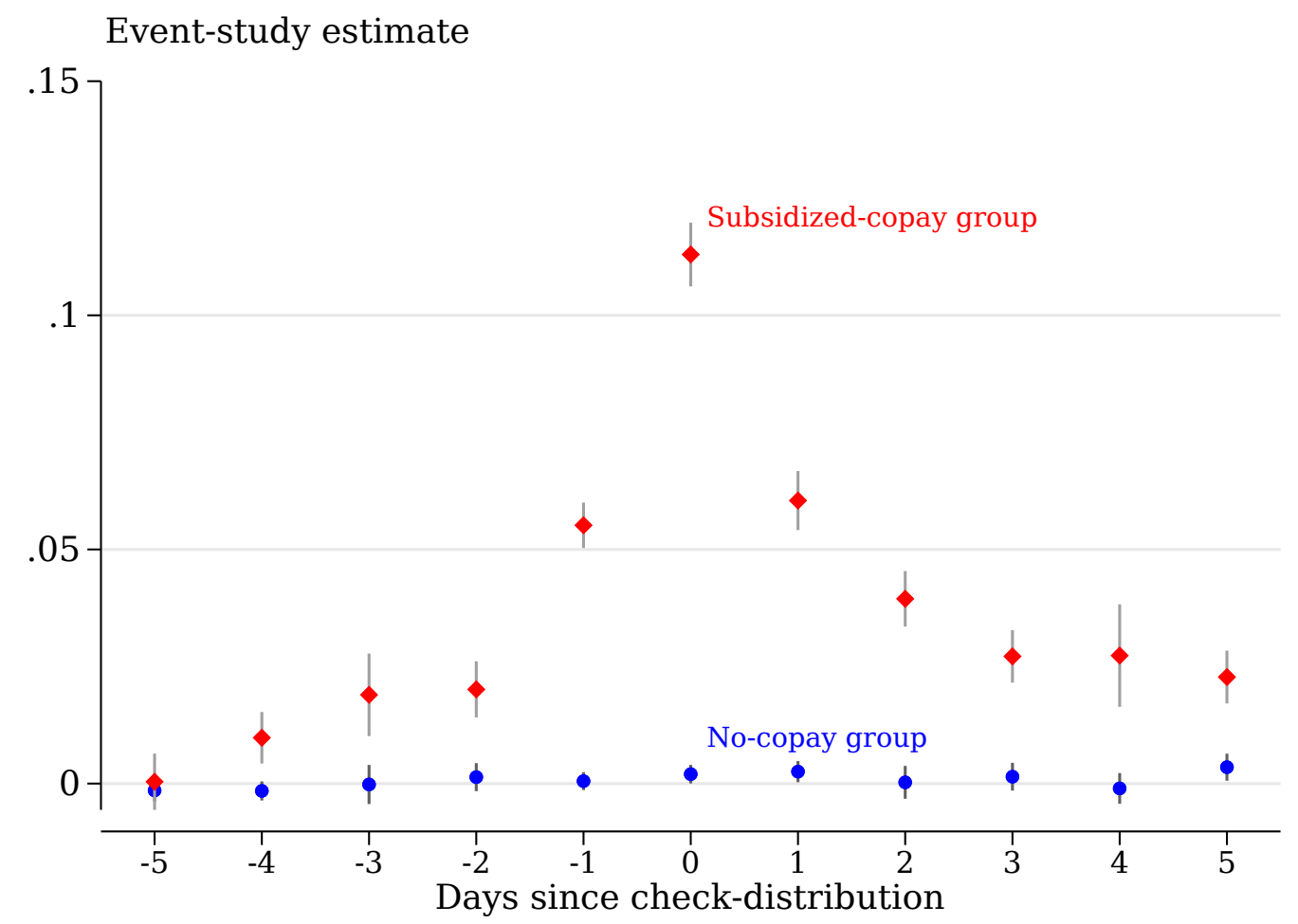

This figure plots estimates of equation (1), event-study estimates of the logarithm of total scripts filled for each event-time day relative to check receipt for the no-copay group and the subsidizedcopay group. The vertical lines across each marker plot 95-percent confidence intervals based on standard errors that are clustered at the level of the birthday group. For more details, see Section 2.2.

Figure 3 plots estimates of $\beta_{0}$ (the check-disbursement day effect) from equation (1) when the logarithm of total fills is the outcome of interest. The figure plots those estimates for each of three groups: those who face no copayments, those who face subsidized copayments, and those who face full copayments. For the group that does not pay copayments, we estimate a precise zero effect: the confidence interval rules out increases in fills larger than 0.4 percent. The effects for the other two groups are both economically and statistically significant: we estimate an increase in prescription fills of 11.3 percent for the subsidized-copay group and an increase of 6.1 percent for the full-copay group. 
Figure 3. The Change in Scripts Filled on Social Security Payday Across Copay Groups and Length of Time Between Checks

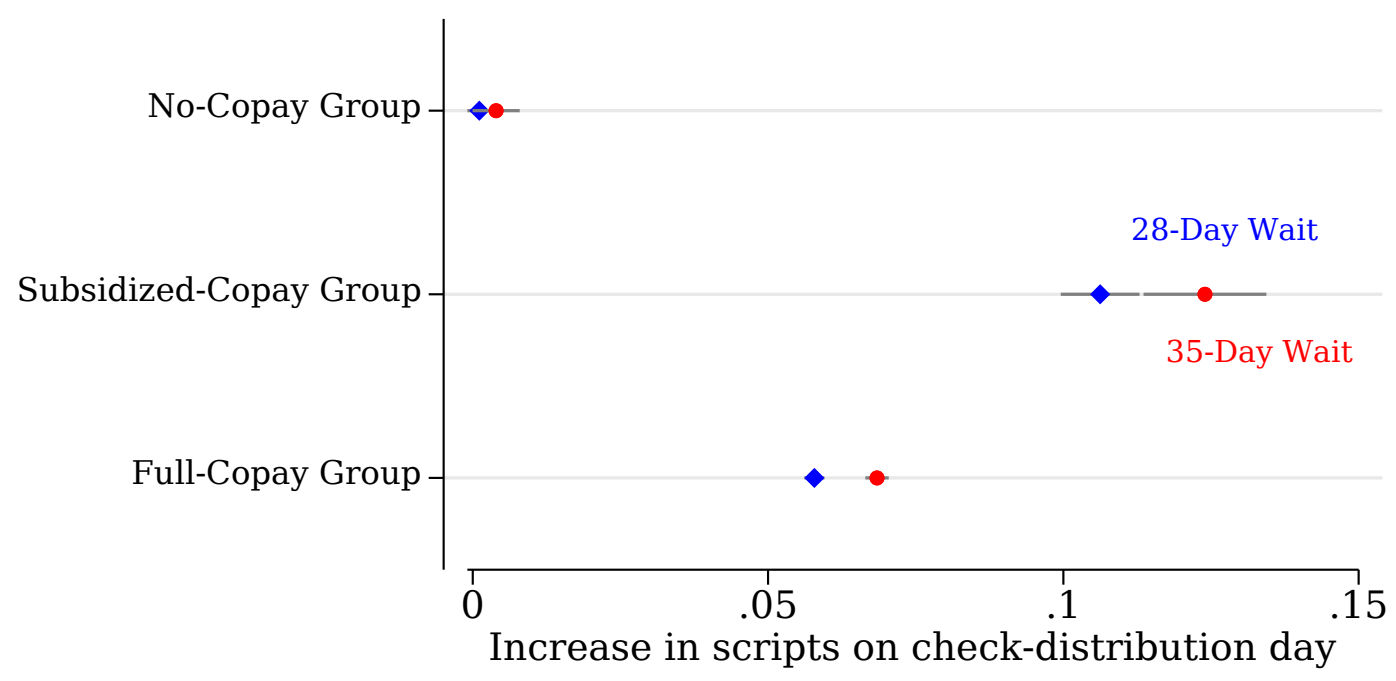

This figure plots estimates of $\beta_{0}$ from equation (1): the event-study coefficient for checkdistribution day when the outcome is the logarithm of the total scripts filled by copay group (no-copay group, subsidized-copay group, and full-copay group) and by the days since the last check (28-day wait and 35-day wait). The horizontal lines along each marker plot 95-percent confidence intervals based on standard errors that are clustered at the level of the birthday group. For more details, see Section 2.2.

Figure 3 also presents effects across the two different kinds of Social Security payments: those that arrive after a 28-day wait and those that arrive after a 35-day wait. ${ }^{16}$ We observe a larger increase in prescription-drug fills when it has been longer since recipients' last check was sent. For the subsidized-copay group, for instance, we observe an effect of 10.6 percent for checks arriving after a 28-day wait versus an effect of 12.4 percent for checks arriving after a 35-day wait.

It is natural to investigate the "missing mass" in scripts that would account for the increase on Social Security check-distribution days. Unfortunately, such an investigation would require much more statistical power than is available in this setting. For new scripts, We observe a 6-percent increase in new fills for the full-copay group on check-distribution day. ${ }^{17}$ Suppose that increase stemmed from consumers delaying their filling equally across five other days. In that case, we would expect a $6 / 5=1.2$ percent decrease in fills on those days. We do not have sufficient statistical power to

\footnotetext{
${ }^{16}$ Appendix Figure C1 presents the same results but for two sub-groups that comprise the subsidized-copayment group.

${ }^{17}$ We focus here on new scripts, because that avoids an additional complication. The time series for all fills tends to peak 30 days after the consumers' previous fill, because they have used up their pills. New fills does not involve that re-filling dynamic.
} 
detect such an effect.

\subsection{Heterogeneous Effects}

A remaining question involves treatment-effect heterogeneity. How does the effect of Social Security checks differ by the importance or expense of the drug in question? Are effects larger for certain groups of recipients? To address these questions, we estimate equation (1) separately for different types of drugs.

Figure 4 plots the estimated increase in scripts on the day that checks are distributed, among the subsidized-copay group, across different types of drugs. ${ }^{18}$ The first two rows suggest that, on Social Security paydays, fills increase more for branded drugs than for generic drugs. Next, we stratify drugs by whether or not they involve a large out-of-pocket cost for recipients. ${ }^{19}$ The results suggest a larger effect of Social Security checks for expensive drugs. Since branded drugs are typically more expensive, these two patterns are consistent with one another.

The next two rows present estimates that stratify drug purchases by whether the purchase is a recipient's first fill of the drug, or whether it is a refill of their prescription. The results indicate a significant effect for both refills and initial fills. The delay of a prescription refill does not necessarily imply that the recipient is going without drugs: they may be splitting pills or consuming from a stockpile of pills. But the delay of a first prescription fill implies that the recipient is going without drugs. ${ }^{20}$

Importantly, these results suggest that the distribution of Social Security checks increases the actual consumption of drugs. Of course, we only observe the filling of prescriptions, not the swallowing of pills. That said, if first prescription fills are delayed, consumption must be foregone. Similarly, the next two rows of Figure 4 show an effect of Social Security checks on both drugs that are taken routinely (chronic drugs) and also drugs that are taken for short episodes (acute drugs). ${ }^{21}$ The figure suggests a statistically significant effect of Social Security checks for both types of

\footnotetext{
${ }^{18}$ Appendix Figure A10 presents estimates for the full-copay group.

${ }^{19}$ For each drug, we calculate the average out-of-pocket cost for all Medicare recipients. We then categorize a drug as expensive if the average out-of-pocket cost is above the mean of this variable.

${ }^{20}$ Appendix Figure A11a further explores this issue. It plots actual scripts filled against "expected" scripts filled. "Expected scripts filled" is the number of prescriptions that would occur on that day if all recipients with a prior prescription consumed one pill per day and then filled the script as soon as they were out of pills. The figure shows a clear spike in actual fills on check-distribution day but no spike in expected fills on that day. This suggests that the effect of any one Social Security check is not a mechanical consequence of the last month's prescriptions.

${ }^{21}$ We define a drug as "chronic" if the median number of fills of the drug in a year among people with at least one fill of the drug is greater than 2 (Einav and Finkelstein, 2018).
} 
drugs. The effect on acute drugs is particularly troubling: the use of acute drugs is typically more medically urgent and patients are unlikely to have pills leftover from previous prescriptions. If consumers were simply re-timing purchases but not consumption, we might expect to see no effect for acute drugs.

Figure 4. Heterogeneous Effects Across Types of Drugs

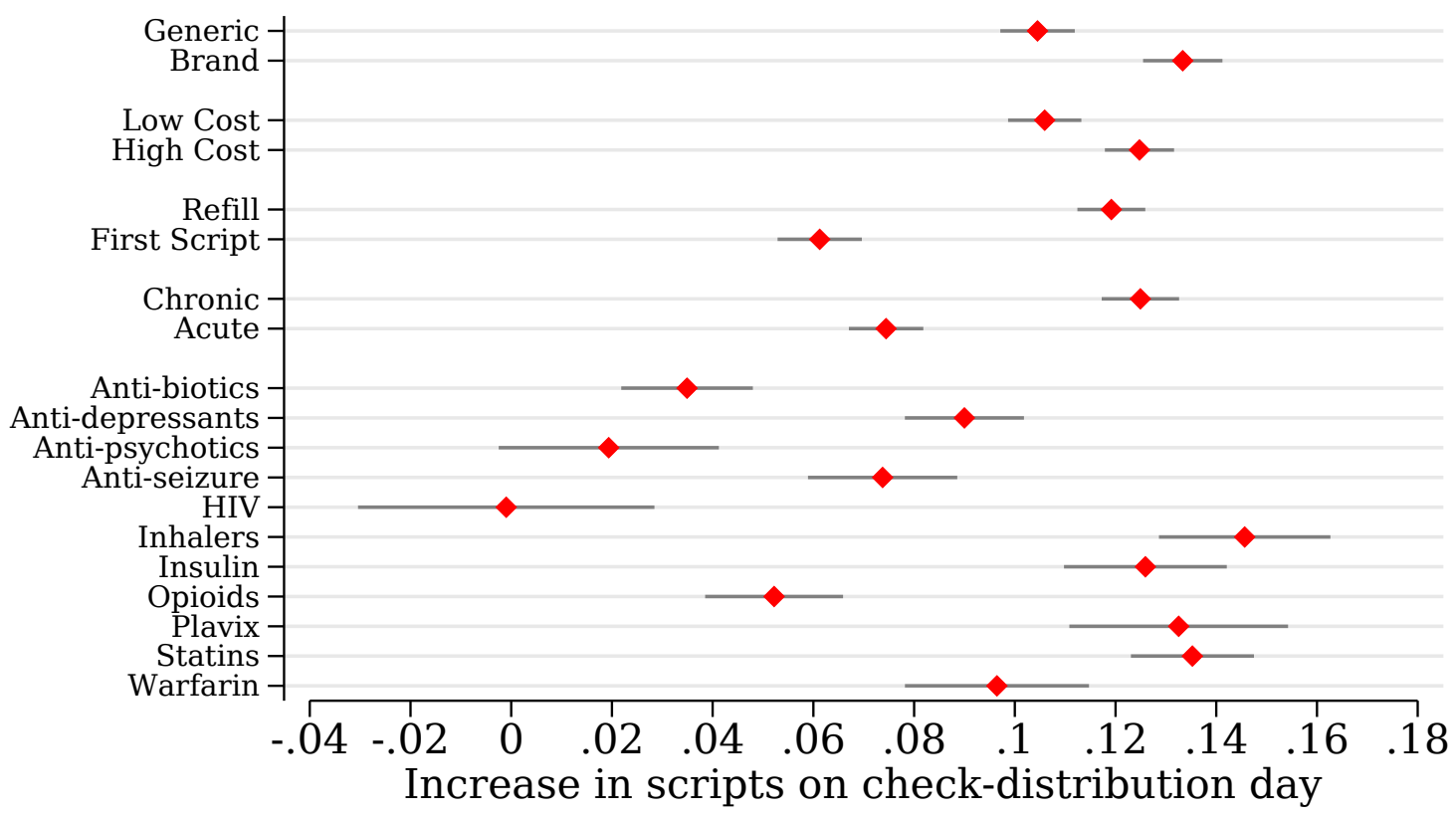

This figure plots estimates of $\beta_{0}$ from equation (1): the event-study coefficient for check-distribution day when the outcome is the logarithm of scripts filled for a particular type of drug. The sample for this figure is restricted to the subsidized-copay group. The horizontal lines through each marker plot 95-percent confidence intervals based on standard errors that are clustered at the level of the birthday group. For more details, see Section 2.2.

The last set of rows in Figure 4 present estimates of the effect of Social Security checks on prescription fills for particular drugs. We interviewed a panel of physicians and asked for examples of common drugs that lead to severe, short-term consequences if patients do not adhere to their prescriptions. The physicians suggested the following drugs: blood thinners (Warfarin and Plavix) - used to prevent stroke among patients at high risk for blood clots; antiretrovirals (HIV) - used to keep HIV from progressing to AIDS; anti-psychotics - used to treat psychotic disorders such as bipolar disorder and schizophrenia; anti-seizure medications - used to prevent seizures among patients who are particularly vulnerable to them; anti-biotics - drugs typically used to treat acute infections that could spread and do much more harm; insulin - used to regulate blood sugar among diabetics; statins - drugs used to lower cholesterol levels and 
thereby decrease the risk for heart attacks and strokes; and inhaler-based medications - typically used in emergency situations when breathing becomes difficult for patients with asthma or COPD. We add to this list one more class of drugs, opioid pain-killers. Opioids are an interesting case study, because delaying consumption of opioids leads to the recurrence of pain and thus may be extremely salient to patients.

Overall, Figure 4 suggests some heterogeneity in the effect of Social Security checks across these drugs. Prescription fills for HIV antiretrovirals exhibit no statistically significant effect. Blood thinners, insulins, statins, and inhalers exhibit the largest effects. Those effects are troubling to physicians: these drugs tend to be seen as high value by physicians and important for the health of the patient. Indeed, physicians believe that, among patients at high risk for a stroke, skipping blood-thinning medications can lead to a life-threatening stroke (e.g., Cummings et al., 2013). Skipping insulin prescriptions can also have short-term medical consequences, and the absence of an inhaler-based medication at the time of an acute respiratory event can lead to hospitalization. Many other drugs, such as anti-seizure medications, anti-depressants, anti-psychotics, and anti-biotics involve statistically significant, but smaller effects, ranging from around 2 percent (anti-psychotics) to around 9 percent (anti-depressants). Finally, the estimated effects for opioids are indeed smaller than the estimated effects for many other drugs, perhaps indicating that the salience of the effects of non-adherence plays a role in the decision to delay or forgo filling prescriptions during low-liquidity periods. ${ }^{22}$

We next assess whether different types of recipients are more likely to drive the increase in fills on Social Security paydays. Figure 5 presents estimates of the effect of Social Security check receipt for a variety of sub-groups of recipients. We observe smaller effects for White recipients relative to non-White recipients, though both groups exhibit large effects and the difference is not statistically significant. Further, we find effects for recipients with a variety of chronic health conditions. Recipients with chronic obstructive pulmonary disease (COPD), heart disease, and diabetes all exhibit large check effects. Effects are slightly smaller but still clinically significant for recipients with depression and cancer. recipients with Alzheimer's Disease exhibit smaller effects still, consistent with the possibility that those patients are more likely to have children or other care-takers managing their prescriptions. Overall, these results indicate that the effects we observe are not solely driven by healthy recipients, but also by recipients with a variety of chronic health conditions.

\footnotetext{
${ }^{22}$ Appendix Figure A10 presents results for the high-copay group, showing largely similar patterns.
} 
Figure 5. Heterogeneous Effects Across Recipient Characteristics

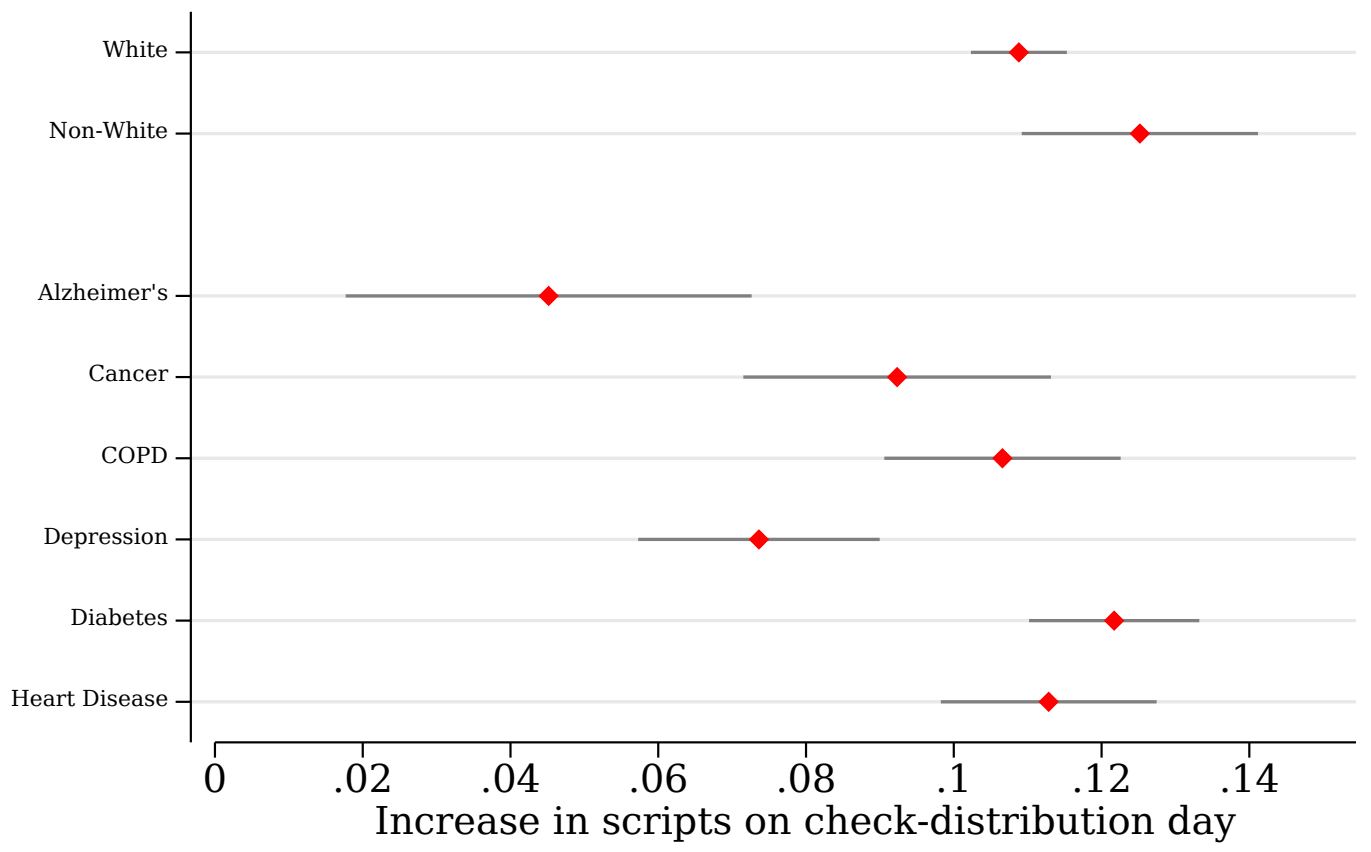

These figures plot estimates of $\beta_{0}$ from equation (1): the event-study coefficient for checkdistribution day when the outcome is the logarithm of scripts filled for groups of particular beneficiaries. We divide beneficiaries by race (white or non-white), and the chronic conditions of COPD, Heart Disease, Diabetes, Depression, Alzheimer's, and Cancer. The sample is restricted to the subsidized-copay group. The horizontal lines across each marker plot 95-percent confidence intervals based on standard errors that are clustered at the level of the birthday group. For more details, see Section 2.2.

Appendix Figure A10 presents analogous results for the high-copay group. Similarly, for that group, all types of recipients exhibit statistically significant increases in prescription fills on Social Security paydays. The major difference we observe for the high-copay group is the size of the disparity in the effects between white and nonwhite recipients. For white recipients, the effect of Social Security check receipt is just under 6 percent. For non-white recipients, the effect is around 11 percent, almost twice as large. That pattern highlights a difference between the full-copay group and the subsidized-copay group. When we restrict the sample to the subsidized-copay group, we limit the sample to recipients who are low income. For the full-copay group, on the other hand, there is substantial heterogeneity in income. 
Figure 6. Heterogeneous Effects By Income

Increase in scripts on check-distribution day

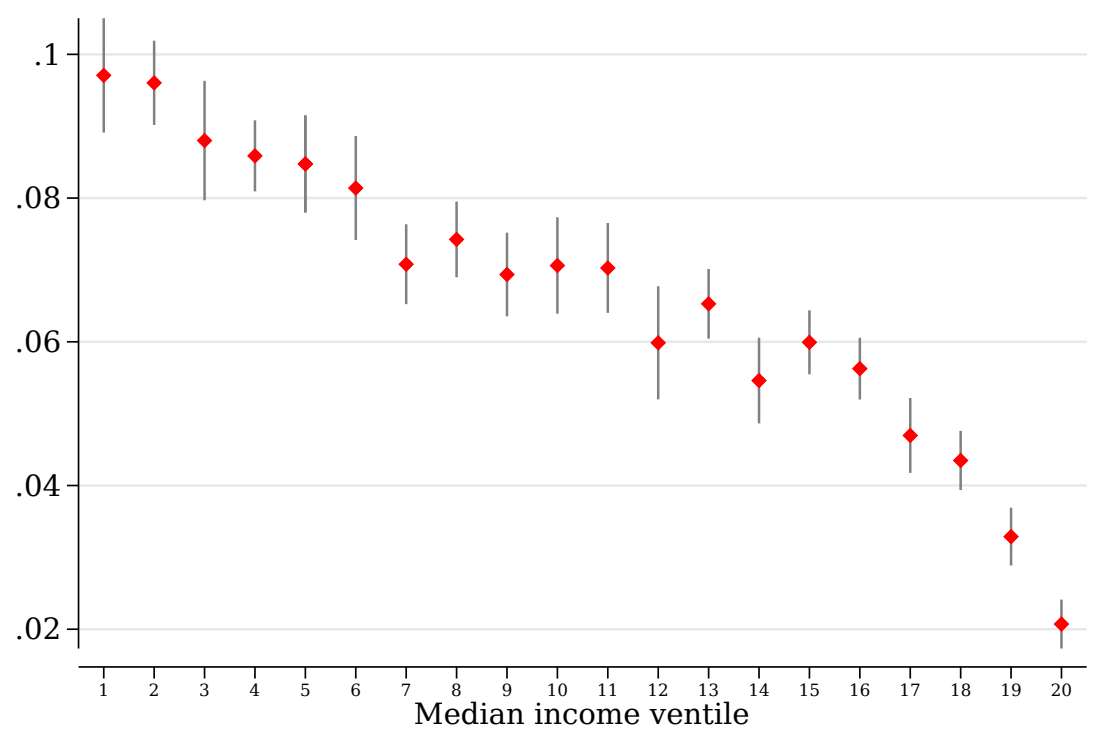

This figure plots estimates of $\beta_{0}$ from equation (1), the estimated event-study coefficient on check-distribution day for the logarithm of total scripts filled, by ventile of median income for each recipient's ZIP Code of residence. The sample is restricted to the full-copay group. The vertical lines through each marker plot 95-percent confidence intervals based on standard errors that are clustered at the level of the birthday group. For more details, see Section 2.2.

Figure 6 investigates the role of income in the full-copay group further. The figure divides the full-copay group by ventiles of income and plots estimates of $\beta_{0}$ from equation (1). As a proxy for household income, we link every ZIP Code of residence in the data to the median household income as measured by the 2006-2010 American Community Survey. The figure suggests a clear gradient, with larger effects of Social Security checks for recipients living in lower-income ZIP Codes. The payday effect for the lowest-income ventile (just under 10 percent) is five times as large as the payday effect for the highest-income ventile (roughly 2 percent). ${ }^{23}$ The lowest-income ZIP Codes in the full-copay group thus exhibit an effect that is almost as large as the effect exhibited by the entire subsidized-copay group. Such a pattern indicates that

\footnotetext{
${ }^{23}$ Unsurprisingly, Figure 6 suggests that liquidity sensitivity is more widespread in lower-income areas than in higher-income areas. The figure also suggests statistically significant evidence for liquidity sensitivity in relatively high-income areas. That finding, though perhaps surprising, is consistent with the previous literature. For instance, Olafsson and Pagel (2018) find that households in the bottom income quartile spend 70 percent more on days when they receive their income, and that households in the top income quartile spend 40 percent more on days when they receive their income.
} 
liquidity sensitivity is also present among recipients not enrolled in the LIS, especially those with low incomes.

It is important to recognize that interpreting Figures 3, 4, 5, and 6 is a non-trivial task. On the one hand, the figures exhibit patterns that are intuitive. For instance, expensive drugs are more difficult for low-income consumers to purchase, and so it is unsurprising that we find larger effects of Social Security checks on expensive drugs. At the same time, the estimates capture treatment effects based on different populations, and the populations differ from each other in observed and unobserved ways. One explanation for the larger effects for more-expensive drugs is the higher out-of-pocket price. An alternative explanation is that those who take those drugs are simply more liquidity-sensitive than those who take less-expensive drugs.

Regardless, these results indicate a high level of sensitivity to liquidity across many Medicare recipients. The effects do not seem to be driven solely by healthy recipients or by low-value drugs with questionable therapeutic benefit. Instead, the effects are driven by medically vulnerable recipients and by drugs for which non-adherence can have severe short-term consequences. Such recipients seem to be delaying or forgoing filling prescriptions until they receive their Social Security checks.

The results suggest that the consumption of healthcare is liquidity sensitive. That liquidity sensitivity may be due to behavioral frictions that make it psychologically difficult to expend resources when cash is scarce, even when the desired goods or services have important health consequences. The liquidity sensitivity may, alternatively, be driven by straightforward liquidity constraints. Section 4.1 discusses these two possible mechanisms in more detail.

\section{The Effects of More-Generous Coverage on Low-Income Households}

The results above suggest an increase in prescription drug fills when consumers who face copayments receive their Social Security checks. This section studies what occurs when those consumers experience a change in the copayments they face, transitioning from a group that faces copayments to the no-copayment group or vice-versa. ${ }^{24} \mathrm{We}$

\footnotetext{
${ }^{24}$ Many recipients transitioning between copayment groups also experience a change in their premium subsidy. Such a change in the subsidy could affect drug utilization via an income effect. Appendix B.3 tests for that possibility by studying transitions involving the lowest-income recipients in the subsidized-copayment group. Premiums are fully subsidized for those recipients. As a result, those recipients experience a decrease in copayments with no change in premiums when they
} 
leverage these transitions as a way to assess how liquidity sensitivity relates to the generosity of health insurance. More-generous coverage may allow some recipients to consume healthcare when they need it rather than having to wait for their Social Security checks to arrive. This section tests for such a possibility.

To do so, we identify all recipients who switch from a copay group (subsidized or full) to the no-copay group or vice-versa between 2007 and 2015. We restrict the sample to recipients continuously enrolled in Medicare Part D for at least one year before the transition and at least one year after. That restriction allows us to observe pre- and post-transition consumption patterns. We also remove from the sample those recipients who were in the no-copayment group at some point during the 24 months prior to the transition, and we limit the sample to those who were continuously enrolled in the no-copayment group for 24 months after the transition. Appendix Figure A12 plots the time series of enrollment across copayment groups for our sample of recipients, before and after the transition. The figure shows that around half of the recipients transition from the subsidized-copay group and half from the full-copayment group. ${ }^{25}$

One concern with studying transitions across copayment groups is that the transitions may be endogenous. Some recipients may apply for the LIS program because they anticipate needing more prescription drugs. In addition, the transitions can sometimes be triggered by health events, such as a hospitalization. Hospital staff may help a recipient enroll in the LIS program or in Medicaid. The health event would then confound our analysis.

Appendix B.1 discusses this issue. Several patterns in the data suggest that endogenous transitions do not drive the results. First, we estimate similar elasticities when we study transitions to the no-copayment group as when we study transitions from the no-copayment group. And that pattern is reassuring, because transitions to the no-copayment group are more likely to be endogenous than transitions out of the no-copayment group. ${ }^{26}$ In addition, Appendix B.1 demonstrates that transitions

are moved to the no-copayment group. The estimates suggest elasticities that are almost identical to the elasticities we estimate for other recipients, suggesting that income effects are unlikely to drive our findings.

${ }^{25}$ Appendix Figure A13 plots the same time series for transitions from the no-copay group to either the full-copay group or subsidized-copay group.

${ }^{26}$ While entry to the LIS program (the transition to the no-copay group) requires the recipient to fill out an application, exits from the LIS program (the transition from the no-copay group) are typically triggered by a change in the recipient's income. A change in income is reported to the Social Security Administration (SSA) by the Internal Revenue Service. When the change in income is observed, SSA attempts to contact the recipient to redetermine eligibility. If the recipient can 
between the full-copay group and the subsidized copay-group are likely not triggered by health events. Reassuringly, we find similar elasticities of demand by studying those transitions.

We study transitions in coverage in three steps. First, we study how changes in the generosity of insurance affect utilization, estimating an overall price elasticity of demand. Second, we study how changes in generosity affect liquidity sensitivity. Third, we study how the two phenomena interact: we assess whether those who exhibit the most liquidity sensitivity are more or less price sensitive.

\subsection{The Effect of Lower Copayments on Demand}

We first study how changes in copayments affect the demand for prescription drugs. Figure 7 plots mean out-of-pocket payments per script and total monthly scripts before and after recipients transition from either copayment group (the full-copayment group or the subsidized-copayment group) to the no-copayment group. The first panel shows a clear drop in average out-of-pocket payments when recipients transition to the no-copay group. Average out-of-pocket payments per script decrease from roughly $\$ 7$ to zero.

The second panel of Figure 7 provides evidence that, in response to lower outof-pocket costs, recipients consume more drugs. Recipients increase their drug consumption throughout this sample period. This is not surprising: drug consumption increases with age. But there is a clear shift in consumption upon a recipient's transition to the no-copay group. Recipients who switch groups fill an extra 0.3 scripts per month, an increase of a little less than 10 percent from baseline. After that level shift, the previous trend continues.

show that she is still eligible, she remains in the LIS program. If the recipient cannot show that she is still eligible - or if she simply does not return the re-determination paperwork - then she is removed from the program. It is possible that recipients who have overcome a health shock will take that paperwork less seriously. But this seems unlikely: the LIS program is valuable to all recipients given its large premium and copayment subsidies. More importantly, even if there were to be selection out of the program based on healthcare needs, our examination of these transitions relies on the exogeneity of the timing of exit from the LIS program. The timing of those exits is unlikely to be related to changes in health given that the timing of removal is based on a bureaucratic schedule rather than any action of the recipient. 
Figure 7. Re-Centered Time Series For Recipients who Switch From A Copay Group to the No-Copay Group

(a) Out-of-Pocket Per Script

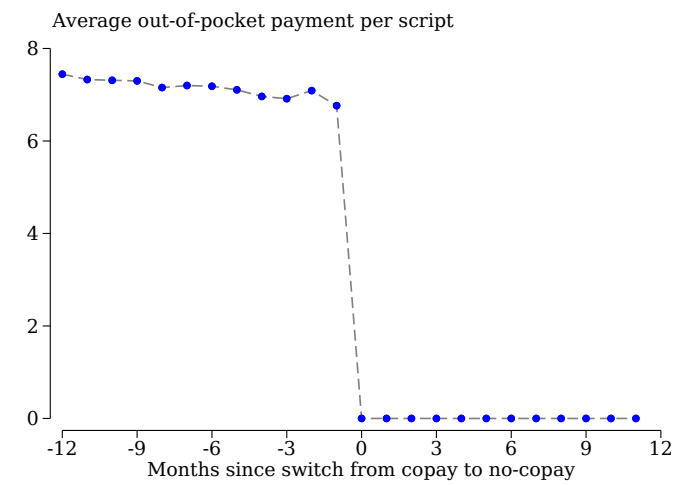

(b) Monthly Total Scripts

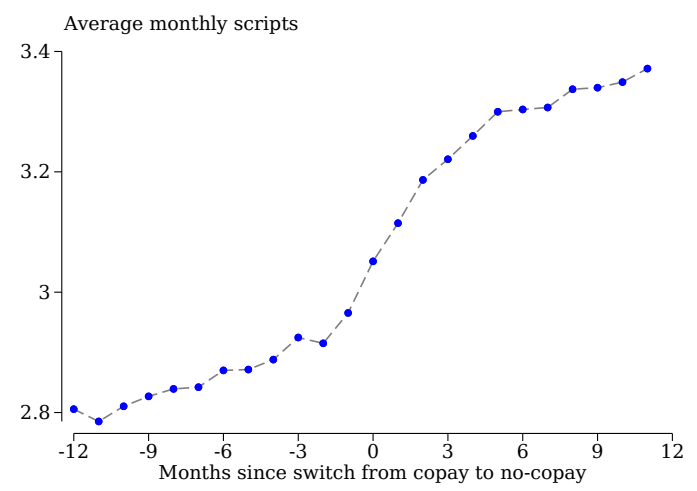

These figures describe prescription-drug expenditures for recipients who transition from either the full-copay group or the subsidized-copay groups to the no-copay group. Panel (a) plots the average out-of-pocket spending per script and Panel (b) plots the average monthly total scripts. For more details, see Section 3.2.

Figure 8 shows the response of recipients who make the opposite transition, moving from the no-copay group to a group that faces copayments. Those recipients experience a change that is the mirror image of that cataloged in Figure 7, though the trends in Figure 8 are noisier, because fewer recipients leave the no-copay group. Average out-of-pocket payments increase from $\$ 0$ to around $\$ 7$ and utilization decreases by roughly 0.3 scripts per month. 
Figure 8. Re-Centered Time Series For Recipients who Switch From the No-Copay Group to a Copay Group

(a) Out-of-Pocket Per Script

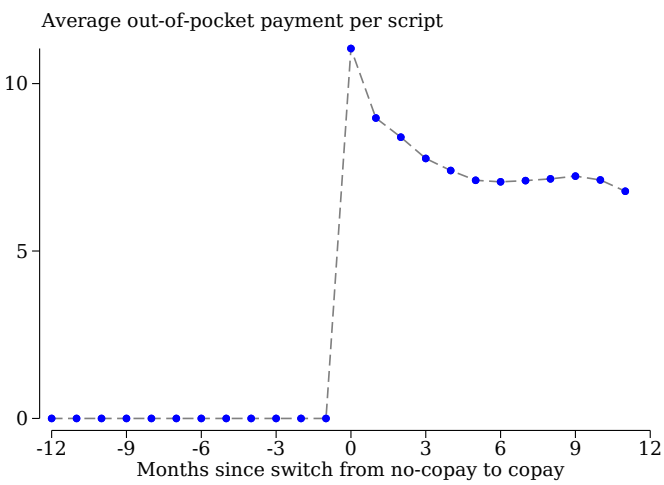

(b) Monthly Total Scripts

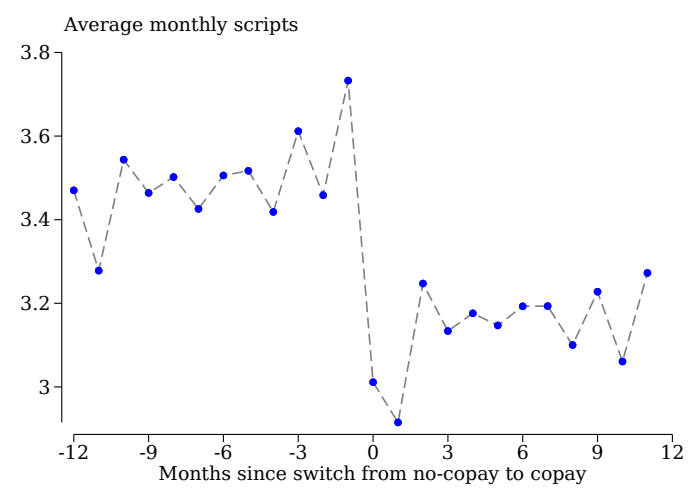

These figures describe prescription-drug expenditures for recipients who transition from the no-copay group to either the subsidized-copay group or the full-copay group. Panel (a) plots the average out-of-pocket spending per script and Panel (b) plots the average monthly total scripts. For more details, see Section 3.2.

Table 2 summarizes Figures 7 and 8 by presenting estimates of the following regression:

$$
\log \left(Y_{i c t}\right)=\alpha_{i}+\gamma_{t}+\beta \times \mathbf{1}\left\{t-s_{c} \geq 0\right\}+\varepsilon_{i c t} .
$$

For each recipient $i$ in cohort $c$ of recipients who transition copayment groups in the same calendar month $s_{c}$, we study their out-of-pocket payments and overall number of fills in each calendar month $t$. We include a fixed effect for each recipient, $\alpha_{i}$, and a fixed effect for each calendar month, $\gamma_{t}$. The parameter of interest in equation (2) is $\beta$, which captures the change in the outcome of interest after recipients transition to the other copayment group. ${ }^{27}$

\footnotetext{
${ }^{27}$ Appendix Figures A14 and A15 present event-study estimates, showing similar patterns to those presented in Figures 7 and 8 but with standard errors. Appendix D examines the robustness of these estimates under a number of different estimation strategies.
} 
Table 2. Effect of Changes in Generosity of Coverage

\begin{tabular}{|c|c|c|c|}
\hline & $\begin{array}{l}\quad(1) \\
\text { Log Total } \\
\text { Scripts }\end{array}$ & $\begin{array}{l}\quad(2) \\
\text { Log Out-of } \\
\text {-Pocket }\end{array}$ & $\begin{array}{c}\text { (3) } \\
\text { Elasticity }\end{array}$ \\
\hline \multicolumn{4}{|c|}{ A. Transition from Copay to No Copay } \\
\hline $\begin{array}{l}\text { Post } \\
\text { Transition }\end{array}$ & $\begin{array}{c}0.0808^{* * *} \\
(0.0028)\end{array}$ & $\begin{array}{c}-1.2690^{* * *} \\
(0.0087)\end{array}$ & $\begin{array}{c}-0.0636^{* * *} \\
(0.0022)\end{array}$ \\
\hline $\begin{array}{l}\text { Mean } \\
N\end{array}$ & $\begin{array}{c}2.97 \\
1,103,232\end{array}$ & $\begin{array}{c}6.76 \\
1,103,232\end{array}$ & $1,103,232$ \\
\hline \multicolumn{4}{|c|}{ B. Transition from No Copay to Copay } \\
\hline $\begin{array}{l}\text { Post } \\
\text { Transition }\end{array}$ & $\begin{array}{c}-0.0640^{* * *} \\
(0.0033)\end{array}$ & $\begin{array}{c}1.3096^{* * *} \\
(0.0156)\end{array}$ & $\begin{array}{c}-0.0489^{* * *} \\
(0.0019)\end{array}$ \\
\hline $\begin{array}{l}\text { Mean } \\
N\end{array}$ & $\begin{array}{c}3.73 \\
579,264\end{array}$ & $\begin{array}{c}0.00 \\
579,264\end{array}$ & 579,264 \\
\hline
\end{tabular}

This table presents estimates of the impact of switching to the no-copay group from the copay groups (top panel) and vice versa (bottom panel) on the outcomes listed. Standard errors in parentheses clustered on cohort of recipients transitioning copay groups for the first two columns. Standard errors are based on the delta method for the elasticity estimation in the third column. The data is limited to 12 months before and 12 months after the switch. Recipientspecific fixed effects and year-times-month-specific fixed effects not shown. These coefficients come from estimating equation (2). The means listed are the means of the given dependent variable one month before the transition across copayment groups. For more details, see Section 3.2. ${ }^{*} p<0.1,{ }^{* *} p<0.05,{ }^{* * *} p<0.01$

The top panel of Table 2 presents estimates of equation (2) for recipients who transition from a group that faces copayments to the no-copayment group. The change in out-of-pocket payments and utilization together suggest a price elasticity of demand of -0.06 . This elasticity is similar to previous estimates (Einav et al., 2015).

The bottom panel of Table 2 suggests a similar pattern, in reverse, for those who switch from the no-copayment group to a copayment-facing group. The implied elasticity is -0.05 . The patterns across the two types of transitions - some copay to no copay and no copay to some copay - are roughly mirror images of each other. When recipients experience a decrease in copayments, utilization increases, and the 
opposite occurs when recipients experience an increase in copayments. That mirrorimage pattern is reassuring; if there were a confounding factor associated with these transitions, we would expect the confound to affect one direction more than the other. And yet, we estimate similar elasticities based on recipients transitioning to the nocopayment group and those transitioning from the no-copayment group.

Appendix Table A4 reports elasticity estimates for the high-value drugs analyzed in Figure 4. Prior work has shown that consumption of high-value drugs is just as price sensitive as consumption of other drugs, suggesting that consumers respond to higher prices in ways that may be inappropriate (Brot-Goldberg et al., 2017). Appendix Table A4 is consistent with this prior work: the price elasticity of demand for high-value drugs is also around -0.05 , almost identical to the overall elasticity. This suggests that small changes in prices have big effects on the consumption of these drugs, even though physicians believe these drugs to be especially important for recipients' health.

\subsection{The Effect of Lower Copayments on Payday Filling}

This section tests how changes in the generosity of insurance affect "payday filling," the likelihood that recipients fill their prescriptions when their Social Security checks arrive. To do so, we calculate the share of each recipient's Wednesday fills that occur on their Social Security payday. ${ }^{28}$ We calculate the share of Wednesday fills occurring on Social Security paydays for each quarter and each cohort of recipients who transition from a group that faces copayments to the no-copay group. (We define a cohort as including all recipients who switch groups in a given quarter.) If recipients fill prescriptions on a schedule unrelated to their Social Security paydays, then roughly 23 percent of their Wednesday fills should occur on their Social Security payday. That number comes from a simple calculation: there are 12 Social Security checks sent each year, and either 52 or 53 Wednesdays in the year. If, however, some recipients delay filling scripts until their paychecks arrive, then the share of their Wednesday fills that occur on their payday would rise above 23 percent.

Figure 9 plots this measure for recipients who transition into the no-copay group. Prior to the transition into the no-copay group, recipients fill roughly 24-25 percent of their Wednesday fills on their Social Security payday. In the months immediately following their transition to near-full insurance, however, the share drops sharply to

\footnotetext{
${ }^{28} \mathrm{We}$ focus on the share of Wednesday fills that occur on payday, because there are day-of-the-week effects in prescription-filling behavior.
} 
roughly 22-23 percent. More-generous insurance, it seems, reduces the propensity for recipients to fill their scripts on their Social Security payday. Appendix Table A2 presents estimates of a regression in which the share of Wednesday fills on payday is the outcome of interest. The estimates suggest that that measure decreases by 2.6 percentage points (10.3 percent) when recipients transition into the no-copay group. ${ }^{29}$

Figure 9. The Share of Recipients Filling Scripts on Their Social Security Payday Before and After They Transition to the No-Copayment Group

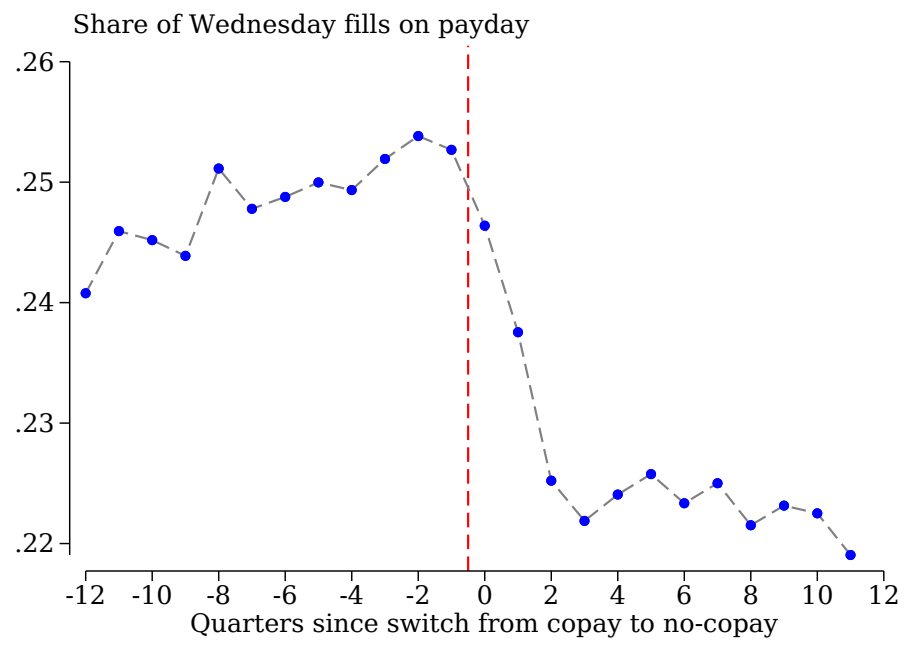

This figure plots the share of Wednesday prescription fills that fall on Social Security payday for each quarter relative to the quarter that recipients switched copay groups. The estimates are for recipients who switched from either the full-copay or subsidized-copay group to the no-copay group. For more details, see Section 3.2.

These results are consistent with those presented in Section 2: they suggest no effect of Social Security checks on prescription fills for those in the no-copayment group. But the results go further in that they show that a given recipient changes how she fills prescriptions in response to more-generous coverage. It appears that when recipients are given full insurance, they start filling their prescriptions when they want or need the medicine rather than when they receive their Social Security checks.

\footnotetext{
${ }^{29}$ The pattern for recipients who transition from the no-copayment group is exceedingly noisy. That might be a result of the small sample size: we observe roughly half as many transitions from the no-copayment group as transitions to the no-copayment group. Nonetheless, Appendix Table A2 also presents estimates for those transitions.
} 


\subsection{The Interaction Between Price Sensitivity and Liquidity Sensitivity}

The results above demonstrate that prescription fills are both liquidity sensitive and price sensitive among low-income recipients. A remaining question regards the relationship between those two findings. This section tests how price sensitivity compares across recipients who demonstrate varying levels of liquidity sensitivity.

We focus on recipients who transition to the no-copay group. We stratify those recipients by the share of their Wednesday fills that occurred on their Social Security paydays before the transition. Appendix E demonstrates that recipients in the top two deciles of this measure are indeed liquidity sensitive while the prescription fills of recipients in other deciles of this measure exhibit much less sensitivity to Social Security checks.

Figure 10. Comparison of Elasticities Across Recipients' Propensity to Fill on Social Security Paydays

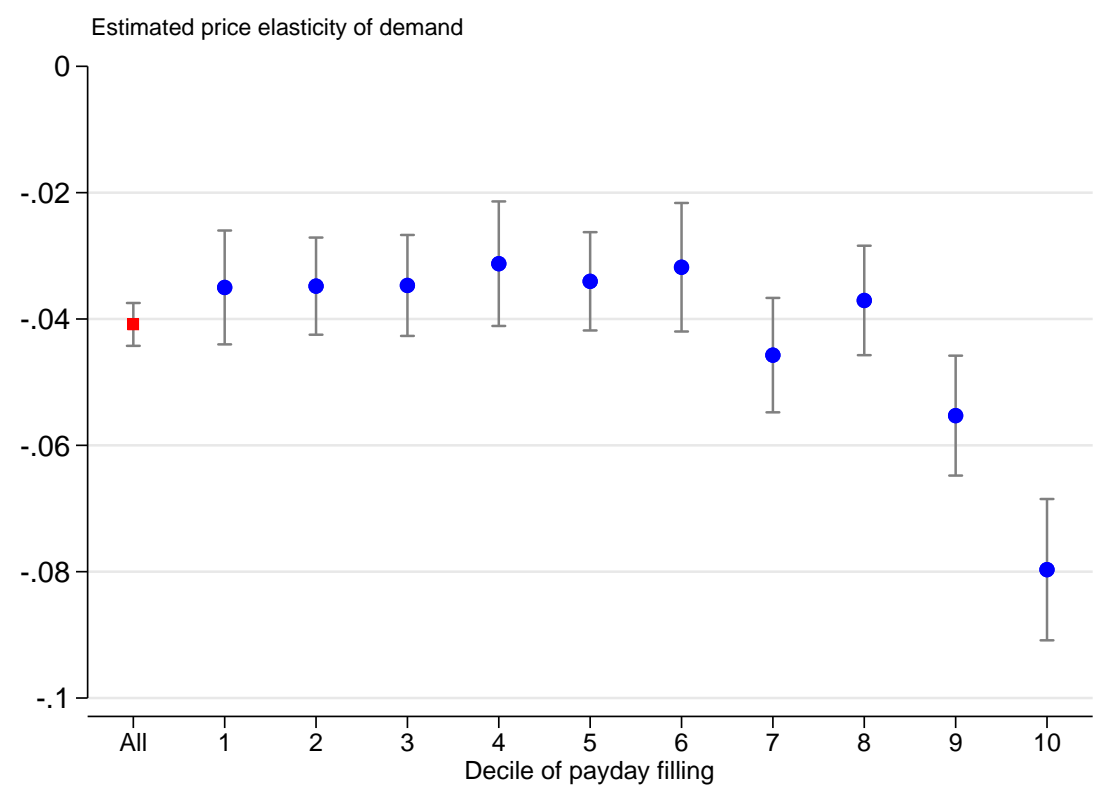

This figure presents estimated price elasticities of demand when recipients are divided into deciles based on the proportion of their Wednesday prescription fills that fall on their Social Security payday. The sample is restricted to recipients who switch from either the full-copay group or the subsidized-copay group to the no-copay group one year before and after their switch. These coefficients come from estimating an individual-level version of equation (2). Standard errors are based on the delta method. For more details, see Section 3.3.

Figure 10 presents estimates of the price elasticity of demand across this proxy for liquidity sensitivity. For each decile, the figure plots an estimate of the price elasticity 
of demand based on the recipients' transition to the no-copay group. ${ }^{30}$ The figure suggests that nearly all deciles exhibit roughly the same price elasticity of demand, with the exception of the last two deciles. Recipients in the top decile exhibit a price elasticity of demand that is roughly twice as large as the elasticity of demand exhibited by other recipients. Recipients in the ninth decile also exhibit higher price sensitivity than others, though the difference is not as large. In that way, Figure 10 suggests that those recipients who are liquidity sensitive are also the most price sensitive. ${ }^{31}$ Appendix Figure B4 also shows a similar pattern for recipients transitioning from the full-copayment group to the subsidized-copayment group.

Appendix Figure A16 repeats this exercise for the set of high-value drugs analyzed in Figure 4. The figure suggests that liquidity-sensitive recipients are much more sensitive to price, even for these drugs, which physicians believe are critical for patients' health.

This section's results shed some light on the overall effect of Social Security checks described in Section 2. Section 2 demonstrates that recipients increase their prescription fills on their Social Security paydays. But the exercises in that section do not distinguish between two potential mechanisms. First, liquidity-sensitive recipients may solely re-time their drug consumption based on when their check arrives. Alternatively, liquidity-sensitive recipients may not consume as many drugs as they would if they did not face liquidity-related frictions. Figure 10 suggests that both mechanisms are relevant. Recipients respond to lower copayments by increasing the number of drugs they purchase, and liquidity-sensitive recipients respond even more. This is true for drug consumption overall, and for high-value drugs that physicians believe to be especially important for recipients' health. Thus, the results of Section 2 are likely not solely a matter of re-timing; rather, liquidity-sensitive Medicare recipients demand fewer drugs than they otherwise would. We next consider the positive and normative implications of that finding.

\footnotetext{
${ }^{30}$ Appendix Table A3 presents regression estimates for each decile, the estimated price-elasticity of demand along with the change in out-of-pocket payments and change in utilization. We separate out recipients with no Wednesday fills (and thus no share of Wednesday fills on payday) and recipients with zero payday fills but with some Wednesday fills.

${ }^{31}$ One alternative explanation for these results might be that the recipients in the top decile are also more likely (relative to the other deciles) to come from the full-copayment group rather than the subsidized-copayment group and thus have a larger demand-response because they face a larger price change. To address this possibility, Appendix B.2 presents the results separately for recipients transitioning from the full-copayment group and recipients transitioning from the subsidized-copayment group. We find identical patterns, with the top decile always having an elasticity around twice as large as the other deciles.
} 


\section{Implications for Health Insurance}

This section assesses the implications of this paper's results for the economics of health insurance. First, we consider potential mechanisms behind the results. Second, we discuss the implications of the results for the value of insurance. Third, we assess implications for the conventional view of moral hazard.

\subsection{Potential Mechanisms}

The results in Section 2 imply that, for some recipients, it is more costly to fill prescriptions at the end of a pay period than at the beginning of a pay period. We posit three potential explanations for that pattern: increasing returns to shopping, liquidity constraints, and mental accounting.

A first potential explanation is that consumers tend to do all of their shopping at once for the sake of returns to scale. For instance, suppose that some consumers have to pay a bus fare in order to travel to the pharmacy. In that case, they may choose to visit the pharmacy at the same time as they do their other shopping. And thus, they would delay filling their prescriptions until they were prepared to purchase many other goods, as well.

Such an explanation is easy to reject. We find no effect of Social Security checks for the no-copay group. Those consumers still receive Social Security checks, and they, presumably, still face the same potential returns to scale from shopping - they still have to pay a fare for the bus. Nevertheless, the prescription fills of that group do not exhibit liquidity sensitivity.

A second explanation is that some Medicare recipients are liquidity constrained. At the end of each pay period, some recipients have little cash on hand. Those consumers may face a steep price to access additional liquidity. They may, for instance, face high interest rates from lenders, or have maxed out their credit cards. Such consumers then have no choice but to wait for their next Social Security check before they can fill their prescriptions.

On the one hand, the results above are consistent with such an explanation. The consumption literature suggests that lower-income consumers are more likely to be liquidity constrained (Olafsson and Pagel, 2018), and indeed, Figure 6, above, suggests that the effects of Social Security checks on prescription fills are driven by lowerincome Medicare recipients. Moreover, more-expensive purchases are more likely to be unattainable for liquidity-constrained consumers, and Figure 4, above, suggests 
that the effects of Social Security checks are larger for more-expensive drugs.

On the other hand, it is surprising that the small copayments faced by the subsidized-copay group ( $\$ 2-\$ 5$ per prescription in many cases) would pose such an obstacle. ${ }^{32}$ Thus, we cannot reject a third, alternative explanation: the liquidity sensitivity we observe may be driven by behavioral biases. In particular, Medicare recipients may delay filling their prescriptions based on a type of mental accounting (Thaler, 1985, 1999). They may not be truly liquidity constrained, so much as that the mental account that they devote to medical expenses may be empty. Unlike liquidity constraints, mental accounting does not imply large financial costs to accessing the cash necessary for copayments; rather, it implies large psychological costs. ${ }^{33}$

In summary, we cannot reject either liquidity constraints or mental accounting as the mechanism driving the income-timing effects we document. It is possible that both mechanisms are empirically relevant, though for different recipients.

Importantly, those two explanations lead to different implications for policy. If liquidity constraints are responsible for the liquidity sensitivity that we observe, then providing recipients with access to short-term credit against their future Social Security checks may be beneficial. If mental accounting is the explanation, however, it is less clear how short-term credit will affect recipients' behavior. Instead, moving from monthly Social Security payments to smaller, weekly payments may be an appropriate policy response. By setting payments such that recipients are more likely to have cash on hand at any given point in time, policymakers can help recipients avoid the psychological constraints related to the end of the pay period and fill their prescriptions on time. ${ }^{34}$

\subsection{The Consumption-Smoothing Benefits of Insurance}

Regardless of whether liquidity constraints or mental accounting drive the effects we document, the results suggest a benefit of insurance that is often not discussed. Typically, insurance is viewed as providing risk protection at the expense of moral hazard. Generous insurance also provides an additional benefit: it allows healthcare consumption to be less liquidity sensitive.

\footnotetext{
${ }^{32}$ The exact copayments change each year. In 2006, most recipients in the subsidized-copay group paid $\$ 2$ for generic drugs and $\$ 5$ for branded drugs; in 2015 , those copayments were $\$ 2.65$ and $\$ 6.60$, respectively.

${ }^{33}$ Baicker et al. (2015) discuss optimal cost-sharing mechanisms when healthcare consumption is shaped by behavioral biases.

${ }^{34}$ Interestingly, Shapiro (2005) and others have made a similar policy recommendation for the distribution of food stamps.
} 
That benefit can be seen in the results above. Low-income Medicare recipients exhibit liquidity sensitivity, but those who face no copayments do not. When recipients enter the LIS program and their copayments are eliminated, their healthcare consumption becomes less liquidity sensitive. In other words, when consumers are provided with more-generous insurance, their healthcare consumption becomes less dependent on the timing of their income.

The results thus suggest the need for a new framework to evaluate cost sharing for low-income households. The conventional framework evaluates policies as trading off the costs of moral hazard relative to the benefits of risk protection. This paper's results suggest an additional benefit of generous coverage: consumption smoothing. The consumption-smoothing benefits of generous coverage are especially important for low-income populations, and may also have clinical value in cases where the benefits of drug consumption decline in the time since the prescription was written.

Ericson and Sydnor (2018) study how rational consumers choose health insurance plans when they are liquidity constrained. Liquidity-constrained households value plans that require premiums to be paid at short intervals rather than in lump sums. That preference is driven not by risk aversion but due to the financing role of insurance. Our results provide the first empirical evidence - of which we are aware-for that financing role.

\subsection{Implications for the Price Elasticity of Demand for Healthcare}

Section 3.3 demonstrates that those who are most liquidity sensitive respond the most to lower copayments. We next explore the implications of that result.

\subsubsection{Differential Response by the Liquidity Sensitive}

Figure 10 indicates that those who are most likely to time their drug consumption against their income exhibit the highest elasticity of demand. Indeed, their elasticities are more than two times the elasticity of the average recipient. As a first approach to interpret this result, we make a strong assumption regarding homogeneity. Suppose that there are two types of Medicare recipients: the "payday fillers" who tend to time their drug consumption against their Social Security checks, and all other Medicare recipients. We assume that the payday fillers would exhibit the same price elasticity as other recipients if they did not face liquidity-related frictions (whether financial or psychological). In other words, we assume that all recipients have the same individual 
demand curve for prescription drugs, and only frictions related to liquidity lead the payday fillers to a different demand curve.

Under that assumption, the elimination of those liquidity-related frictions would shift the price elasticity of demand for payday fillers to the average elasticity of demand for all other recipients. Such a shift would then lower the overall elasticity of demand by 15 percent. ${ }^{35}$ In that sense, 15 percent of the overall estimate of demand response is not attributable to moral hazard, but rather to the liquidity effects we document.

Granted, such a calculation is based on a strong assumption of homogeneity. We can, instead, consider a type of bounding exercise. Suppose that payday fillers would exhibit an elasticity of demand at least as large as that of the average recipient if they did not face liquidity-related frictions. ${ }^{36}$ In that case, 15 percent is an upper bound for the portion of the demand response that is driven by liquidity sensitivity.

An additional approach to understand the implications of the differential demandresponse to cost sharing involves a focus on high-value drugs. Appendix Figure A16 studies only the consumption of high-value drugs and shows that liquidity-sensitive recipients are much more price sensitive than other recipients. The average price elasticity of demand for high-value drugs across all deciles of payday filling is -0.039 . If liquidity-sensitive recipients were excluded from that sample, the overall price elasticity of demand would fall to -0.035 . That represents a 10 -percent reduction in price sensitivity for high-value drugs.

That contrast for high-value drugs is intriguing. A demand response for highvalue drugs is potentially irrational (Baicker et al., 2015; Brot-Goldberg et al., 2017). These drugs are especially important for recipients' health, and so it is surprising that demand is not inelastic. The larger elasticity for liquidity-sensitive Medicare recipients raises the question of whether liquidity sensitivity is one mechanism behind this price sensitivity.

\subsubsection{A Simple Theoretical Framework for Liquidity Sensitivity}

This paper's results suggest that liquidity-sensitive recipients are disproportionately responsible for high levels of price sensitivity. What are the implications of that finding? The theoretical and empirical literature on health insurance typically in-

\footnotetext{
${ }^{35}$ The elasticity of demand for all recipients is -0.041 ; the elasticity of demand for those in deciles 1 through 8 is -0.035 .

${ }^{36}$ That assumption implies that the payday fillers' "frictionless" demand curves are weakly flatter than the demand curve of the non-payday fillers, making them more price sensitive.
} 
terprets a demand response to cost sharing as evidence of moral hazard. That interpretation, however, assumes that demand for healthcare reflects consumers' valuation of healthcare. If consumers face financial or psychological constraints that prevent them from shifting money over time, then demand and valuation may diverge and a demand-response to more-generous insurance cannot be interpreted as solely a welfare-reducing moral-hazard effect. ${ }^{37}$ Instead, the demand-response to moregenerous insurance also reflects the relaxation of liquidity-related frictions that previously prevented recipients from consuming drugs that they value more than their cost. We offer a simple, graphical framework to illustrate how these frictions affect conventional welfare analysis.

Baicker et al. (2015) model the welfare consequences of more-generous health insurance coverage when consumers are constrained by behavioral frictions. We build on their model in order to consider how the welfare consequences of more-generous coverage differ between the conventional, frictionless model and a model that incorporates liquidity-related frictions.

Figure 11 illustrates the model graphically. The first panel describes the conventional view on moral hazard. The panel plots the market demand curve for prescription drugs. That demand curve represents consumers' true valuation for the drugs. The efficient quantity is $Q^{*}$, determined by the intersection of the demand and marginal cost curves. ${ }^{38}$ At this quantity, consumers value the marginal prescription drug at exactly the marginal cost. First, consumers face a high copayment, $p_{H}$, which is below the marginal cost of prescription drugs. As a result, when faced with high copayments, consumers purchase a quantity of drugs $Q_{H}>Q^{*}$. And $Q^{H}$ exceeds the efficient quantity because the price falls below the marginal cost, resulting in consumers purchasing drugs that they value less than the marginal cost. The deadweight loss from this over-consumption of prescription drugs is equal to the area of triangle $A B E$.

\footnotetext{
${ }^{37}$ Chetty (2008) makes this point in the context of unemployment insurance.

${ }^{38}$ The correct definition of marginal cost in this setting is somewhat unclear. The marginal cost of producing drugs is often close to zero, much lower than the price of those drugs. To conduct a full welfare analysis, one must also consider drug manufacturer market power, the presence of "rebates" to pharmacy benefit managers, the incentives for drug development and innovation, so on and so forth. In the empirical section below, we sidestep these issues and specify the marginal cost as the observed average payment for the drug in the claims data.
} 
Figure 11. A Simple Framework For How Liquidity Sensitivity Affects Demand for Prescription Drugs

(a) Conventional View

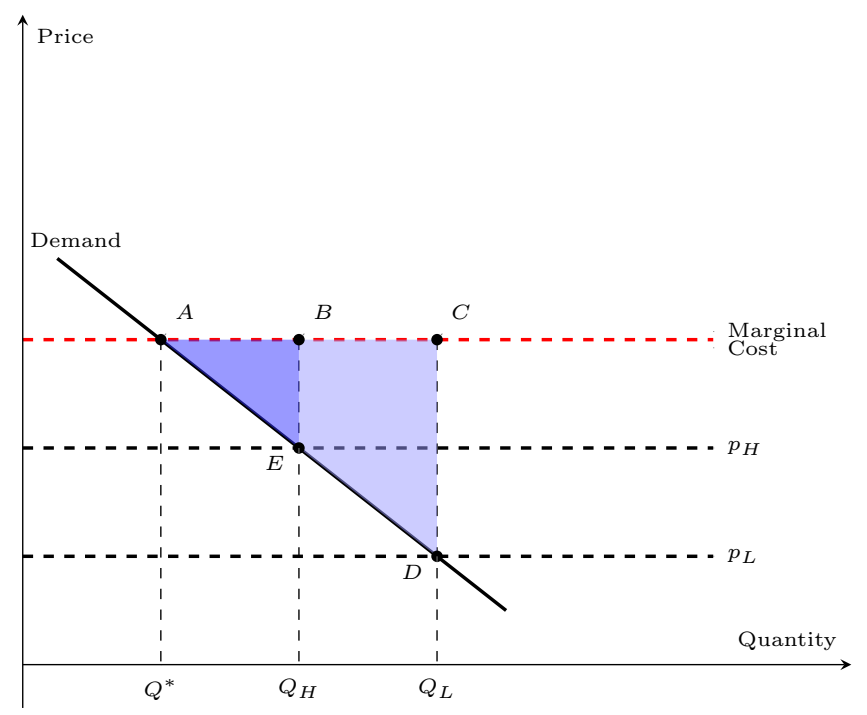

(b) Incorporating Liquidity

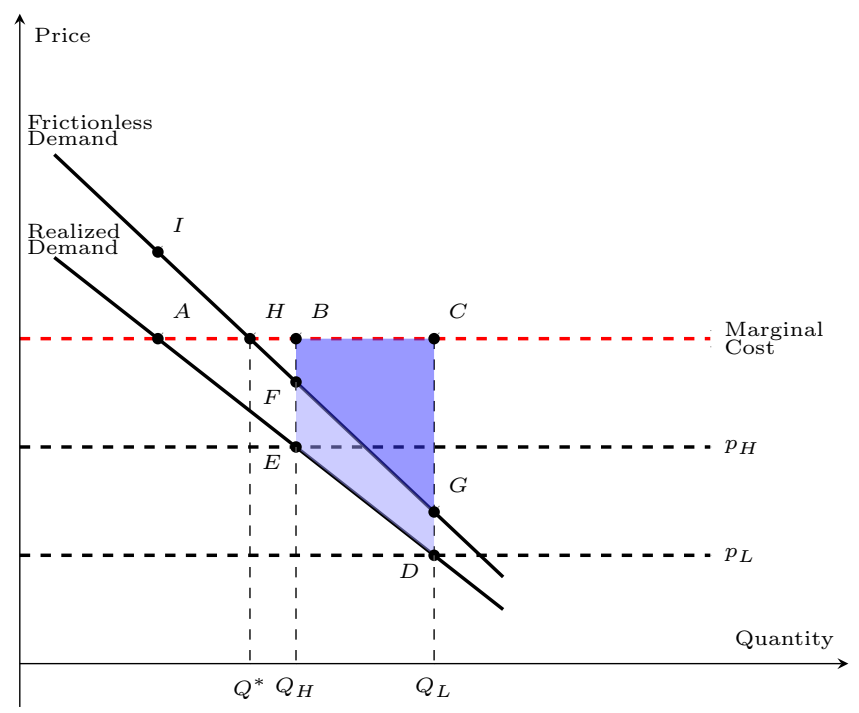

These figures comprise a simple framework for modelling the relationship between liquidity, the purchase of prescription drugs, and consumer welfare.

Next, consumers are put on a more-generous insurance plan that lowers the out-ofpocket cost of prescription drugs to $p_{L}$. In response, the quantity of drugs consumed increases from $Q_{H}$ to $Q_{L}$. The lower copayments lead to yet more over-consumption: consumers fill more prescriptions that they value less than marginal cost. This is the standard moral-hazard effect, and it leads to a welfare loss. The additional deadweight loss from moving from $p_{H}$ to $p_{L}$ is equal to the area of the trapezoid $B C D E$.

The second panel of Figure 11 adds a complication to this standard view. Suppose that consumers face a liquidity-related friction. Consumer behavior is still modeled with the same "realized demand" curve, but this curve no longer describes consumers' true underlying valuation for prescription drugs. Instead, a second "frictionless" demand curve describes their true valuation of drugs in the absence of liquidityrelated frictions. In that sense, the liquidity-related friction drives a wedge between consumers' valuation of the drug and what they actually purchase. Now, the efficient quantity of drugs, $Q^{*}$, is higher than before; it is the quantity that sets the consumers' valuation (as illustrated by the frictionless, not the realized, demand curve) just equal to marginal cost. Further, the deadweight loss from moving from $p_{H}$ to $p_{L}$ is now smaller than it had been in the first panel. While the quantities purchased at $p_{H}$ and $p_{L}$ are the same as before, consumer valuations of those quantities are now 
higher. In the conventional case, the deadweight loss from moving from $p_{H}$ to $p_{L}$ is equal to $B C D E$. In the case with liquidity frictions, the deadweight loss is equal to $B C G F$. The trapezoid DEFG represents the difference between these two measures of deadweight loss.

In that sense, Figure 11 suggests that the conventional view of moral hazard overstates the welfare loss from inefficient over-consumption under generous coverage. The conventional view is incomplete for low-income consumers who are more likely to be liquidity sensitive. Like behavioral frictions more broadly, liquidity-related frictions may cause consumers to under-consume drugs that they value more than the price.

Given the empirical setting of Section 3, we are focused on transitions from high copayments, $p_{H}$, to low copayments, $p_{L}$. But it is also worth noting that Figure 11 also speaks to the transition from uninsured status to insurance with high copayments. The conventional view, in the first panel of Figure 11, suggests a deadweight loss of $A B E$ when gaining high-copayment insurance. The right-hand side of Figure 11, however, suggests a much smaller deadweight loss, $B F H$, because the efficient amount of drug consumption no longer occurs when consumers face a price equal to the marginal cost. ${ }^{39}$ In this model, health insurance no longer solely generates moral hazard in exchange for risk protection, it also allows recipients to consume medical care that they would otherwise forgo due to liquidity-related frictions.

\subsubsection{A Simple Calibration}

The empirical results in Section 3 allow us to take that theoretical model one step further. We use the empirical estimates to infer the demand curves described by Figure 11. In particular, we observe the quantity of prescription drugs that Medicare recipients fill when in a copayment group, and then the quantity they fill when shifted onto the no-copayment group. We also observe the average out-of-pocket payments for both groups. Those estimates comprise two price-quantity pairs, which we use to estimate a linear demand curve. ${ }^{40}$

We begin by constructing the "realized" demand curve, the demand curve observed

\footnotetext{
${ }^{39}$ Further, the deadweight loss $B F H$ will be offset by a welfare gain from consumers purchasing drugs between points $A$, where consumers are under-consuming, and $H$, the efficient level.

${ }^{40}$ In practice, demand curves may not be globally linear. However, for our calculations to be valid, we only require local linearity between the two price-quantity points. In this setting, those two points are relatively "close" to one another, thus the linear approximation may be reasonable.
} 
for all recipients who fill scripts. ${ }^{41}$ The estimates in Appendix Table A3 indicate that the transition to the no-copay group decreases the average number of scripts filled by 6 percent from a baseline of 3.52. In addition, the average out-of-pocket price decreases to zero from a baseline of $\$ 7.60$.

Unlike the realized demand curve, we do not actually observe the "frictionless" demand curve. In order to construct it, we make additional assumptions. First, we assume that the recipients in deciles 1 through 8 of Figure 10 face no liquidityrelated frictions and so the demand curve they exhibit is their "frictionless demand." Indeed, Appendix E demonstrates that those recipients do not exhibit increases in prescription fills on payday. Second, we make the strong assumption that, in the absence of liquidity-related frictions, recipients in deciles 9 and 10 would exhibit the same demand curve as recipients in deciles 1 through 8 . In other words, we assume that the two groups have similar preferences over drugs, but that recipients in deciles 9 and 10 act differently solely due to liquidity-related frictions. We note that these two assumptions are strong, in that they require the realized demand curve for recipients in deciles 1 through 8 to reflect the actual valuation of drugs, effectively assuming away any other behavioral frictions or mistakes. That requirement is unlikely to hold in practice, and thus we see this exercise as a useful illustration of how liquidity-related frictions may impact welfare and not as a definitive welfare analysis.

Using those two demand curves, we can calculate the key areas from Figure 11. First, we calculate area $B C D E$, the deadweight loss due to marginal drug consumption under the conventional view of moral hazard. ${ }^{42}$ That area is approximately $\$ 19$. Second, we calculate the area $B C F G$, the deadweight loss associated with marginal drug consumption stemming from lower copayments once accounting for liquidityrelated frictions. That area is approximately $\$ 17$. Those two numbers together suggest that the deadweight loss when considering liquidity frictions is roughly 9 percent lower than the deadweight loss estimated via the conventional approach. The first row of Table 3 presents those numbers.

\footnotetext{
${ }^{41}$ For this exercise, we use the measure of liquidity sensitivity developed in Section 3.3, the share of Wednesday fills filled on payday. We restrict the sample to recipients who have a non-zero and non-missing value for that measure, because we use that measure to construct the "frictionless" demand curve.

${ }^{42}$ This calculation requires the marginal cost in addition to the two demand curves. We set the marginal cost equal to $\$ 60$, the average cost of prescription drugs purchased by recipients transitioning to the no-copayment group. Note that a lower (higher) marginal cost would result in a larger (smaller) reduction in deadweight loss from incorporating liquidity-related frictions.
} 
Table 3. Estimates of Deadweight Loss

\begin{tabular}{cccc}
\hline & $\begin{array}{c}\text { Conventional } \\
(\text { Area } B C D E)\end{array}$ & $\begin{array}{c}\text { Accounting for Liquidity } \\
(\text { Area } B C F G)\end{array}$ & $\begin{array}{c}\text { Liquidity Share } \\
(F E D G / B C D E)\end{array}$ \\
\hline Overall & $\$ 18.6$ & $\$ 16.9$ & 0.09 \\
Decile 10 & $\$ 21.6$ & $\$ 10.0$ & 0.54 \\
\hline
\end{tabular}

This table presents estimates of deadweight loss based on the model presented in Section 4.3.2. The first column presents estimates of deadweight loss due to moral hazard ("Conventional") when Medicare recipients experience a drop in the copayments they face. The second column presents an estimate of deadweight loss due to moral hazard, but also accounting for the liquidity-related frictions that distort the recipients' healthcare consumption.

The second row of Table 3 presents a parallel exercise. While the first row studies the market as a whole, the second row focuses on those who are most liquidity sensitive. We calculate the demand curve implied by the behavior of the most liquiditysensitive consumers: those in the top decile of the proxy introduced in Figure 10. We then assume, as above, that those consumers would exhibit a demand curve identical to the one exhibited by deciles 1 through 8 . Given these assumptions, the wedge between the realized and frictionless demand curves for this highly liquidity-sensitive group is, unsurprisingly, larger than the overall market-level wedge. Focusing on this group alone, incorporating liquidity-related frictions into the model accounts for over 50 percent of the deadweight loss that would be calculated for these consumers under the conventional model.

Taken literally, such an exercise suggests that the true deadweight loss of moral hazard is lower once one accounts for liquidity-related frictions. The difference is nontrivial, although far from the entire deadweight loss is eliminated. The conventional view of moral hazard is unquestionably important - these results simply raise the possibility that liquidity sensitivity also matters, especially for certain consumers. Liquidity-related issues should be considered when designing insurance contracts for low-income populations. ${ }^{43}$

Of course, the model on which we rely here is a highly stylized and simplified version of the model developed by Baicker et al. (2015). The calculation rests on strong assumptions, especially the assumption that the realized demand curve for

\footnotetext{
${ }^{43}$ Other behavioral frictions - over-confidence, self-control problems, projection bias, and so onalso matter, further complicating the optimal insurance contract and obfuscating the role of, and even the definition of, moral hazard.
} 
recipients in deciles 1 through 8 represents the true valuation for recipients in deciles 9 and 10. Despite the heroic nature of those assumptions, we present this exercise to illustrate how liquidity sensitivity causes the conventional method for calculating deadweight loss to be misleading. Ultimately, this exercise is more suggestive than conclusive. Future researchers ought to develop more-robust models that can estimate how accounting for liquidity sensitivity can shift deadweight loss and, for that matter, optimal copayments. Our goal here is to show that the implications could potentially be substantial and thus encourage further research in this area.

\section{Conclusion}

The results above suggest that Medicare Part D recipients delay the purchase of prescription drugs until their Social Security checks arrive. We estimate a 10-12percent increase in prescription fills among low-income recipients facing subsidized copayments on the day that their checks arrive. Even among the general Part-D population that receives no subsidies, prescription fills increase by roughly 6 percent on Social Security paydays.

Those increases in prescription fills upon payday diminish when recipients' copayments are reduced. In addition, we use the transition to lower copayments to estimate a price-elasticity of demand. Recipients who tend to fill their prescriptions on their Social Security paydays exhibit a much higher elasticity of demand.

The results thus suggest that discussions over cost-sharing mechanisms need to go beyond the traditional trade-off between moral hazard and risk protection. Some low-income consumers exhibit healthcare consumption that is "liquidity sensitive," and so cost sharing leads to additional complications for them.

Future research ought to explore the direct policy implications of liquidity-sensitive healthcare consumption. Insurers could provide financing options or alternative ways of collecting copayments. Copayments for outpatient and inpatient visits are often handled after the fact - the patient is sent a bill - and one might argue that prescription fills ought to be handled similarly. In addition, one could argue that those who

are liquidity sensitive and also at high risk for adverse events would benefit from a reduction in the cost sharing they face.

More generally, this paper emphasizes an additional benefit of full insurance. Full insurance not only reduces the uncertainty faced by consumers. It also allows lowincome recipients' consumption to be less sensitive to their liquidity. Liquidity sensi- 
tivity may be even more of an issue for other populations beyond Medicare recipients. For instance, consider adults who lack stable employment and thus face volatile incomes. That population does not have to wait a few weeks for a Social Security check - they may wait months for work. For them, full insurance allows the smoothing of healthcare consumption between employed and unemployed states. But for any population, the timeliness of healthcare consumption can have medical consequences. And so making healthcare consumption less liquidity sensitive ought to be a worthwhile policy goal. 


\section{References}

Abadie, Alberto, Susan Athey, Guido W Imbens, and Jeffrey Wooldridge, "When Should You Adjust Standard Errors for Clustering?," Working Paper 24003, National Bureau of Economic Research 2017.

Abaluck, Jason and Jonathan Gruber, "Choice Inconsistencies Among the Elderly: Evidence from Plan Choice in the Medicare Part D Program," American Economic Review, 2011, 101 (4), 1180-1210.

Agarwal, Sumit and Wenlan Qian, "Consumption and Debt Response to Unanticipated Income Shocks: Evidence from a Natural Experiment in Singapore," American Economic Review, 2014, 104 (12), 4205-4230.

_, Chunlin Liu, and Nicholas S Souleles, "The Reaction of Consumer Spending and Debt to Tax Rebates Evidence from Consumer Credit Data," Journal of Political Economy, 2007, 115 (6), 986-1019.

Aron-Dine, Aviva, Liran Einav, and Amy Finkelstein, "The RAND Health Insurance Experiment, Three Decades Later," Journal of Economic Perspectives, 2013, $27(1), 197-222$.

Baicker, Katherine, Sendhil Mullainathan, and Joshua Schwartzstein, "Behavioral Hazard in Health Insurance," Quarterly Journal of Economics, 2015, 130 (4), 1623-1667.

Baker, Scott R. and Constantine Yannelis, "Income Changes and Consumption: Evidence from the 2013 Federal Government Shutdown," Review of Economic Dynamics, 2017, 23 (1), 99-124.

Barcellos, Silvia and Mirielle Jacobson, "The Effects of Medicare on Medical Expenditure Risk and Financial Strain," American Economic Journal: Economic Policy, 2015, 7 (4), 41-70.

Baugh, Brian and Jialan Wang, "When Is It Hard to Make Ends Meet?," Mimeo, 2018.

_, Itzhak Ben-David, and Hoonsuk Park, "Disentangling Financial Constraints, Precautionary Savings, and Myopia: Household Behavior Surrounding Federal Tax Returns," Working Paper 19783, National Bureau of Economic Research 2014.

Beatty, Timothy K.M., Marianne P. Bitler, Xinzhe Huang Cheng, and Cynthia van der Werf, "SNAP and Paycheck Cycles," Southern Economic Journal, 2019, 86 (1), 18-48.

Berniell, Inés, "Pay Cycles: Individual and Aggregate Effects of Paycheck Frequency," Mimeo, 2019. 
Bertrand, Marianne and Adair Morse, "What Do High-Interest Borrowers Do with Their Tax Rebate?," American Economic Review, 2009, 99 (2), 418-423.

Brot-Goldberg, Zarek C., Amitabh Chandra, Benjamin R. Handel, and Jonathan T. Kolstad, "What Does a Deductible Do? The Impact of CostSharing on Health Care Prices, Quantities, and Spending Dynamics," Quarterly Journal of Economics, 2017, 132 (3), 1261-1318.

Card, David, Raj Chetty, and Andrea Weber, "Cash-on-Hand and Competing Models of Intertemporal Behavior: New Evidence from the Labor Market," Quarterly Journal of Economics, 2007, 122 (4), 1511-1560.

Carvalho, Leandro S., Stephan Meier, and Stephanie W. Wang, "Poverty and Economic Decision-Making: Evidence from Changes in Financial Resources at Payday," American Economic Review, 2016, 106 (2), 260-284.

Centeno, Mário and Álvaro A. Novo, "Reemployment Wages and UI Liquidity Effect: A Regression Discontinuity Approach," Portuguese Economic Journal, 2009, 8 (1), 45-52.

Chandra, Amitabh, Jonathan Gruber, and Robin McKnight, "Patient costsharing and hospitalization offsets in the elderly," American Economic Review, 2010, 100 (1), 193-213.

Cheng, Xinzhe Huang and Timothy K.M. Beatty, "Food Price Variation over the SNAP Benefit Cycle," Mimeo, 2016.

Chetty, Raj, "Moral Hazard vs. Liquidity and Optimal Unemployment Insurance," Journal of Political Economy, 2008, 116 (2), 173-234.

- and Amy Finkelstein, "Social Insurance: Connecting Theory to Data," in Alan J. Auerbach, Raj Chetty, Martin Feldstein, and Emmanuel Saez, eds., Handbook of Public Economics, Volume 5, Elsevier, 2013, pp. 111-193.

Cummings, Doyle M, Abraham J Letter, George Howard, Virginia J Howard, Monika M Safford, Valerie Prince, and Paul Muntner, "Medication adherence and stroke/TIA risk in treated hypertensives: results from the REGARDS study," Journal of the American Society of Hypertension, 2013, 7 (5), 363-369.

de Meza, David, "Health Insurance and the Demand for Medical Care," Journal of Health Economics, 1983, 2 (1), 47-54.

Dobkin, Carlos, Amy Finkelstein, Ray Kluender, and Matthew J. Notowidigdo, "The Economic Consequences of Hospital Admissions," American Economic Review, 2018, 108 (2), 308-52. 
- and Steven L. Puller, "The Effects of Government Transfers on Monthly Cycles in Drug Abuse, Hospitalization and Mortality," Journal of Public Economics, 2007, 91 (11), 2137-2157.

Einav, Liran, Amy Finkelstein, and Maria Polyakova, "Private provision of social insurance: drug-specific price elasticities and cost sharing in Medicare Part D," American Economic Journal: Economic Policy, 2018, 10 (3), 122-53.

_ , _, and Paul Schrimpf, "The Response of Drug Expenditure to Non-Linear Contract Design: Evidence from Medicare Part D," Quarterly Journal of Economics, 2015, 130 (2), 841-899.

_ and _, "Moral Hazard in Health Insurance: What We Know and How We Know It," Journal of the European Economic Association, 2018, 16 (4), 957-982.

Ericson, Keith Marzilli and Justin R. Sydnor, "Liquidity Constraints and the Value of Insurance," Working Paper 24993, National Bureau of Economic Research 2018.

Evans, William N. and Timothy J. Moore, "The Short-Term Mortality Consequences of Income Receipt," Journal of Public Economics, 2011, 95 (11-12), $1410-1424$.

Finkelstein, Amy, Nathaniel Hendren, and Mark Shepard, "Subsidizing Health Insurance for Low-Income Adults: Evidence from Massachusetts," American Economic Review, 2019, 109 (4), 1530-67.

Foley, C. Fritz, "Welfare Payments and Crime," Review of Economics and Statistics, 2011, 93 (1), 97-112.

Gelman, Michael, Shachar Kariv, Matthew D. Shapiro, Dan Silverman, and Steven Tadelis, "How Individuals Respond to a Liquidity Shock: Evidence from the 2013 Government Shutdown," Journal of Public Economics, 2019, Forthcoming.

Goetz, Thomas, "Health Insurance Aside, Americans Still Struggle To Pay for Their Medications," https://www.goodrx.com/blog/ health-insurance-aside-americans-still-struggle-to-pay-for-their-medications/ 2018.

Goldin, Jacob, Tatiana Homonoff, and Katherine Meckel, "Issuance and Incidence: SNAP Benefit Cycles and Grocery Prices," Mimeo, 2019.

Goldsmith-Pinkham, Paul, Maxim Pinkovskiy, and Jacob Wallace, "Medicare and the Geography of Financial Health," Mimeo, 2020. 
Gross, David B. and Nicholas S. Souleles, "Do Liquidity Constraints and Interest Rates Matter for Consumer Behavior? Evidence from Credit Card Data," Quarterly Journal of Economics, 2002, 117 (1), 149-185.

Gross, Tal and Jeremy Tobacman, "Dangerous Liquidity and the Demand for Health Care Evidence from the 2008 Stimulus Payments," Journal of Human Resources, 2014, 49 (2), 424-445.

_, Matthew J. Notowidigdo, and Jialan Wang, "The Marginal Propensity to Consume Over the Business Cycle," American Economic Journal: Macroeconomics, 2020, 12 (2), 351-384.

Gruber, Jonathan, "The Consumption Smoothing Benefits of Unemployment Insurance," American Economic Review, 1997, 87 (1), 192-205.

Handel, Benjamin R, "Adverse selection and inertia in health insurance markets: When nudging hurts," American Economic Review, 2013, 103 (7), 2643-82.

Hansen, Gary D. and Ayse Imrohoroglu, "The Role of Unemployment Insurance in an Economy with Liquidity Constraints and Moral Hazard," Journal of Political Economy, 1992, 100 (1), 118-142.

Hastings, Justine and Ebonya Washington, "The First of the Month Effect: Consumer Behavior and Store Responses," American Economic Journal: Economic Policy, 2010, 2 (2), 142-162.

Hu, Luojia, Robert Kaestner, Bhashkar Mazumder, Sarah Miller, and Ashley Wong, "The Effect of the Patient Protection and Affordable Care Act Medicaid Expansions on Financial Well-Being," Journal of Public Economics, 2018, 163, 99-112.

Johnson, David S., Jonathan A. Parker, and Nicholas S. Souleles, "Household Expenditure and the Income Tax Rebates of 2001," American Economic Review, 2006, 96 (5), 1589-1610.

Kaiser Family Foundation, "Employer Health Benefits," http://files.kff .org/ attachment/Report-Employer-Health-Benefits-Annual-Survey-2018 2018.

_, "Medicaid and CHIP Eligibility, Enrollment, and Cost Sharing Policies as of January 2019: Findings from a 50-State Survey," https://www.kff.org/report-section/ medicaid-and-chip-eligibility-enrollment-and-cost-sharing-policies-as-of-january-2 2019.

Kaplan, Greg and Giovanni L. Violante, "A Model of the Consumption Response to Fiscal Stimulus Payments," Econometrica, 2014, 82 (4), 1199-1239. 
Ketcham, Jonathan D, Claudio Lucarelli, Eugenio J Miravete, and M Christopher Roebuck, "Sinking, swimming, or learning to swim in Medicare Part D," American Economic Review, 2012, 105 (2), 2639-73.

LaLumia, Sara, "The EITC, Tax Refunds, and Unemployment Spells," American Economic Journal: Economic Policy, 2013, 5 (2), 190-223.

Leary, Jesse B. and Jialan Wang, "Liquidity Constraints and Budgeting Mistakes: Evidence from Social Security Recipients," Mimeo, 2016.

Mahoney, Neale, "Bankruptcy as Implicit Health Insurance," American Economic Review, 2015, 101 (4), 710-46.

Malani, Anup and Sonia Jaffe, "The Welfare Implications of Health Insurance," Working Paper 24851, National Bureau of Economic Research 2018.

Manning, Willard G., Joseph P. Newhouse, Naihua Duan, Emmett B. Keeler, and Arleen Leibowitz, "Health Insurance and the Demand for Medical Care: Evidence from a Randomized Experiment," American Economic Review, 1987, 77 (3), 251-277.

Mazumder, Bhashkar and Sarah Miller, "The effects of the Massachusetts health reform on household financial distress," American Economic Journal: Economic Policy, 2016, 8 (3), 284-313.

Nyman, John A., "The Value of Health Insurance: The Access Motive," Journal of Health Economics, 1999, 18 (2), 141-152.

O'Carroll, Patrick, "Hearing on the Direct Deposit of Social Security Benefits," https://oig.ssa.gov/newsroom/congressional-testimony/ hearing-direct-deposit-social-security-benefits, Social Security Administration Office of the Inspector General 2012.

Olafsson, Arna and Michaela Pagel, "The Liquid Hand-to-Mouth: Evidence from Personal Finance Management Software," Review of Financial Studies, 2018, 31 (11), 4398-4446.

Parker, Jonathan A., "The Reaction of Household Consumption to Predictable Changes in Social Security Taxes," American Economic Review, 1999, 89 (4), 959973.

_, Nicholas S. Souleles, David S. Johnson, and Robert McClelland, "Consumer Spending and the Economic Stimulus Payments of 2008," American Economic Review, 2013, 103 (6), 2530-2553.

Polyakova, Maria, "Regulation of insurance with adverse selection and switching costs: Evidence from Medicare Part D," American Economic Journal: Applied Economics, 2016, 8 (3), 165-95. 
Shapiro, Jesse M., "Is there a Daily Discount Rate? Evidence from the Food Stamp Nutrition Cycle," Journal of Public Economics, 2005, 89 (2), 303-325.

Shigeoka, Hitoshi, "The Effect of Patient Cost Sharing on Utilization, Health, and Risk Protection," American Economic Review, 2014, 104 (7), 2152-2184.

Souleles, Nicholas S., "The Response of Household Consumption to Income Tax Refunds," American Economic Review, 1999, 89 (4), 947-958.

Stephens, Melvin Jr., "'3rd of tha Month:' Do Social Security Recipients Smooth Consumption Between Checks?," American Economic Review, 2003, 93 (1), 406422.

_ , "Paycheque Receipt and the Timing of Consumption," Economic Journal, 2006, 116 (513), 680-701.

Thaler, Richard H., "Mental Accounting and Consumer Choice," Marketing Science, 1985, 4 (3), 177-266.

_ , "Mental Accounting Matters," Journal of Behavioral Decision Making, 1999, 12 (3), 183-206.

Vellekoop, Nathanael, "Explaining Intra-Monthly Consumption Patterns: The Timing of Income or the Timing of Consumption Commitments?," Working Paper 237, SAFE 2018.

Zeckhauser, Richard, "Medical Insurance: A Case Study of the Tradeoff Between Risk Spreading and Appropriate Incentives," Journal of Economic Theory, 1970, 2 (1), 10-26.

Zhang, C. Yiwei, "Consumption Responses to Pay Frequency: Evidence from 'Extra' Paychecks," Advances in Consumer Research, 2017, 45, 170-174. 


\section{A Appendix Tables and Figures}

Appendix Table A1. Summary Statistics for Transitions Across Copay Groups

\begin{tabular}{|c|c|c|c|c|}
\hline & $\begin{array}{l}\quad(1) \\
\text { Copay } \\
\text { to No-Copay }\end{array}$ & $\begin{array}{l}\qquad(2) \\
\text { No-Copay to } \\
\text { Copay }\end{array}$ & $\begin{array}{l}\quad(3) \\
\text { Full-Copay to } \\
\text { Subsidized- } \\
\text { Copay }\end{array}$ & $\begin{array}{l}\quad(4) \\
\text { Subsidized- } \\
\text { Copay to } \\
\text { Full-Copay }\end{array}$ \\
\hline $\begin{array}{l}\text { Number of beneficiaries } \\
\text { in } 20 \% \text { sample }\end{array}$ & 45,968 & 24,136 & 13,838 & 11,853 \\
\hline $\begin{array}{l}\text { Mean total scripts } \\
\text { per year }\end{array}$ & 38.74 & 45.18 & 40.80 & 38.68 \\
\hline $\begin{array}{l}\text { Mean out-of-pocket } \\
\text { spending per year }\end{array}$ & $\$ 218.94$ & $\$ 254.28$ & $\$ 386.00$ & $\$ 372.88$ \\
\hline $\begin{array}{l}\text { Mean out-of-pocket } \\
\text { spending per script }\end{array}$ & $\$ 6.66$ & $\$ 6.30$ & $\$ 10.64$ & $\$ 10.30$ \\
\hline $\begin{array}{l}\text { Mean share filling } \\
\text { a script each day }\end{array}$ & 0.0044 & 0.0045 & 0.0049 & 0.0042 \\
\hline Share male & 0.348 & 0.365 & 0.316 & 0.444 \\
\hline Average age & 71.11 & 70.60 & 71.39 & 70.70 \\
\hline $\begin{array}{l}\text { Average number of } \\
\text { chronic conditions }\end{array}$ & 3.76 & 3.88 & 3.98 & 3.73 \\
\hline Share white & 0.692 & 0.681 & 0.767 & 0.707 \\
\hline
\end{tabular}

This table presents summary statistics for recipients who switch copay groups. For more details, see Section 3.2. 
Appendix Table A2. Effect of Changes in the Generosity of Coverage on the Share of Wednesday Fills that Occur on Social Security Payday

\begin{tabular}{|c|c|c|c|c|c|c|}
\hline & $\begin{array}{l}\quad(1) \\
\text { Copay } \\
\text { to No-Copay }\end{array}$ & $\begin{array}{l}\text { (2) } \\
\text { Subsidized } \\
\text {-Copay to } \\
\text { No-Copay }\end{array}$ & $\begin{array}{l}\qquad(3) \\
\text { Full-Copay } \\
\text { to No-Copay }\end{array}$ & $\begin{array}{l}\quad(4) \\
\text { No-Copay } \\
\text { to Copay }\end{array}$ & $\begin{array}{l}\quad(5) \\
\text { No-Copay to } \\
\text { Subsidized } \\
\text {-Copay }\end{array}$ & $\begin{array}{l}\quad(6) \\
\text { No-Copay to } \\
\text { Full-Copay }\end{array}$ \\
\hline Post Transition & $\begin{array}{c}-0.0258^{* * *} \\
(0.0021)\end{array}$ & $\begin{array}{c}-0.0253^{* * *} \\
(0.0034)\end{array}$ & $\begin{array}{c}-0.0243^{* * *} \\
(0.0036)\end{array}$ & $\begin{array}{c}-0.0227^{*} \\
(0.0108)\end{array}$ & $\begin{array}{l}-0.0050 \\
(0.0078)\end{array}$ & $\begin{array}{l}-0.0170 \\
(0.0144)\end{array}$ \\
\hline Mean & 0.25 & 0.25 & 0.25 & 0.22 & 0.23 & 0.22 \\
\hline$N$ & 8,939 & 8,822 & 8,867 & 1,023 & 901 & 1,004 \\
\hline
\end{tabular}

This table presents regressions in which the outcome is the share of Wednesday prescriptions filled on the recipient's Social Security payday. The first column studies transitions from either copay group to the no-copay group while the second and third columns study transitions from either copay group to the nocopay group respectively. The fourth column studies transitions from the no-copay group to either copay group while the fifth and sixth columns study transitions from the no-copay group to either copay group, respectively. Each observation consists of a recipient-month. Standard errors in parentheses. These coefficients come from estimating equation (2). Cohort-specific fixed effects and calendar-month-specific fixed effects not shown. For more details, see Section 3.2. ${ }^{*} p<0.1,{ }^{* *} p<0.05,{ }^{* * *} p<0.01$ 
Appendix Table A3. The Effect of Changes in Generosity of Coverage Across Deciles of Share of Wednesday Fills on Payday for Transitions to the No-Copay Group

\begin{tabular}{|c|c|c|c|}
\hline & $\begin{array}{c}(1) \\
\text { Log Total Scripts }\end{array}$ & $\begin{array}{c}(2) \\
\text { Log Out-of-Pocket }\end{array}$ & $\begin{array}{c}(3) \\
\text { Elasticity }\end{array}$ \\
\hline All & $\begin{array}{l}0.08076^{* * *} \\
(0.00280)\end{array}$ & $\begin{array}{c}-1.26905^{* * *} \\
(0.00867)\end{array}$ & $\begin{array}{c}-0.06364^{* * *} \\
(0.00224)\end{array}$ \\
\hline All excl. Zero or Missing & $\begin{array}{c}0.05943^{* * *} \\
(0.00252)\end{array}$ & $\begin{array}{c}-1.45435^{* * *} \\
(0.00910)\end{array}$ & $\begin{array}{c}-0.04086^{* * *} \\
(0.00173)\end{array}$ \\
\hline Decile 1 & $\begin{array}{c}0.05186^{* * *} \\
(0.00684)\end{array}$ & $\begin{array}{c}-1.48130^{* * *} \\
(0.01697)\end{array}$ & $\begin{array}{c}-0.03501^{* * *} \\
(0.00460)\end{array}$ \\
\hline Decile 2 & $\begin{array}{c}0.05171^{* * *} \\
(0.00569)\end{array}$ & $\begin{array}{c}-1.48616^{* * *} \\
(0.01572)\end{array}$ & $\begin{array}{c}-0.03480^{* * *} \\
(0.00392)\end{array}$ \\
\hline Decile 3 & $\begin{array}{c}0.05250^{* * *} \\
(0.00623)\end{array}$ & $\begin{array}{c}-1.51336^{* * *} \\
(0.01813)\end{array}$ & $\begin{array}{c}-0.03469^{* * *} \\
(0.00408)\end{array}$ \\
\hline Decile 4 & $\begin{array}{c}0.04749^{* * *} \\
(0.00750)\end{array}$ & $\begin{array}{c}-1.52003^{* * *} \\
(0.01935)\end{array}$ & $\begin{array}{c}-0.03125^{* * *} \\
(0.00503)\end{array}$ \\
\hline Decile 5 & $\begin{array}{c}0.05026^{* * *} \\
(0.00581)\end{array}$ & $\begin{array}{c}-1.47676^{* * *} \\
(0.01534)\end{array}$ & $\begin{array}{c}-0.03404^{* * *} \\
(0.00397)\end{array}$ \\
\hline Decile 6 & $\begin{array}{c}0.04921^{* * *} \\
(0.00792)\end{array}$ & $\begin{array}{c}-1.54714^{* * *} \\
(0.01802)\end{array}$ & $\begin{array}{c}-0.03181^{* * *} \\
(0.00519)\end{array}$ \\
\hline Decile 7 & $\begin{array}{c}0.06594^{* * *} \\
(0.00644)\end{array}$ & $\begin{array}{c}-1.44231^{* * *} \\
(0.01853)\end{array}$ & $\begin{array}{c}-0.04572^{* * *} \\
(0.00462)\end{array}$ \\
\hline Decile 8 & $\begin{array}{c}0.05631^{* * *} \\
(0.00665)\end{array}$ & $\begin{array}{c}-1.51936^{* * *} \\
(0.01394)\end{array}$ & $\begin{array}{c}-0.03706^{* * *} \\
(0.00442)\end{array}$ \\
\hline Decile 9 & $\begin{array}{c}0.07541^{* * *} \\
(0.00638)\end{array}$ & $\begin{array}{c}-1.36370^{* * *} \\
(0.01575)\end{array}$ & $\begin{array}{c}-0.05530^{* * *} \\
(0.00484)\end{array}$ \\
\hline Decile 10 & $\begin{array}{c}0.09538^{* * *} \\
(0.00636)\end{array}$ & $\begin{array}{c}-1.19704^{* * *} \\
(0.01724)\end{array}$ & $\begin{array}{c}-0.07968^{* * *} \\
(0.00571)\end{array}$ \\
\hline Zero & $\begin{array}{c}0.12181^{* * *} \\
(0.00536)\end{array}$ & $\begin{array}{c}-0.98734^{* * *} \\
(0.01313)\end{array}$ & $\begin{array}{c}-0.12337^{* * *} \\
(0.00578)\end{array}$ \\
\hline Missing & $\begin{array}{c}0.19245^{* * *} \\
(0.00719)\end{array}$ & $\begin{array}{c}-0.15497^{* * *} \\
(0.00692)\end{array}$ & $\begin{array}{c}-1.24187^{* * *} \\
(0.07993)\end{array}$ \\
\hline
\end{tabular}

This table presents estimates of equation (2) across deciles of the proportion of Wednesday fills that fall on a recipient's Social Security payday. The sample is restricted to recipients who switch from either the full-copay group or the subsidized-copay group to the no-copay group, 12 months before and 12 months after their switch. The first row presents estimates for all beneficiaries. The second row presents results for recipients with at least one Wednesday fill on a payday. The subsequent rows present estimates for recipients who have at least one Wednesday fill on a payday and are in the given decile of the proportion of Wednesday fills on payday. The final rows presents results for recipients who have no Wednesday fills on payday or no Wednesday fills. Standard errors in parentheses clustered on cohort of recipients transitioning copay groups for the first two columns. Standard errors are based on the delta method for the elasticity estimation in the third column. Recipientspecific fixed effects and year-times-month-specific fixed effects not shown. For more details, see Section 3.2. ${ }^{*} p<0.1,{ }^{* *} p<0.05,{ }^{* * *} p<0.01$. 
Appendix Table A4. Effect of Changes in Generosity of Coverage

\begin{tabular}{llc}
\hline$(1)$ & $(2)$ & $(3)$ \\
Log Total & Log Out-of & Elasticity \\
Scripts & -Pocket & \\
\hline
\end{tabular}

\begin{tabular}{|c|c|c|c|}
\hline \multicolumn{4}{|c|}{ A. Transition from Copay to No Copay } \\
\hline $\begin{array}{l}\text { Post } \\
\text { Transition }\end{array}$ & $\begin{array}{c}0.0433^{* * *} \\
(0.0018)\end{array}$ & $\begin{array}{c}-0.8191^{* * *} \\
(0.0068)\end{array}$ & $\begin{array}{c}-0.0529^{* * *} \\
(0.0023)\end{array}$ \\
\hline Mean & 0.79 & 5.16 & \\
\hline$N$ & $1,103,232$ & $1,103,232$ & $1,103,232$ \\
\hline \multicolumn{4}{|c|}{ B. Transition from No Copay to Copay } \\
\hline $\begin{array}{l}\text { Post } \\
\text { Transition }\end{array}$ & $\begin{array}{c}-0.0464^{* * *} \\
(0.0016)\end{array}$ & $\begin{array}{c}0.9008^{* * *} \\
(0.0079)\end{array}$ & $\begin{array}{c}-0.0515^{* * *} \\
(0.0014)\end{array}$ \\
\hline Mean & 1.08 & 0.00 & \\
\hline$N$ & 579,264 & 579,264 & 579,264 \\
\hline
\end{tabular}

This table presents estimates of the impact of switching to the no-copay group from the copay groups (top panel) and vice versa (bottom panel) on the outcomes listed. Scripts are restricted to the high value drugs of Plavis, Warfarin, HIV, Anti-psychotics, Anti-seizure, Anti-biotics, Insulin, Statins, Anti-depressants and Inhalers. Standard errors in parentheses clustered on cohort of recipients transitioning copay groups for the first two columns. Standard errors are based on the delta method for the elasticity estimation in the third column. The data is limited to 12 months before and 12 months after the switch. Recipient-specific fixed effects and yeartimes-month-specific fixed effects not shown. These coefficients come from estimating equation (2). The means listed are the means of the given dependent variable one month before the transition across copayment groups. For more details, see Section 3.2. ${ }^{*} p<0.1,{ }^{* *} p<0.05$, ${ }^{* * *} p<0.01$ 
Appendix Figure A1. Schedule of Social Security Benefit Payments 2019

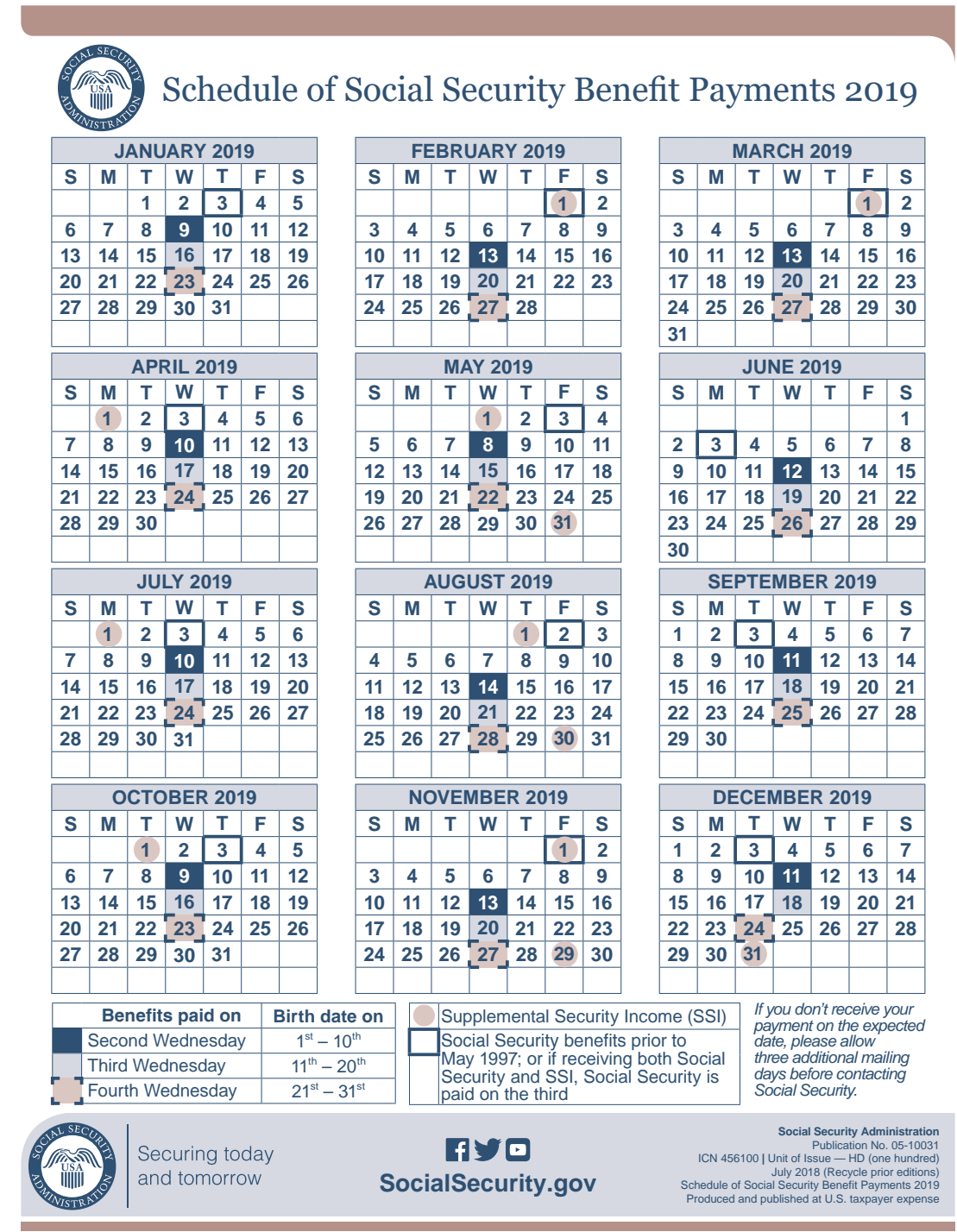

This figure shows the 2019 schedule of Social Security payments. For more details, see Section 1.1. 
Appendix Figure A2. Comparison of Elasticities Across Recipients' Propensity to Fill on Social Security Paydays, Transitions from the Subsidized-Copay Group Only

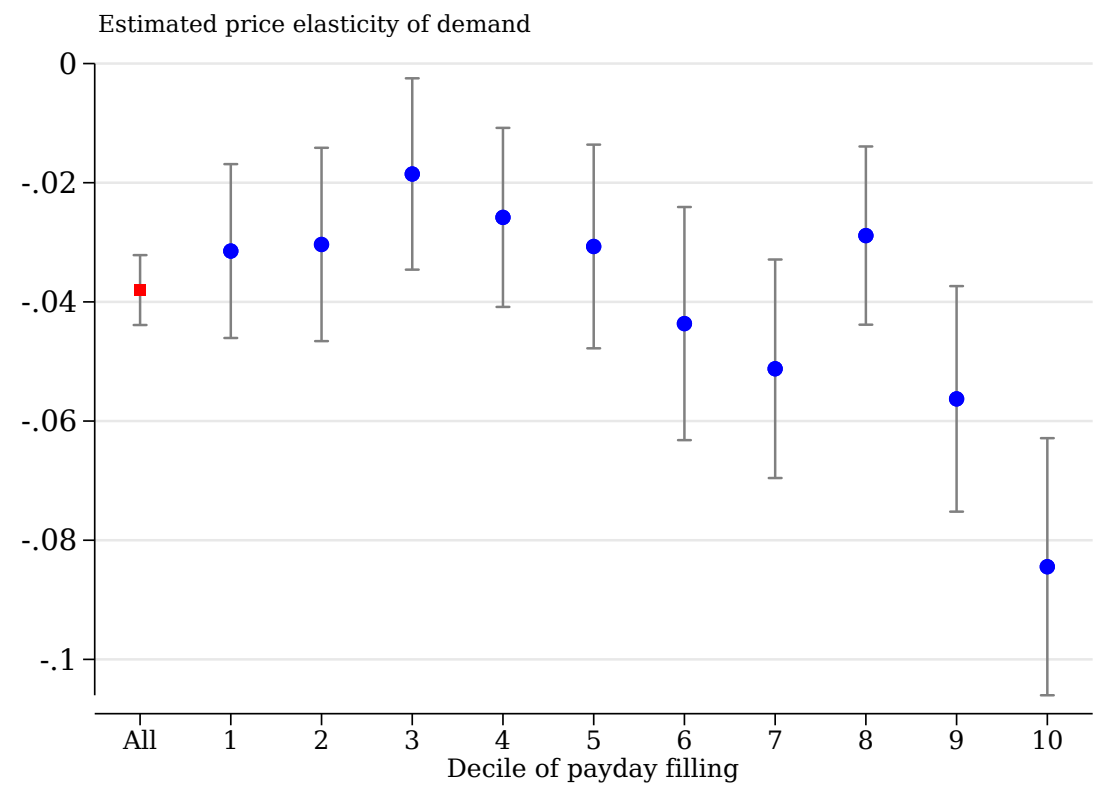

This figure presents estimated price elasticities of demand when recipients are divided into deciles based on the proportion of their Wednesday prescription fills that fall on their Social Security payday. The sample is restricted to recipients who switch from the subsidized-copay group to the no-copay group one year before and after their switch. These coefficients come from estimating an individual-level version of equation (2). Standard errors are based on the delta method. For more details, see Section 3.3. 
Appendix Figure A3. Comparison of Elasticities Across Recipients' Propensity to Fill on Social Security Paydays, Transitions from the Full-Copay Group Only

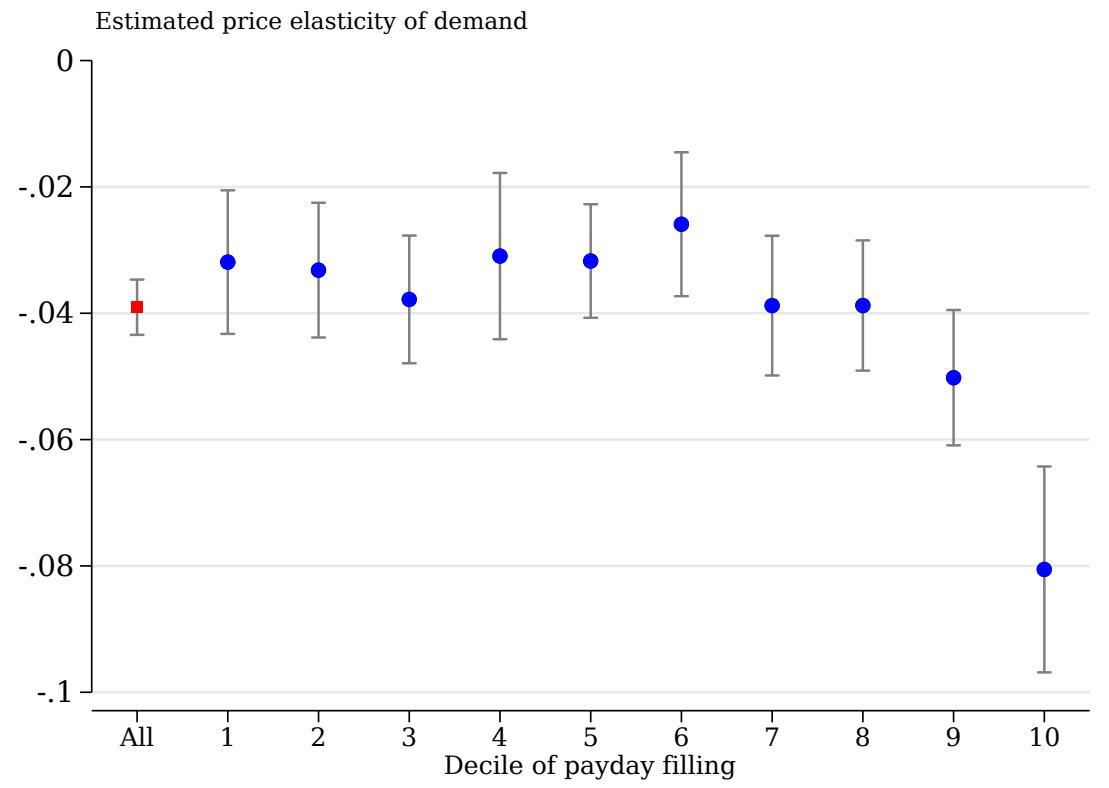

This figure presents estimated price elasticities of demand when recipients are divided into deciles based on the proportion of their Wednesday prescription fills that fall on their Social Security payday. The sample is restricted to recipients who switch from the full-copay group to the no-copay group one year before and after their switch. These coefficients come from estimating an individual-level version of equation (2). Standard errors are based on the delta method. For more details, see Section 3.3. 


\section{Appendix Figure A4. Re-Centered Time Series: Share of Recipients}

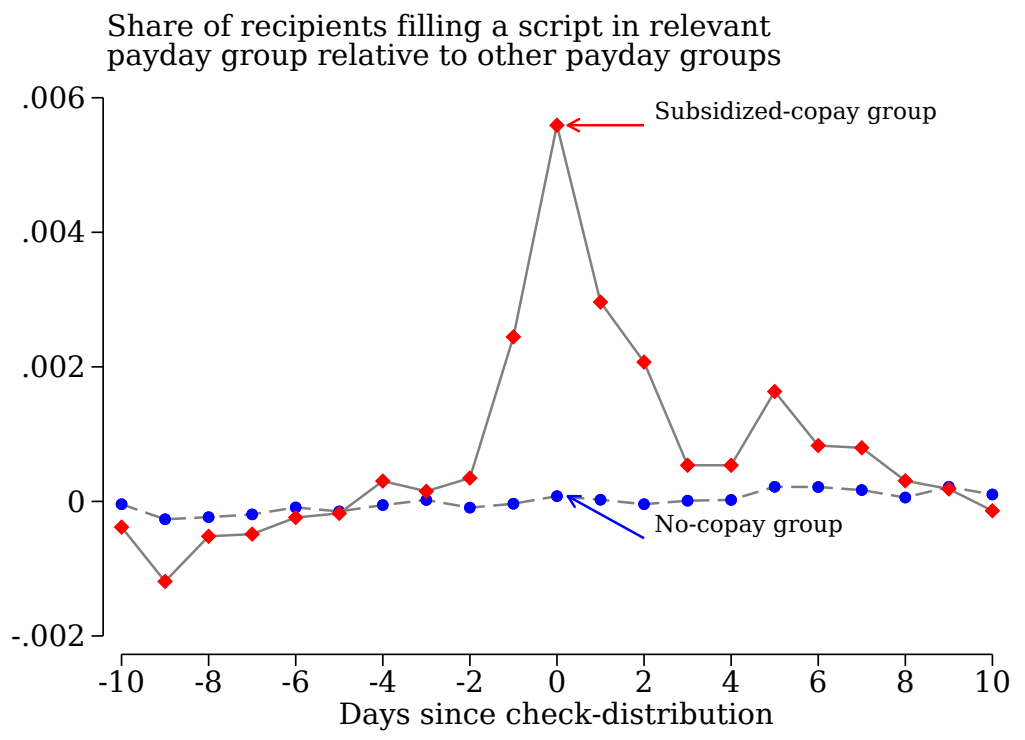

This figure plots the share of recipients filling prescriptions for each event-time day relative to check receipt for the no-copay group and the subsidized-copay group. For each copay group and event day, we calculate the difference in these outcomes across recipients who are nearest to receiving a check and those who are two weeks from their check. For more details, see Section 2.1 . 


\section{Appendix Figure A5. Re-Centered Time Series for the Full-Copay Group}

(a) Logarithm of Total Scripts

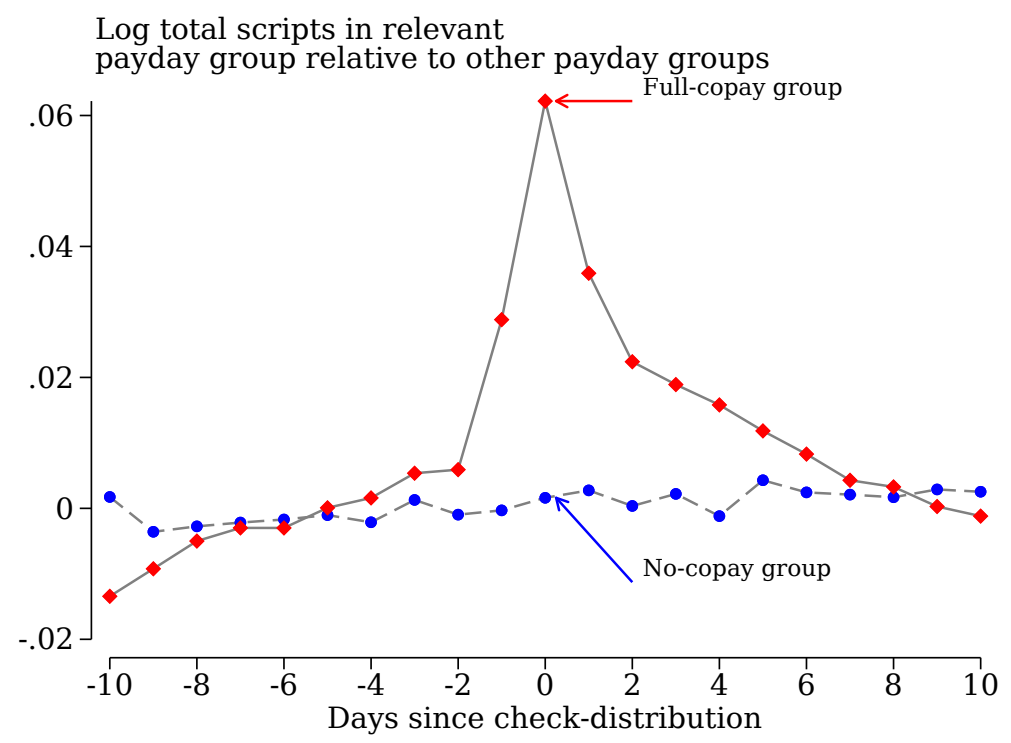

(b) Share of Beneficiaries Who Fill a Script By Day

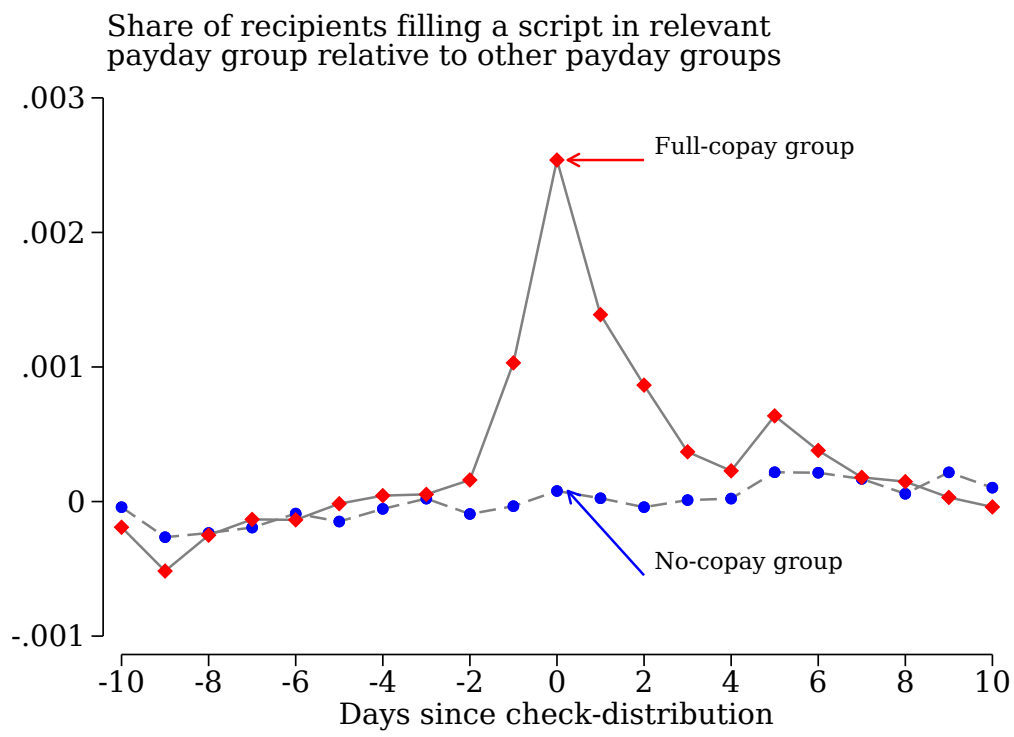

These figures plot measures of prescription drug consumption for each event-time day relative to check receipt for the no-copay group and the full-copay group. Panel (a) plots the share of beneficiaries who fill a script. Panel (b) plots the logarithm of total scripts filled. For each copay group and event day, we calculate the difference in these outcomes across recipients who are nearest to receiving a check and those who are two weeks from their check. For more details, see Section 2.1. 
Appendix Figure A6. The Effect of Social Security Checks on Total Scripts: A ReCentered Time Series

(a) Social Security Checks that Arrive after a 28-Day Wait

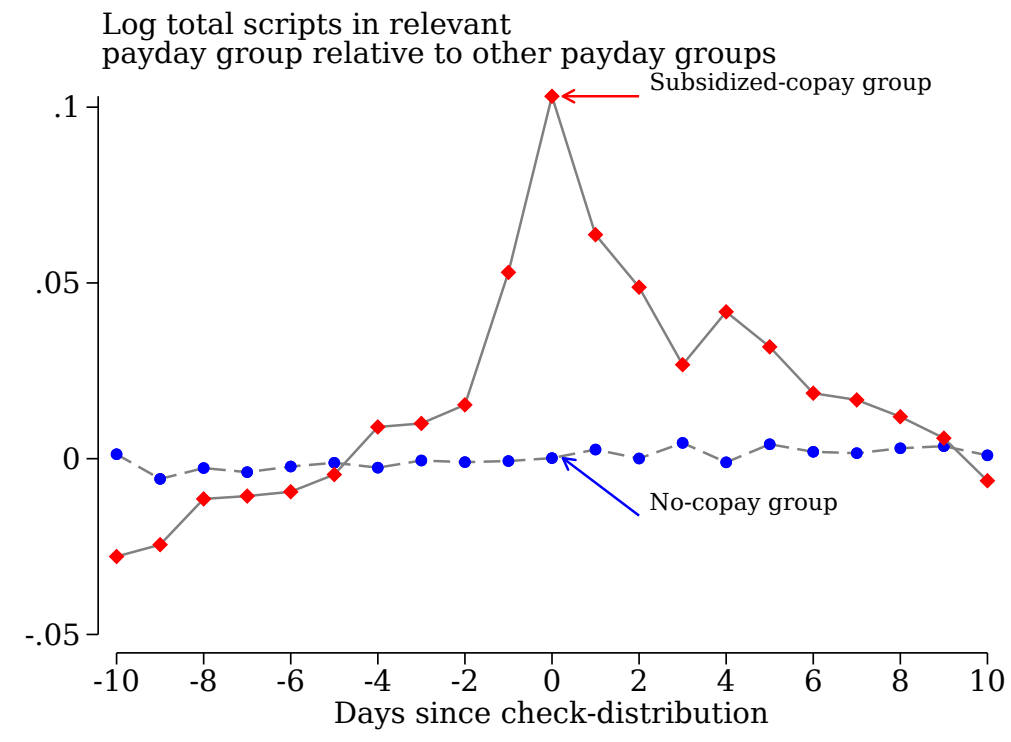

(b) Social Security Checks that Arrive after 35-Day Wait

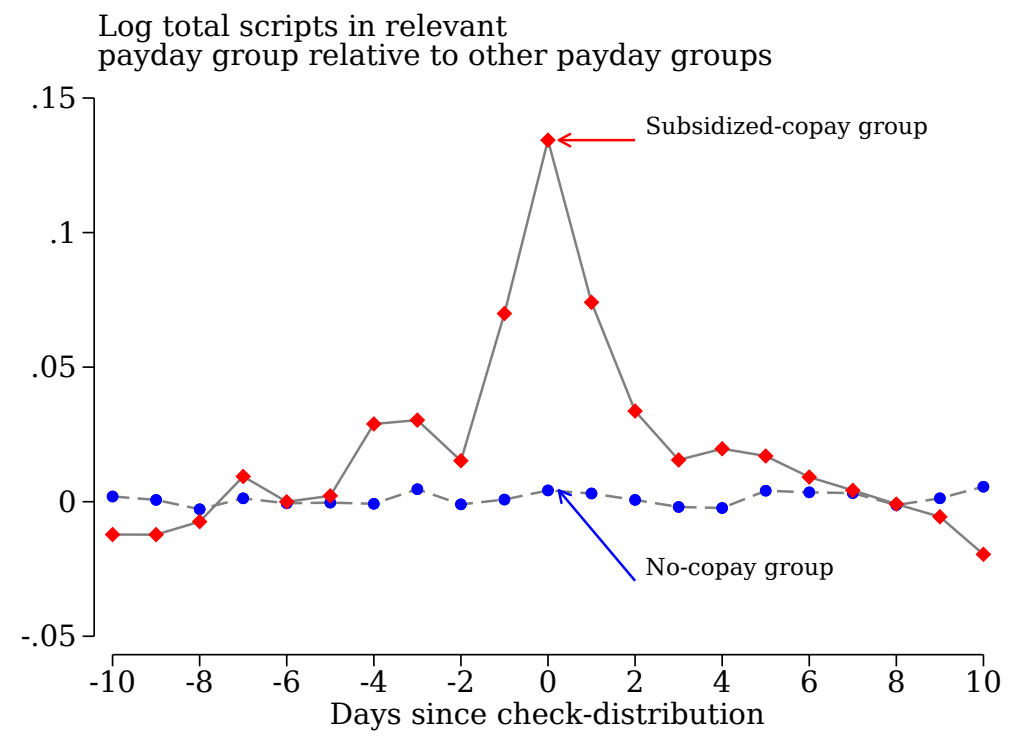

These figure plot the logarithm of the number of prescriptions filled for each event-time day relative to check receipt for the no-copay group and the subsidized-copay group. Panel (a) plots the effect for 28-day waits. Panel (b) plots the effect for 35-day waits. For each copay group and event day, we calculate the difference in these outcomes across recipients who are nearest to receiving a check and those who are two weeks from their check. For more details, see Section 2.1. 
Appendix Figure A7. Event-Study Estimates: Logarithm of the Number of Recipients Filling a Script

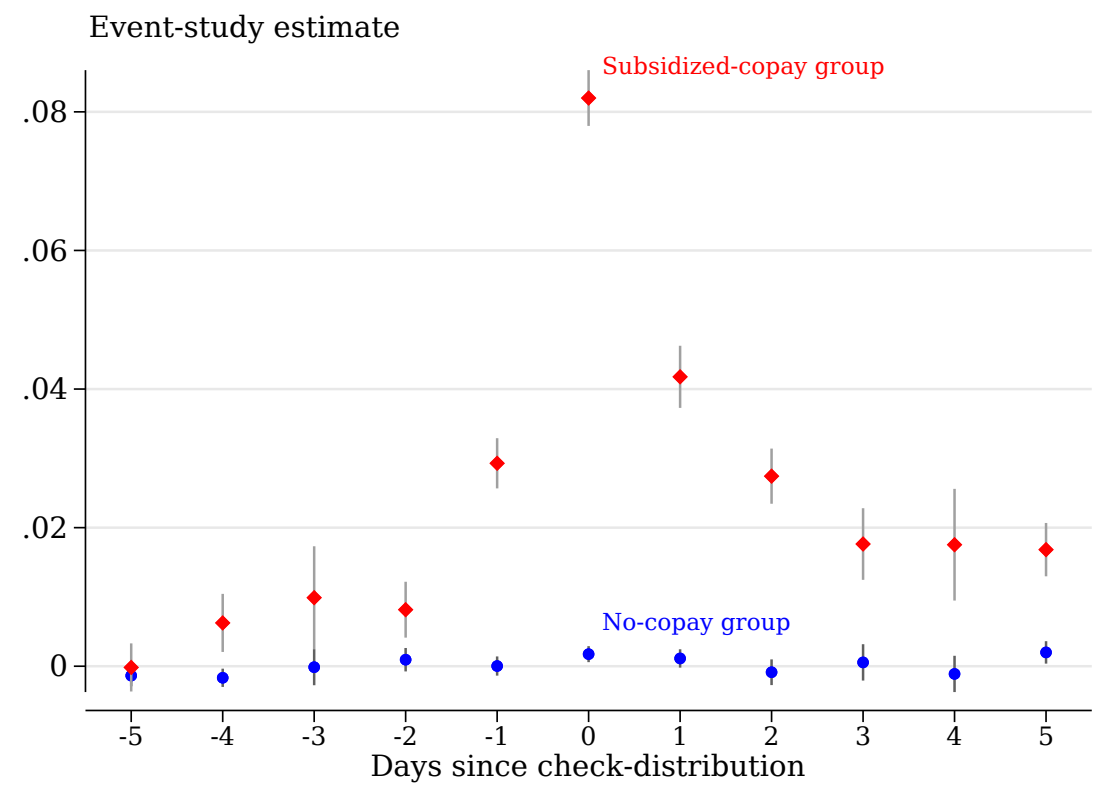

This figure plots event-study estimates of the logarithm of the number of recipients filling any script for each event-time day relative to check receipt for the no-copay group and the subsidized-copay group. The vertical lines across each marker plot 95-percent confidence intervals based on standard errors that are clustered at the level of the birthday group. For more details, see Section 2.2 . 


\section{Appendix Figure A8. Event-Study Estimates for the Full-Copay Group}

(a) Logarithm of Beneficiaries Who Fill a Script

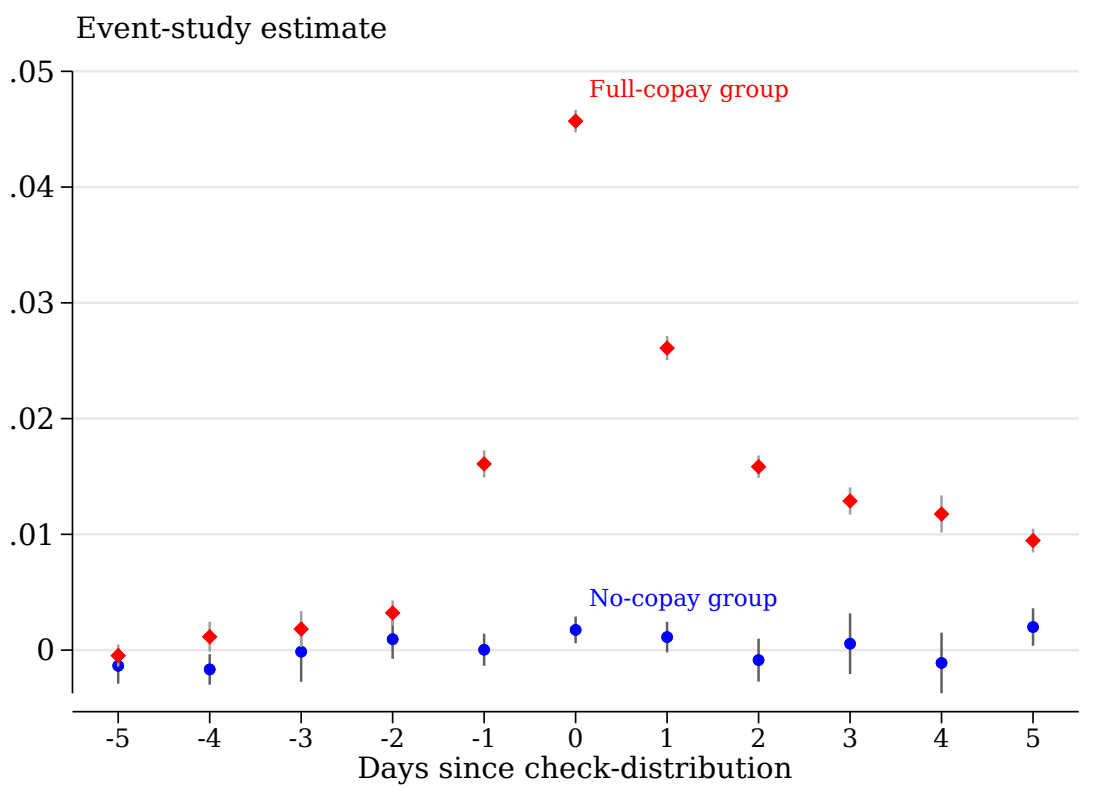

(b) Logarithm of Total Scripts

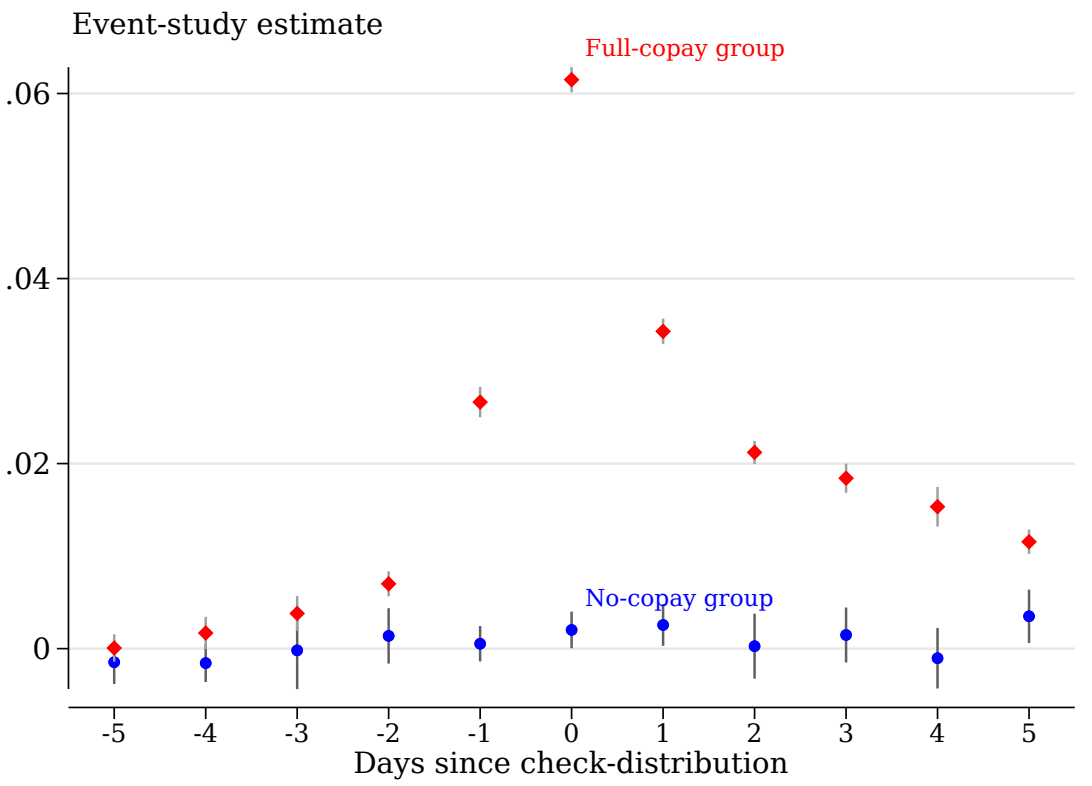

These figures plot event-study estimates of prescription drug consumption for each event-time day relative to check receipt for the no-copay group and the subsidized-copay group. Panel (a) plots estimates of regression (1) when the outcome is the logarithm of the share of beneficiaries who fill a script. Panel (b) plots estimates of equation (1) when the outcome is the logarithm of the total scripts filled. The vertical lines across each marker plot 95-percent confidence intervals based on standard errors that are clustered at the level of the birthday group. For more details, see Section 2.2. 
Appendix Figure A9. The Effect of Social Security Checks on Total Scripts: EventStudy Estimates With Wider Time Horizon

\section{Event-study estimate}

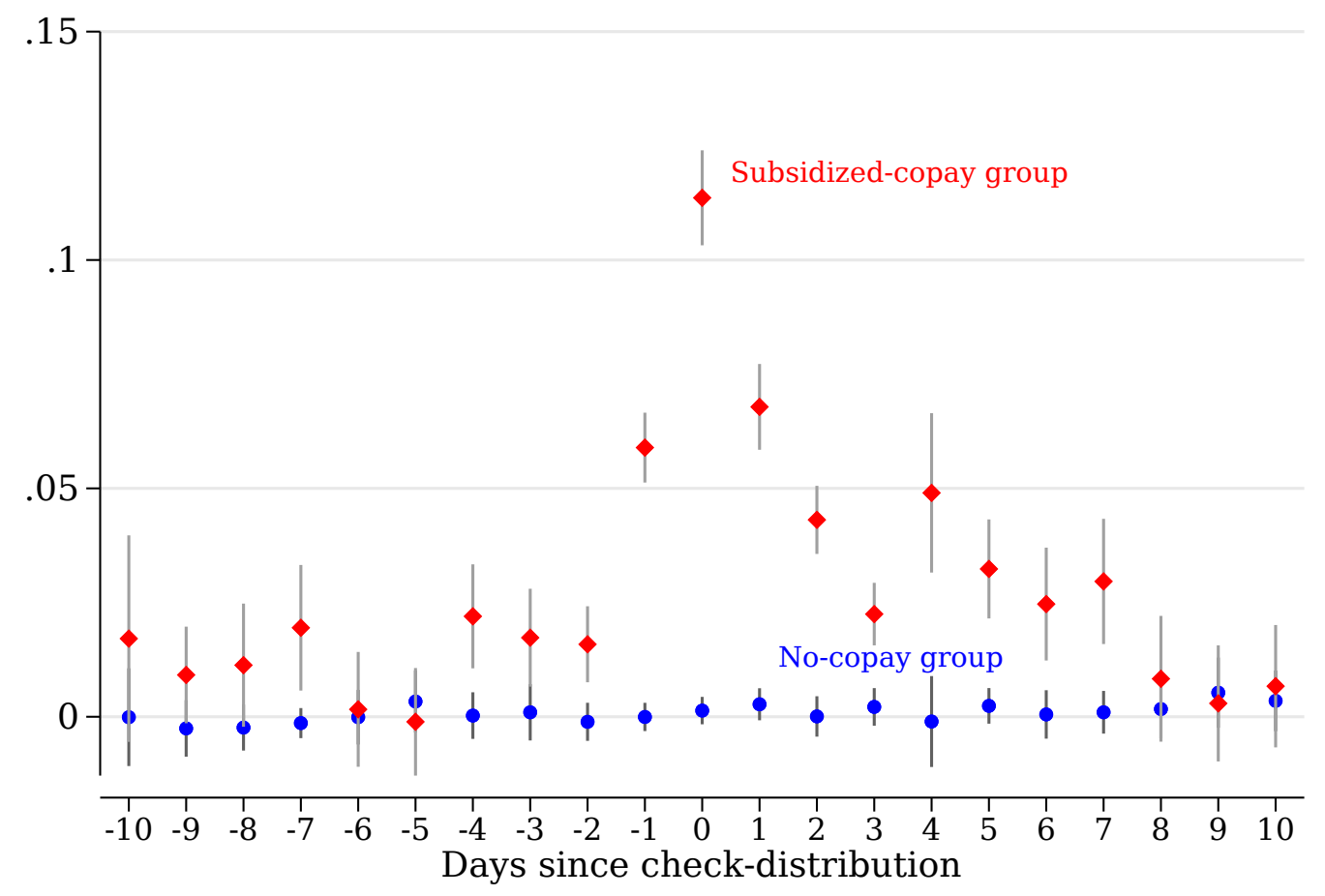

This figure plots estimates of equation (1), event-study estimates of the logarithm of total scripts filled for each event-time day relative to check receipt for the no-copay group and the subsidizedcopay group. The vertical lines across each marker plot 95-percent confidence intervals based on standard errors that are clustered at the level of the birthday group. For more details, see Section 2.2. 


\section{Appendix Figure A10. Heterogeneous Effects for the Full-Copay Group}

\section{(a) Across Types of Drugs}

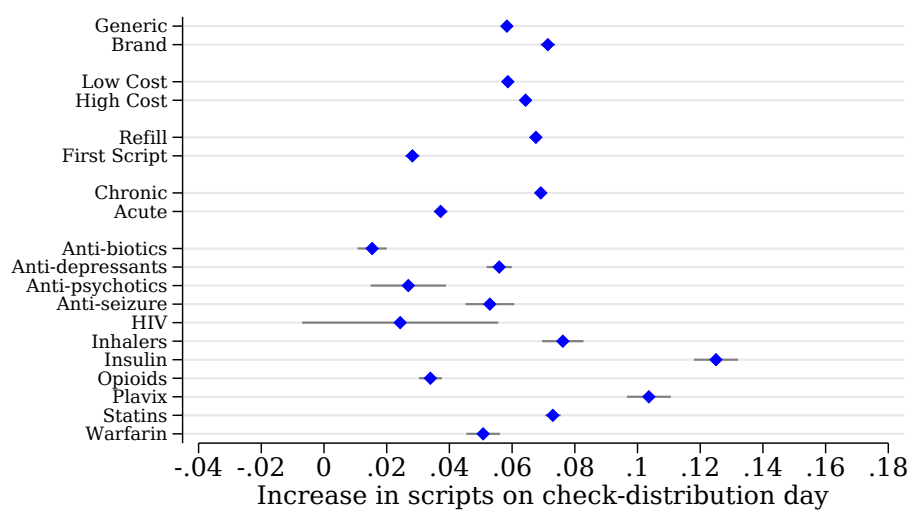

(b) Across Beneficiary Characteristics

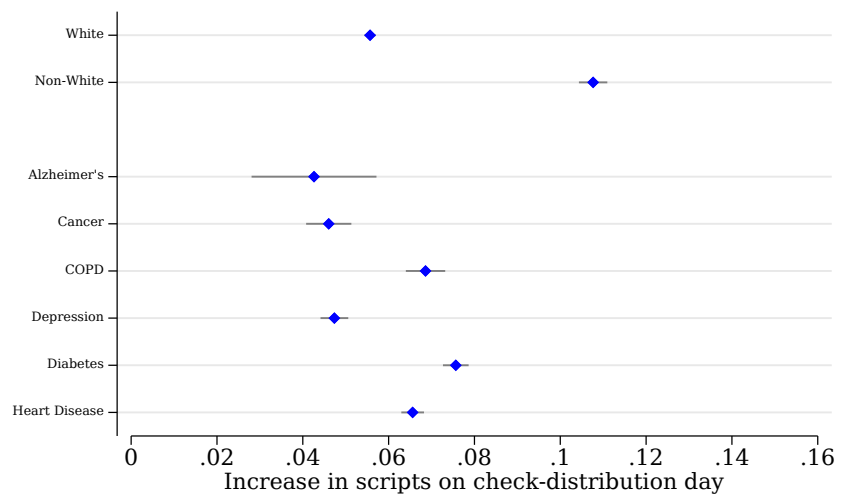

Both panels plot estimated event-study coefficients on check-distribution day for the logarithm of total scripts filled by subgroup. All samples are restricted to the full-copay group. All coefficients come from estimating equation (1). "Expected scripts filled" is the number of prescriptions that would occur on that day if all recipients with a prior prescription consumed one pill per day and then filled the script as soon as they were out of pills. The horizontal lines through each marker plot 95-percent confidence intervals based on standard errors that are clustered at the level of the birthday group. For more details, see Section 2.2. 
Appendix Figure A11. Re-Centered Time Series for the Subsidized-Copay Group, Total Scripts and Expected Refills Based on Prior Fills

(a) Logarithm of Total Scripts: 28-Day Wait

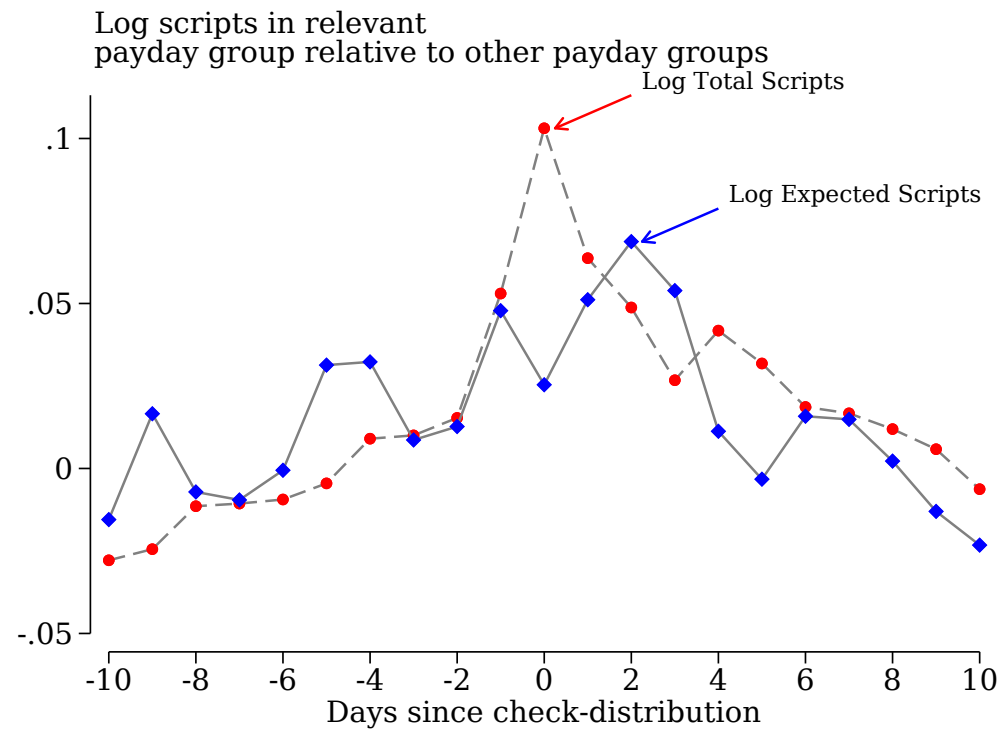

(b) Logarithm of Total Scripts: 35-Day Wait

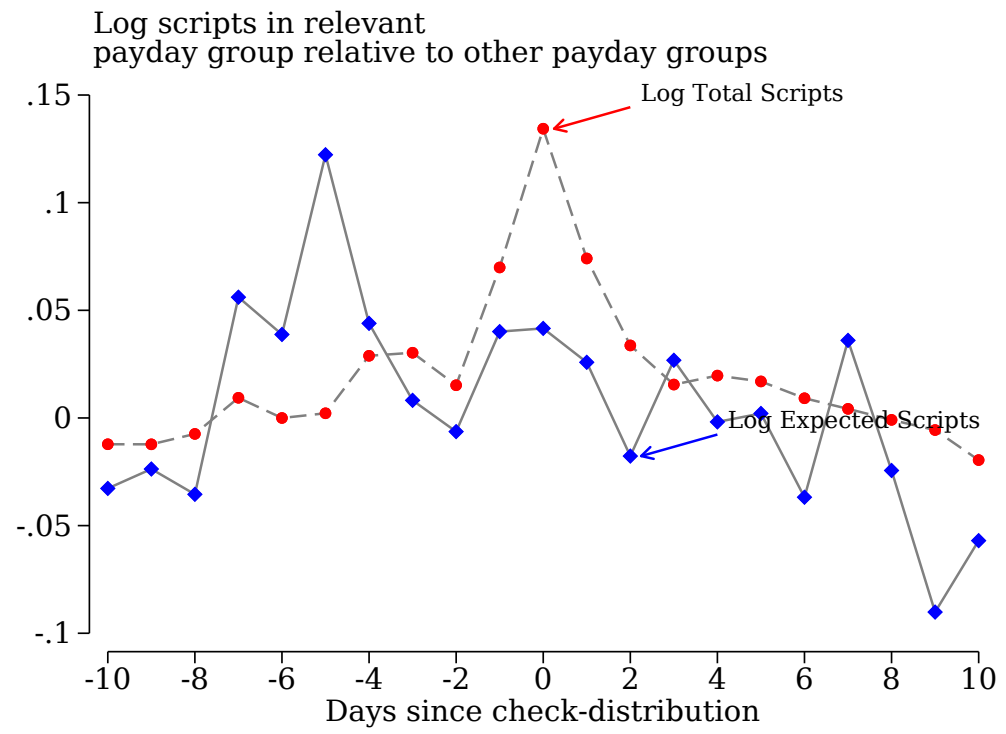

These figures plot measures of prescription drug consumption for each event-time day relative to check receipt for the subsidized-copay group. Panel (a) plots the logarithm of total scripts and expected scripts filled for 28-day waits. Panel (b) plots the logarithm of total scripts and expected scripts filled for 35-day waits. For each copay group and event day, we calculate the difference in these outcomes across recipients who are nearest to receiving a check and those who are two weeks from their check. For more details, see Section 2.1. 
Appendix Figure A12. Re-Centered Time Series For Recipients who Switch from Either Copayment Group to the No-Copayment Group

(a) No-Copay Group

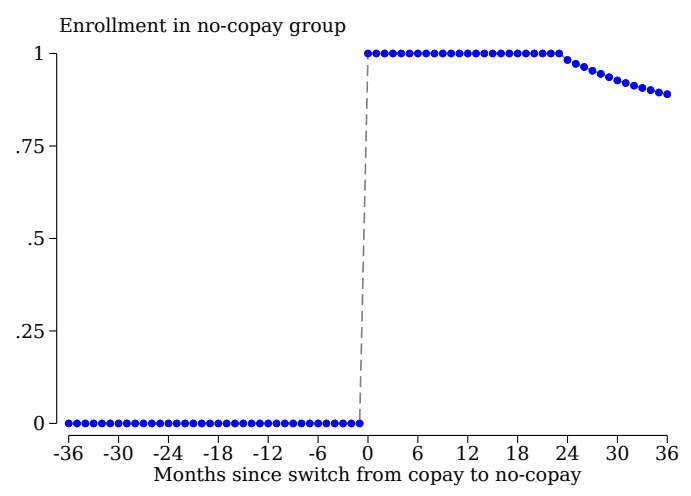

(c) Full-Copay Group

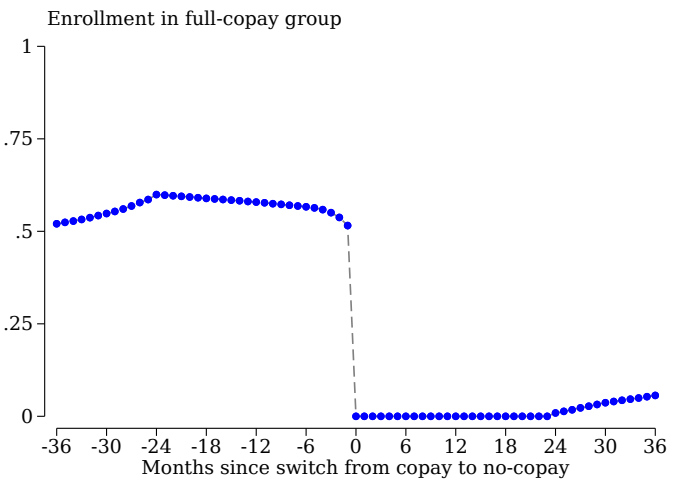

(b) Subsidized-Copay Group

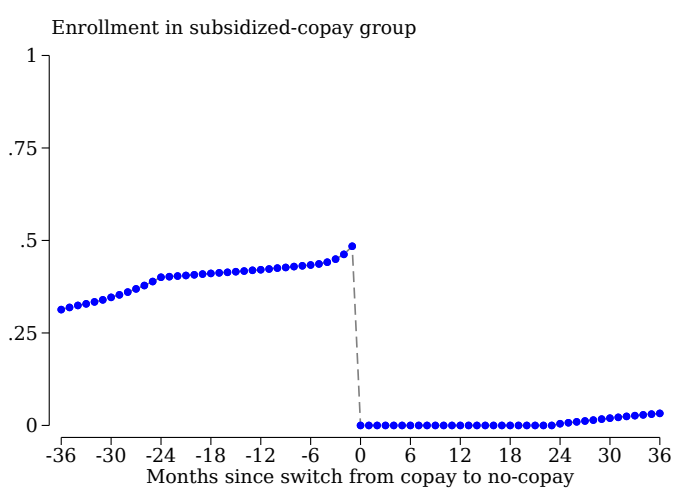

(d) Part D

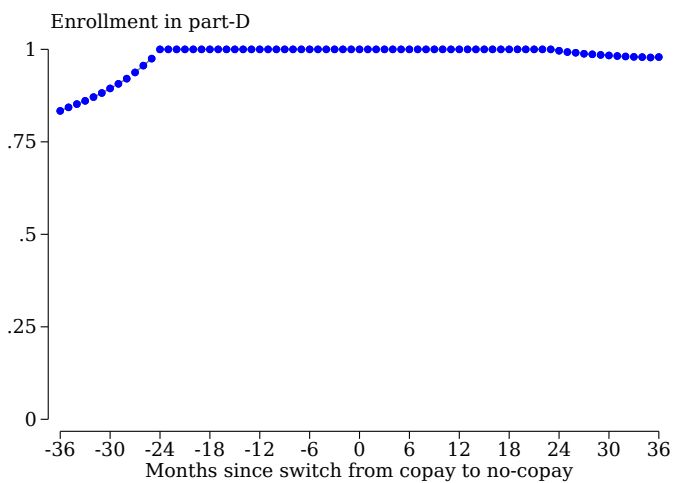

These figures plot the enrollment patterns of recipients who switch from the subsidized-copay group or the full-copay group to the no-copay group over time. Panel (a) describes enrollment in the no-copay group; Panel (b) describes enrollment in the subsidized-copay group; Panel (c) describes enrollment in the full-copay group; and Panel (d) describes enrollment in Medicare Part D overall. For more details, see Section 3.2. 
Appendix Figure A13. Re-Centered Time Series For Recipients who Switch from the No-Copayment Group to Either Copayment Group
(a) No-Copay Group
(b) Subsidized-Copay Group
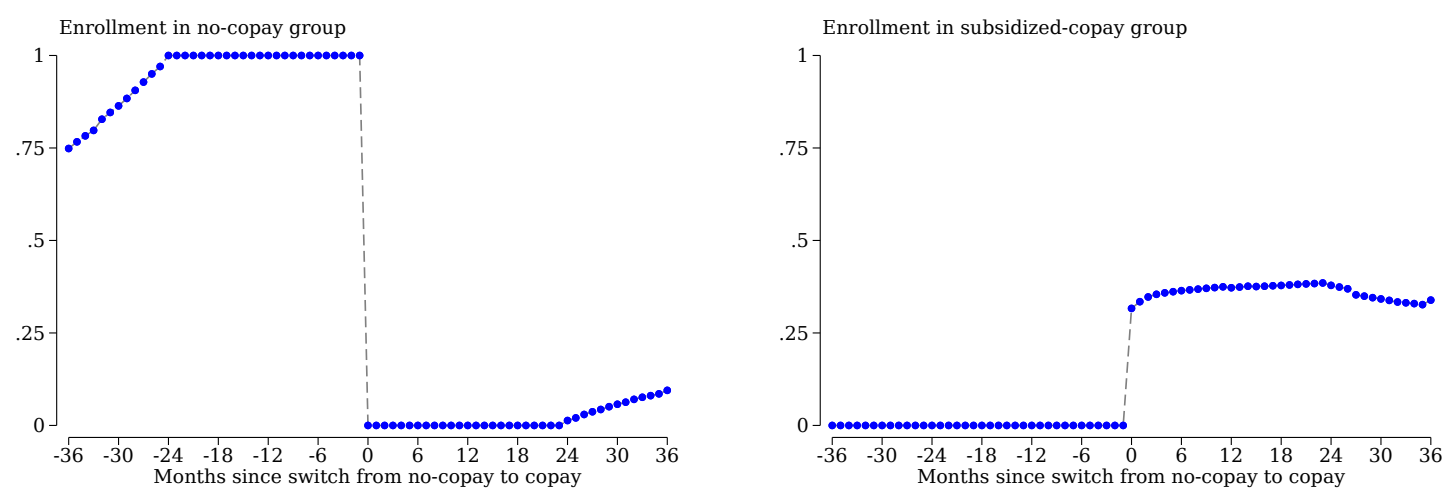

(c) Full-Copay Group

(d) Part-D
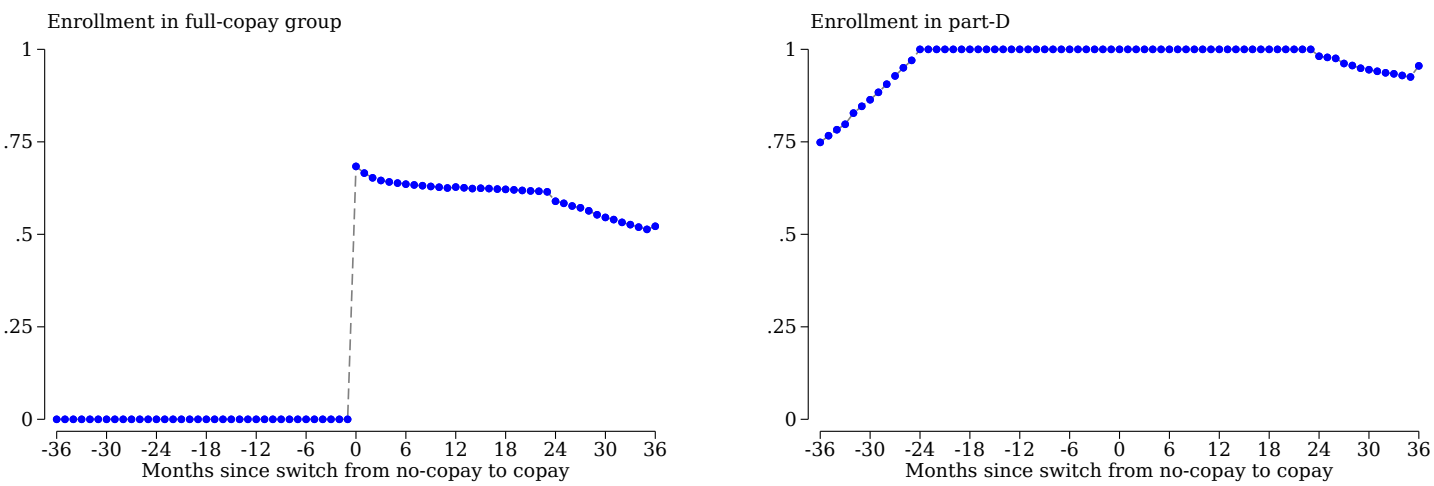

These figures plot the enrollment patterns of recipients who switch to the full-copay or the subsidized-copay group from the no-copay group over time. Panel (a) describes enrollment in the no-copay group; Panel (b) describes enrollment in the subsidized-copay group; Panel (c) describes enrollment in the full-copay group; and Panel (d) describes enrollment in Medicare Part D overall. For more details, see Section 3.2. 
Appendix Figure A14. Event-Study Estimates of the Effect of Switching from Either Copay Group to the No-Copay Group

(a) Total Scripts

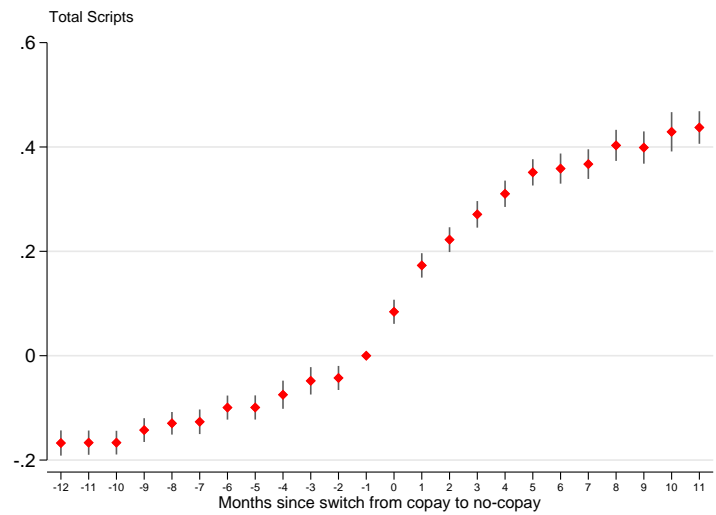

(b) Out-of-Pocket

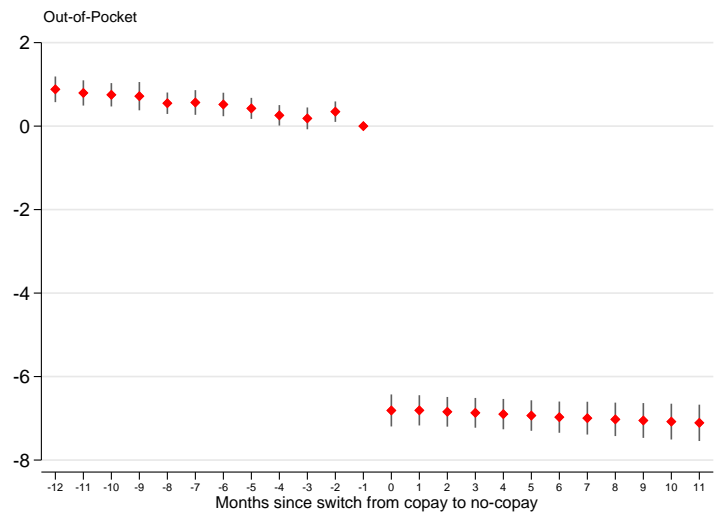

These figures present event-study estimates of the impact of switching to the no-copay group from the full-copay group or the subsidized-copay group. Panel(a) presents estimates when the outcome of interest is total scripts; Panel (b) presents estimates when the outcome of interest is the portion of spending that is out-of-pocket. Standard errors clustered on cohort of recipients transitioning copay groups. For more details, see Section 3.2.

Appendix Figure A15. Event-Study Estimates of the Effect of Switching from the No-Copay Group to Either Copay Group

(a) Total Scripts

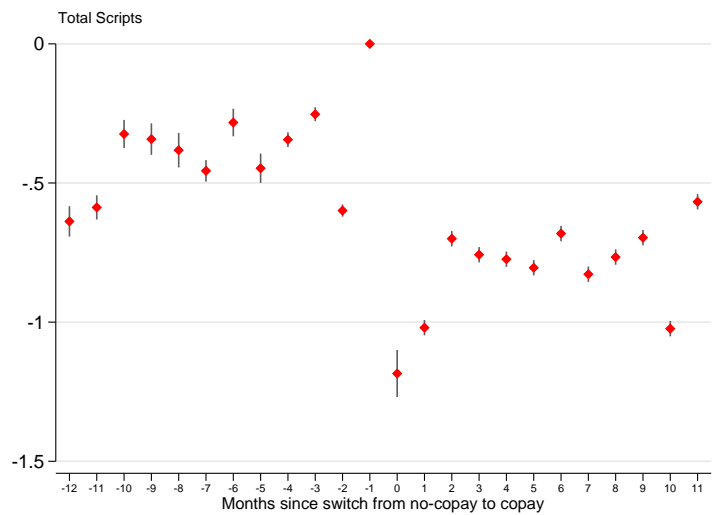

(b) Out-of-Pocket

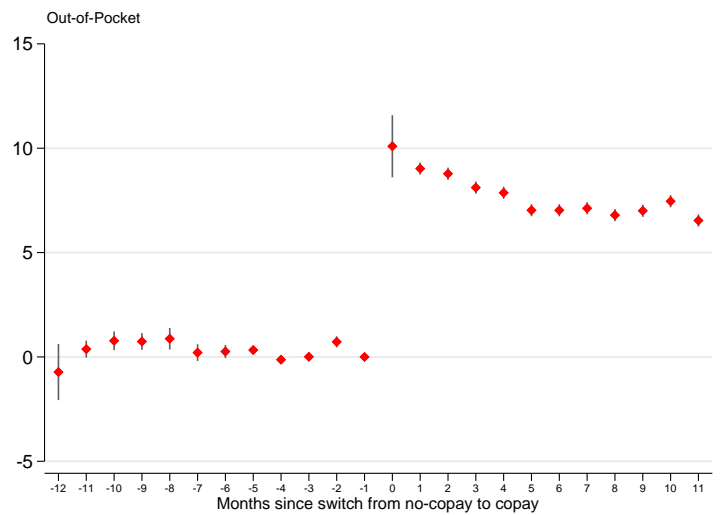

These figures present event-study estimates of the impact of switching from the no-copay group to the subsidized-copay group or the full-copay group. Panel (a) presents estimates when the outcome is total scripts; Panel (b) presents estimates when the outcome is the portion of spending that is out-of-pocket. For more details, see Section 3.2. 
Appendix Figure A16. Comparison of Elasticities Across Recipients' Propensity to Fill Prescriptions for High-Value Drugs on Social Security Paydays

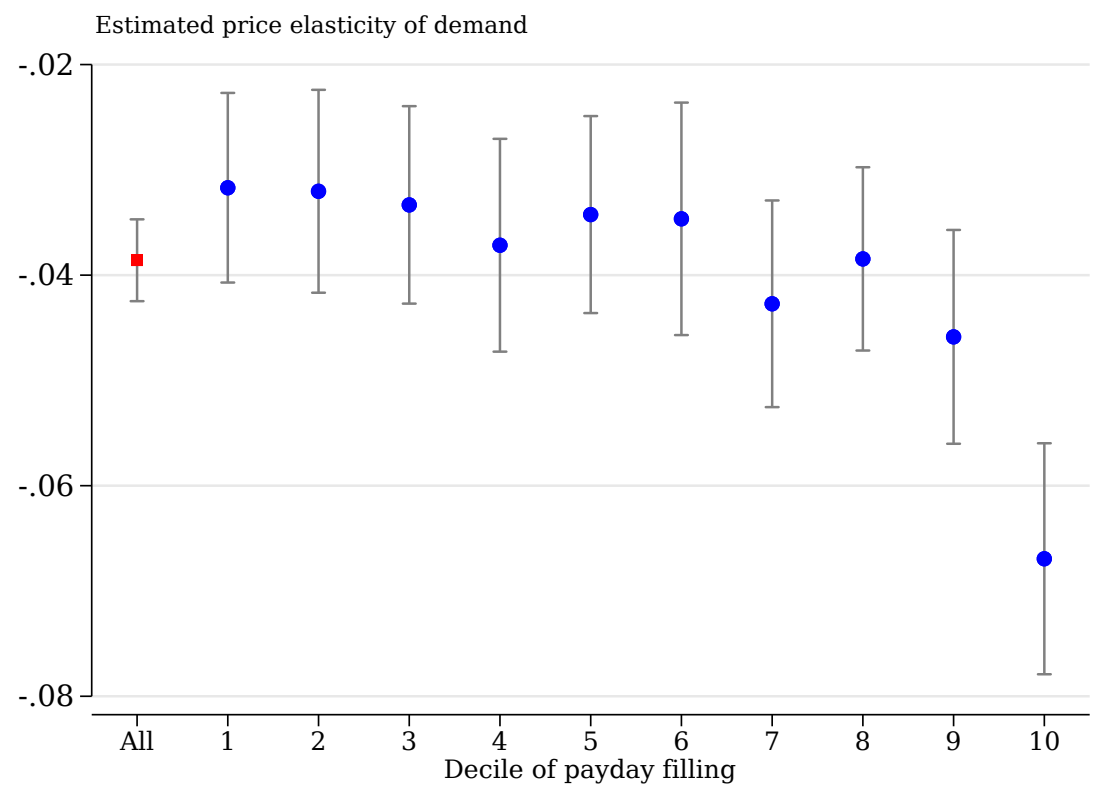

This figure presents estimated price elasticities of demand when recipients are divided into deciles based on the proportion of their Wednesday prescription fills that fall on their Social Security payday. Fills are restricted to the high value drugs of Plavis, Warfarin, HIV, Antipsychotics, Anti-seizure, Anti-biotics, Insulin, Statins, Anti-depressants and Inhalers. The sample is restricted to recipients who switch from either the full-copay group or the subsidizedcopay group to the no-copay group one year before and after their switch. These coefficients come from estimating an individual-level version of equation (2). Standard errors are based on the delta method. For more details, see Section 3.3. 


\section{B Appendix: Other Transitions Across Copayment Groups}

Section 3 studies recipients who transition from the groups that face copayments to the no-copayment group and vice-versa. Recipients, of course, undergo a variety of transitions: no-copayment group to subsidized-copayment group, full-copayment group to subsidized-copayment group, and so on. This appendix first assesses the possibility that some of those transitions are confounded by other health-related events. It then presents evidence that any confounding health-related events likely do not affect the main conclusions of Section 3.

\section{B.1 Potential Confounding Across Different Types of Transitions}

As described in Section 3, it is possible that transitions between copayment groups are endogenous, driven by other time-varying factors that affect the need for healthcare. In particular, in order to enroll in the LIS, a recipient needs to complete an application. Recipients may be more likely to undergo that ordeal if they have just experienced a health shock. Such a pattern would then make it difficult to differentiate between the effects of lower copayments and the effects of the health shock.

To assess the possibility of such a phenomenon, we measure the risk of hospitalization as recipients transition from one copayment group to another. Appendix Figure B1 presents average hospitalization rates by month since a recipient switched groups. Each panel presents means for a different transition.

The first panel of the figure suggests a spike in hospitalization rates when recipients transition to the no-copay group. That pattern is unsurprising: recipients transition onto the no-copay group when they enroll in Medicaid. Enrollment in Medicaid sometimes occurs when an individual has a health shock that results in a hospitalization. Hospital staff often help these patients enroll in Medicaid both because it helps the patients and because it reduces the hospital's exposure to bad debt.

We next investigate whether that spike in hospitalizations upon transition to the no-copayment group affects the results above. In particular, we test how potentially confounding changes in health might affect (1) the finding that payday filling decreases when recipients enroll in more-generous coverage (Section 3.2) and (2) the finding that those who are most liquidity sensitive respond most to lower copayments (Section 3.3). Figure B1 suggests several approaches to determine the extent to which any confounding from contemporaneous health shocks is problematic for those results. 
Appendix Figure B1. Event-Study Estimates of the Effect of Switching Copay Groups on the Number of Inpatient Stays

\section{(a) Copay Group to}

No-Copay Group

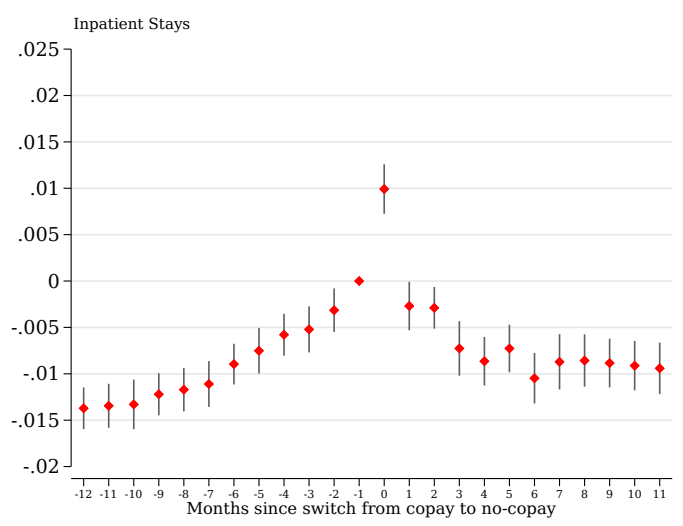

(c) Full-Copay Group to the

Subsidized-Copay Group

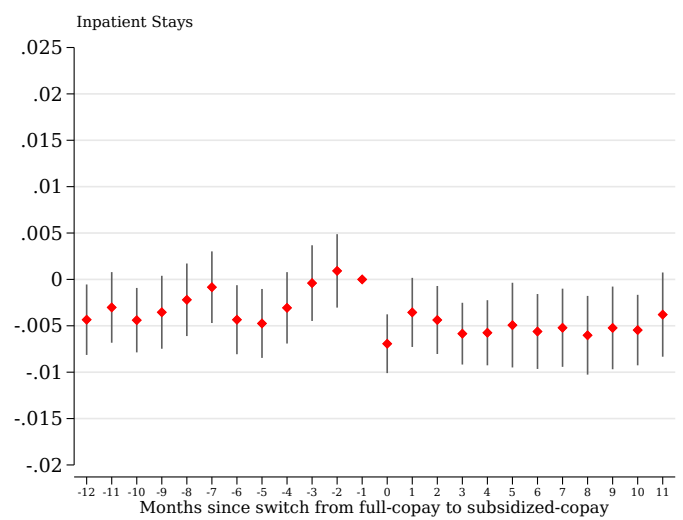

(b) No-Copay Group to Copay Group

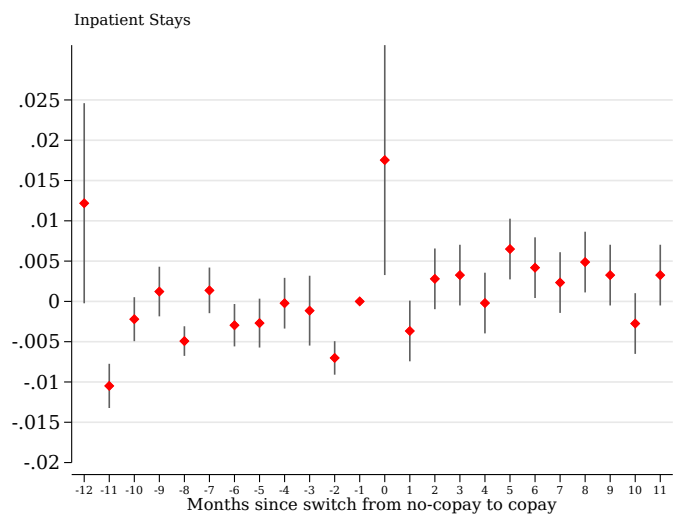

(d) Subsidized-Copay Group to Full-Copay Group

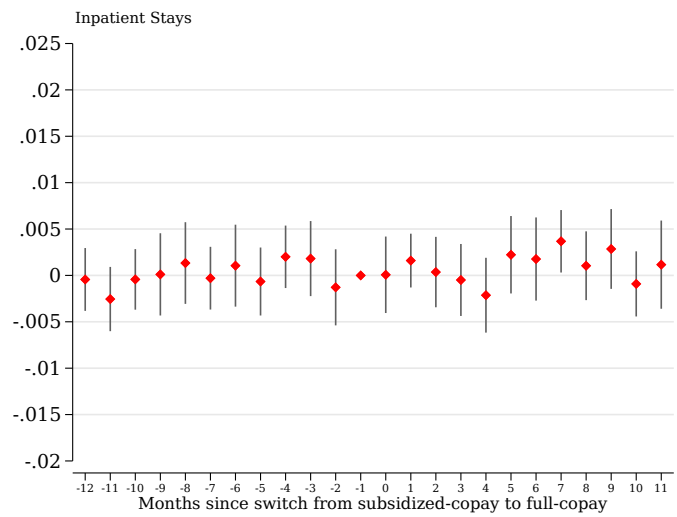

These figures present event-study estimates of the impact of switching on the number of inpatient stays. Panel (a) presents estimates for recipients who switch from either the full-copay or the subsidized-copay to the no-copay group. Panel (b) presents estimates for recipients who switch from the no-copay group to the subsidized-copay group or the full-copay group. Panel (c) presents estimates for recipients who switch from the full-copay group to the subsidizedcopay group. Panel (d) presents estimates for recipients who switch from the subsidized-copay group to the full-copay group. Standard errors clustered on cohort of recipients transitioning copay groups. For more details, see Section 3.2.

"Reverse" Transitions. Section 3 presents a first approach. It studies transitions not only onto the no-copayment group but also from the no-copayment group. Reassuringly, both transitions lead to roughly similar estimates for the elasticity of 
demand (Table 2).

That pattern is reassuring because transitions out of the no-copayment group are less likely to be confounded by time-varying changes in health. Appendix Figure B1 suggests only a short-lived, noisy increase in hospitalizations around those transitions. Moreover, such transitions are more likely to be driven by administrative processes rather than individual decisions. "Reverse" transitions out of the LIS program and out of Medicaid are determined by bureaucratic "eligibility re-determination" processes, involving updates to SSA records and the failure of recipients to submit redetermination paperwork. It is possible that healthier recipients are more likely to complete such paperwork, but the timing of removal from the program would still be exogenous. It is also possible that both eligibility and health are affected by a positive income shock; however, it would take several months, possibly even a full year, before such an income shock would result in removal from the LIS or Medicaid programs. The fact that the elasticities are similar in both directions suggests that any confounding from health shocks for the transitions to the no-copayment group are unlikely to be particularly important for patterns of recipient drug consumption.

Appendix Figure B2. The Share of Recipients Filling Scripts on Payday Before and After Changes in Generosity, Omitting Recipients with Hospitalizations within 5 Months of Transition

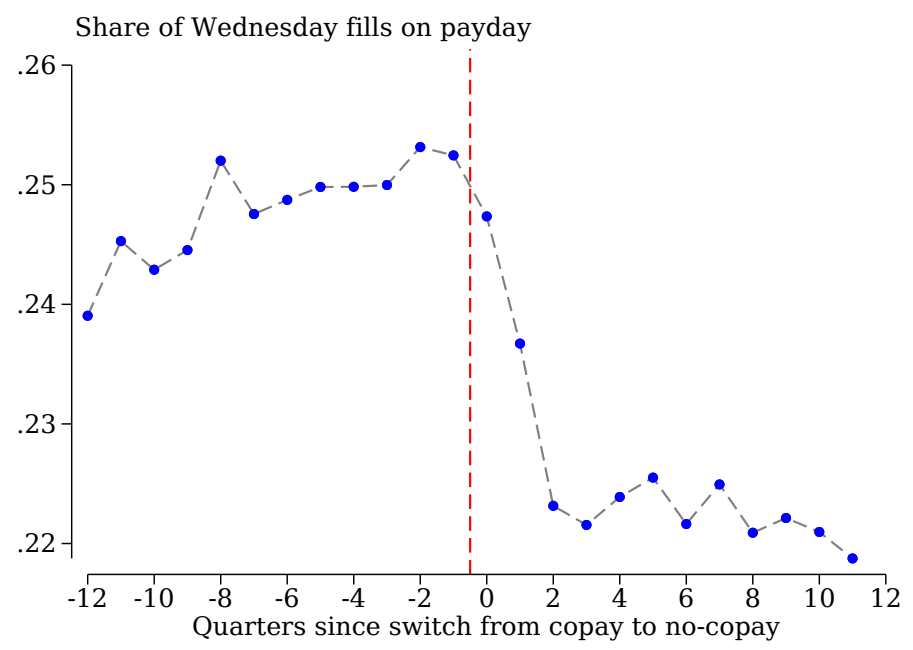

This figure plots the share of Wednesday prescription fills that fall on Social Security payday for each month relative to the month that recipients switched copay groups. The estimates are for recipients who switch from either the full-copay or subsidized-copay group to the no-copay group. The sample excludes recipients with hospitalizations within 2 months before and after the switch. For more details, see Section 3.2. 
Appendix Figure B3. Comparison of Elasticities Across Recipients' Propensity to Fill on Social Security Paydays, Beneficiaries with no Hospitalizations

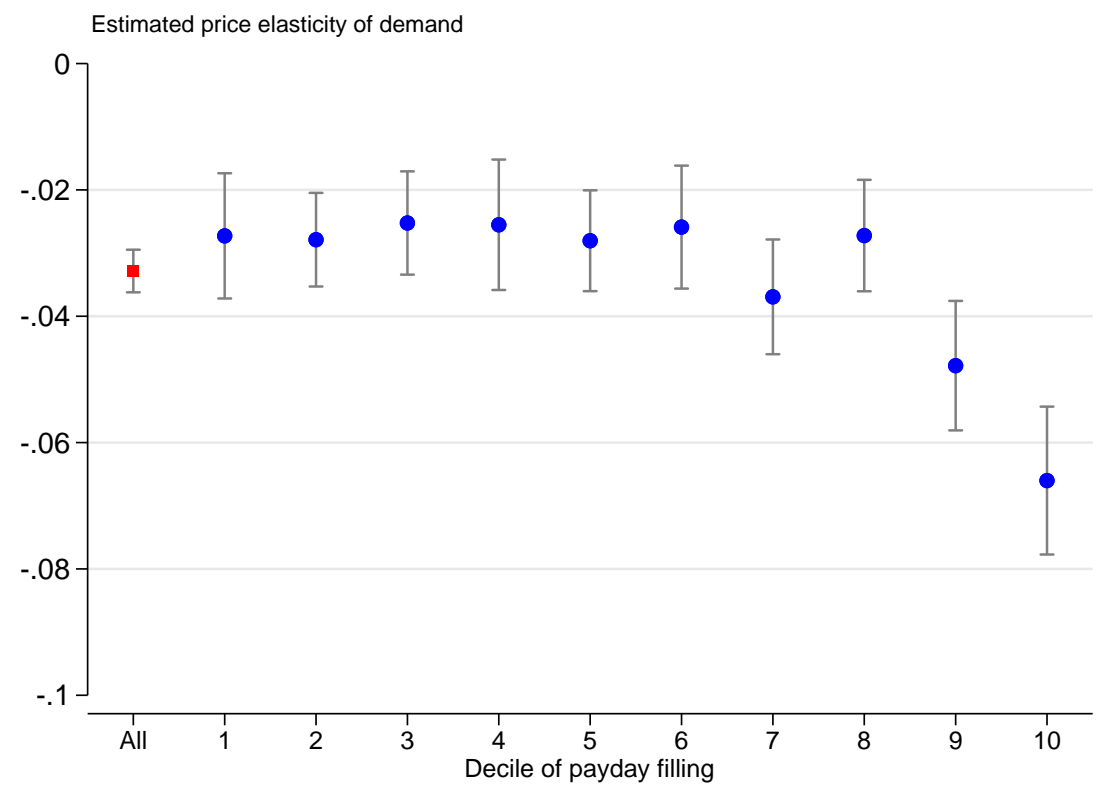

This figure presents estimated price elasticities of demand when recipients are divided into deciles based on the proportion of their Wednesday prescription fills that fall on their Social Security payday. The sample is restricted to recipients who switch from either the full-copay group or the subsidized-copay group to the no-copay group one year before and after their switch. The sample also excludes beneficiaries with hospitalizations within 2 months before and after the switch. These coefficients come from estimating an individual-level version of equation (2).Standard errors are based on the delta method. For more details, see Section 3.3.

Drop recipients with Hospitalizations. A second approach is to re-estimate our main regressions after eliminating from the sample those who experience a hospitalization within five months of the transition. Appendix Table B1 presents regression estimates based on the transition from groups that face copayments to the no-copayment group, and vice-versa. Further, Appendix Figures B2 and B3 present versions of Figures 9 and 10 for this restricted sample. The patterns that appear in the main text also exist for that restricted sample.

\section{Transitions from the Full-Copayment Group to the Subsidized-Copayment}

Group. Finally, a third approach is to study a different transition altogether. Appendix Figure B1 suggests little change in hospitalizations when recipients transition from the full-copay group to the subsidized-copay group, or vice-versa. We thus study that transition next. 
Appendix Table B2 presents estimates of equation (2) for recipients who transition between the full-copay group and the subsidized-copay group. The elasticity estimated from transitions onto the subsidized-copay group is -0.092 and the elasticity estimated from transitions out of the subsidized-copay group is -0.138 . Both are larger than the elasticities we estimated using transitions to and from the no-copay group.

Appendix Table B1. Effect of Changes in Generosity of Coverage, Omitting Recipients with Hospitalizations within 5 Months of Transition

\begin{tabular}{llc}
\hline \multicolumn{1}{c}{$(1)$} & \multicolumn{1}{c}{$(2)$} & $(3)$ \\
Log Total & Log Out-of & Elasticity \\
Scripts & -Pocket & \\
\hline
\end{tabular}

\begin{tabular}{lccc}
\multicolumn{4}{c}{ A. Switch from Copay to No-Copay } \\
Post & $0.0660^{* * *}$ & $-1.2516^{* * *}$ & $-0.0528^{* * *}$ \\
Transition & $(0.0028)$ & $(0.0092)$ & $(0.0022)$ \\
& & & \\
Mean & 2.82 & 6.67 & \\
$N$ & 990,360 & 990,360 & 990,360
\end{tabular}

B. Switch from No-Copay to Copay

$\begin{array}{lccc}\text { Post } & -0.0652^{* * *} & 1.2773^{* * *} & -0.0510^{* * *} \\ \text { Transition } & (0.0038) & (0.0142) & (0.0024) \\ & & & \\ \text { Mean } & 3.55 & 0.00 & \\ N & 540,216 & 540,216 & 540,216\end{array}$

This table presents estimates of the impact of switching to the no-copay group from the copay groups (top panel) and vice versa (bottom panel) on the outcomes listed. Standard errors in parentheses clustered on cohort of recipients transitioning copay groups for the first two columns. Standard errors are based on the delta method for the elasticity estimation in the third column. The data is limited to 12 months before and 12 months after the switch. The sample also excludes beneficiaries with hospitalizations within 2 months before and after the switch. Recipient-specific fixed effects and year-times-month-specific fixed effects not shown. These coefficients come from estimating equation (2). The means presented presented are the means of the given dependent variable one month before the transition across copayment groups. For more details, see Section 3.2. ${ }^{*} p<0.1,{ }^{* *} p<0.05,{ }^{* * *} p<0.01$ 
Appendix Table B2. Effect of Changes in Generosity of Coverage - 12 Months Before/After Transition, Transitions between Full and Subsidizied Copayment Groups

\begin{tabular}{lccc}
\hline & $\begin{array}{c}(1) \\
\text { Log Total } \\
\text { Scripts }\end{array}$ & $\begin{array}{c}\text { Log Out-of } \\
\text {-Pocket }\end{array}$ & $\begin{array}{c}(3) \\
\text { Elasticity }\end{array}$ \\
\hline \multicolumn{4}{c}{ A. Switch from Full-Copay to Subsidized-Copay } \\
Post & $0.0613^{* * *}$ & $-0.6702^{* * *}$ & $-0.0915^{* * *}$ \\
Transition & $(0.0042)$ & $(0.0084)$ & $(0.0066)$ \\
Mean & 3.18 & 14.13 & \\
$N$ & 332,112 & 332,112 & 332,112 \\
B. Switch from Subsidized-Copay to & Full-Copay \\
Post & $-0.0719^{* * *}$ & $0.5204^{* * *}$ & $-0.1382^{* * *}$ \\
Transition & $(0.0068)$ & $(0.0173)$ & $(0.0132)$ \\
& & & \\
Mean & 3.32 & 3.78 & 284,472 \\
$N$ & 284,472 & 284,472 & 28
\end{tabular}

This table presents estimates of the impact of switching to the subsidized-copay group from the full-copay group (top panel) and vice versa (bottom panel) on the outcomes listed. The data is limited to 12 months before and 12 months after the switch. Standard errors in parentheses clustered on cohort of recipients transitioning copay groups for the first two columns. Standard errors are based on the delta method for the elasticity estimation in the third column. Recipientspecific fixed effects and year-times-month-specific fixed effects not shown. These coefficients come from estimating Equation (2). The means presented presented are the means of the given dependent variable one month before the transition across copayment groups. For more details, see Section 3.2. ${ }^{*} p<0.1,{ }^{* *} p<0.05,{ }^{* * *} p<0.01$

Appendix Figure B4 presents a version of Figure 10 for recipients who transition from the full-copay group to the subsidized-copay group. The figure suggests the same pattern as in the main text: liquidity-sensitive recipients exhibit the greatest price sensitivity.

All of these exercises suggest that the findings in Section 3 are not driven by confounding factors. We find similar price elasticities of demand when we study transitions either into or out of the no-copayment group. We find similar patterns when we restrict the sample to recipients who were not hospitalized. And we reach 
similar conclusions when we study transitions that are not accompanied by changes in hospitalization rates: the transitions between the subsidized-copay group and the full-copay group.

Appendix Figure B4. Comparison of Elasticities Across Recipients' Propensity to Fill on Social Security Paydays, Transitions between Full and Subsidized Copayment Groups

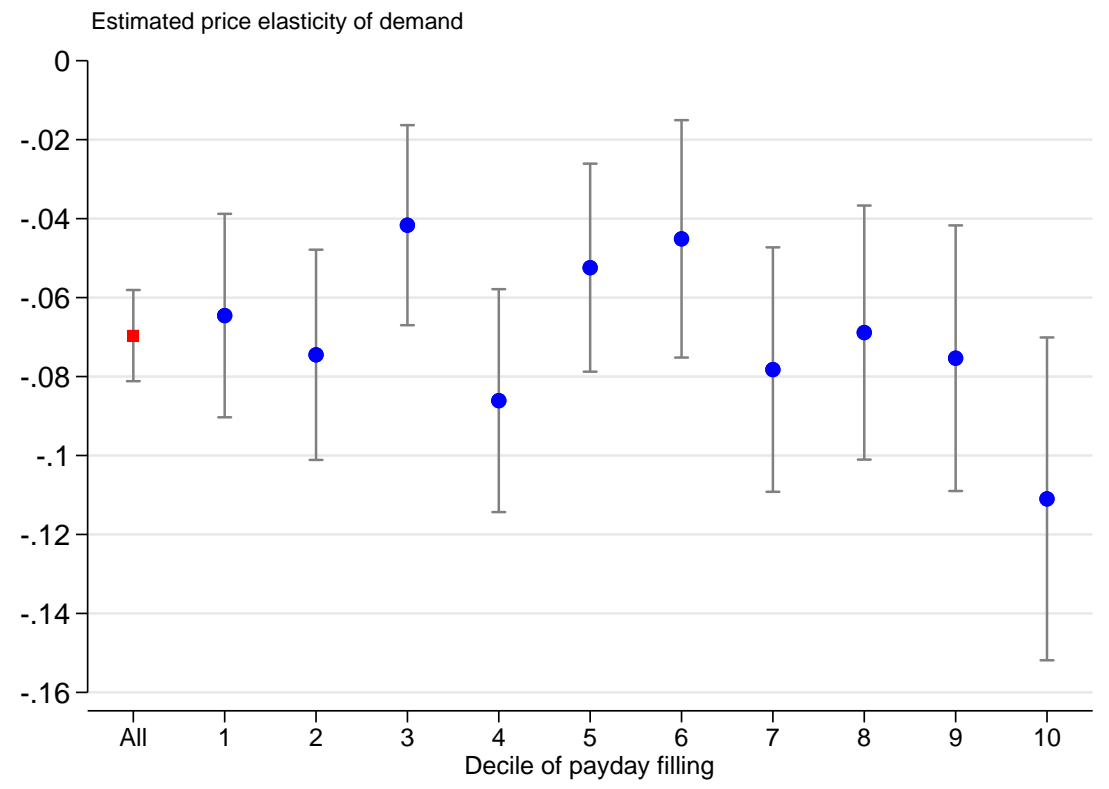

This figure presents estimated price elasticities of demand when recipients are divided into deciles based on the proportion of their Wednesday prescription fills that fall on their Social Security payday. The sample is restricted to recipients who switch from the full-copay group to the subsidized-copay group one year before and after their switch. These coefficients come from estimating an individual-level version of equation (2). Standard errors are based on the delta method. For more details, see Section 3.3.

\section{B.2 Disaggregating Transitions to the No-copayment Group}

Section 3.3 shows that the recipients who exhibit the most liquidity sensitivity prior to their transition to the no-copayment group have elasticities around two-times the size of other recipients. One explanation for this result is that the recipients in the top decile of our measure of liquidity sensitivity are disproportionately more likely (relative to other recipients) to come from the full-copayment group, and elasticities are larger when a recipient experiences a larger price change. To address that concern, we present versions of Figure 10 separately for recipients transitioning to the nocopayment group from the full-copayment group and recipients transitioning to the 
no-copayment group from the subsidized-copayment group. Appendix Figures A2 and A3 present those estimates. The figures suggest the same pattern as in the main text: the recipients in the top decile of liquidity sensitivity have an elasticity that is around twice as large as the elasticity for other recipients.

\section{B.3 Changes in Premiums When Transitioning Across Copayment Groups}

Section 3 focuses on transitions between the copayment groups and the no-copayment group. One complication is that some of those transitions involve a change in not only copayments, but also premiums. The subsidized-copayment group pays no premiums for Medicare Part D, whereas the full-copayment group pays a small premium. In order to assess the degree to which the change in premiums affects the results, we study recipients who switch from the most-generous subsidized-copayment group to the no-copayment group. That transition involves a reduction in copayments but no change in premiums.

Appendix Table B3. Effect of the Switch from the Most-Generous Subsidized-Copay Group to the No-Copay Group - 12 Months Before/After Transition

\begin{tabular}{lccc}
\hline & $\begin{array}{c}(1) \\
\text { Log Total } \\
\text { Scripts }\end{array}$ & $\begin{array}{l}\text { Log Out-of } \\
\text {-Pocket }\end{array}$ & $\begin{array}{c}(3) \\
\text { Elasticity }\end{array}$ \\
\hline Post & $\begin{array}{ccc}0.0685^{* * *} \\
(0.0226)\end{array}$ & $\begin{array}{c}-1.1097^{* * *} \\
(0.0489)\end{array}$ & $\begin{array}{c}-0.0618^{* * *} \\
(0.0209)\end{array}$ \\
Transition & 3.22 & 5.88 & \\
Mean & 5,208 & 5,208 & 5,208 \\
$N$ &
\end{tabular}

This table presents estimates of the impact of switching to the no-copay group from the lowest subsidized-copay group. The data is limited to 12 months before and 12 months after the switch. Standard errors in parentheses clustered on cohort of recipients transitioning copay groups for the first two columns. Standard errors are based on the delta method for the elasticity estimation in the third column. For the first two columns, the natural logarithm of one plus the given dependent variable is the outcome of interest. Recipient-specific fixed effects and year-times-month-specific fixed effects not shown. These coefficients come from estimating equation (2). The means listed are the mean of the given dependent variable one month before the transition across copayment groups. Each observation consists of a person-calendar-month. For more details, see Section 3.2. ${ }^{*} p<0.1,{ }^{* *} p<0.05,{ }^{* * *} p<0.01$

Table B3 presents estimates of equation (2) when applied to that transition. The 
estimates suggest a price elasticity of demand that is similar to what is presented in the main text. We thus conclude that the potential income effect from changes in premiums has relatively little impact on the main results, and that instead the effect of changes in copayments dominates. 


\section{Appendix: The Two Subsidized-Copayment Groups}

For simplicity, this paper describes Medicare Part D recipients as being comprised of three groups: those who face no copayments, those who face subsidized copayments, and those who face full copayments. There are two complications. First, there exists an additional group of recipients who pay zero copayments and zero premiums. This group consists of Medicaid-Medicare-enrolled individuals who are institutionalized. For this group, copayments are fully paid by the Medicare program rather than the Medicaid program. We exclude those recipients from the analysis sample, since they are institutionalized and thus have limited discretion over the timing of their prescription-drug fills.

A second complication is that the subsidized-copayment group actually consists of two sub-categories. First there are the lowest-income recipients, who face extremely low copayments. In 2015 , those recipients were charged $\$ 2.65$ copays for generic drugs and $\$ 6.60$ copays for branded drugs. Second, there are slightly higher-income recipients who face smaller subsidies. Also in 2015, those recipients face an average out-of-pocket price of scripts of roughly $\$ 7.31$, compared to an average of $\$ 2.74$ for recipients in the "lowest-income subsidized-copayment group."

The main text combines these two sub-groups into one for the sake of simplicity. Nevertheless, we can estimate the effect of Social Security checks for both of these sub-groups separately. Appendix Table $\mathrm{C} 1$ presents summary statistics for these two sub-groups. Appendix Figure $\mathrm{C} 1$ presents estimates of $\beta_{0}$ from equation (1) estimated separately for these two groups. Both sub-groups exhibit statistically significant effects of Social Security checks. The effects are largest for the higher-income sub-group: total prescriptions purchased increases by over 13 percent on Social Security check days for that group. That pattern is unsurprising for two reasons. First, despite having higher income, that sub-group still has very low income relative to the general population. Second, that sub-group faces higher copayments than the other subgroup. 
Appendix Table C1. Summary Statistics for the Two Subsidized-Copayment SubGroups

\begin{tabular}{|c|c|c|}
\hline & $\begin{array}{l}\text { Lowest-income, } \\
\text { Subsidized copay }\end{array}$ & $\begin{array}{l}\text { Higher-income, } \\
\text { Subsidized copay }\end{array}$ \\
\hline $\begin{array}{l}\text { Number of beneficiaries } \\
\text { in } 20 \% \text { sample in } 2006\end{array}$ & 14,006 & 6,299 \\
\hline $\begin{array}{l}\text { Number of beneficiaries } \\
\text { in } 20 \% \text { sample in } 2015\end{array}$ & 102,406 & 41,373 \\
\hline $\begin{array}{l}\text { Mean total scripts } \\
\text { per year }\end{array}$ & 43.23 & 46.06 \\
\hline $\begin{array}{l}\text { Mean out-of-pocket } \\
\text { spending per year }\end{array}$ & $\$ 124.49$ & $\$ 320.24$ \\
\hline $\begin{array}{l}\text { Mean out-of-pocket } \\
\text { spending per script }\end{array}$ & $\$ 3.04$ & $\$ 7.71$ \\
\hline $\begin{array}{l}\text { Mean share filling } \\
\text { a script each day }\end{array}$ & 0.056 & 0.064 \\
\hline Share male & 0.400 & 0.373 \\
\hline Average age & 70.21 & 70.58 \\
\hline $\begin{array}{l}\text { Average number of } \\
\text { chronic conditions }\end{array}$ & 3.93 & 4.14 \\
\hline Share white & 0.660 & 0.776 \\
\hline
\end{tabular}

This table presents summary statistics for the two sub-groups that receive subsidized copayments. For more details, see Appendix C. 


\section{Appendix Figure C1. Changes in Scripts Filled by Group and Wait}

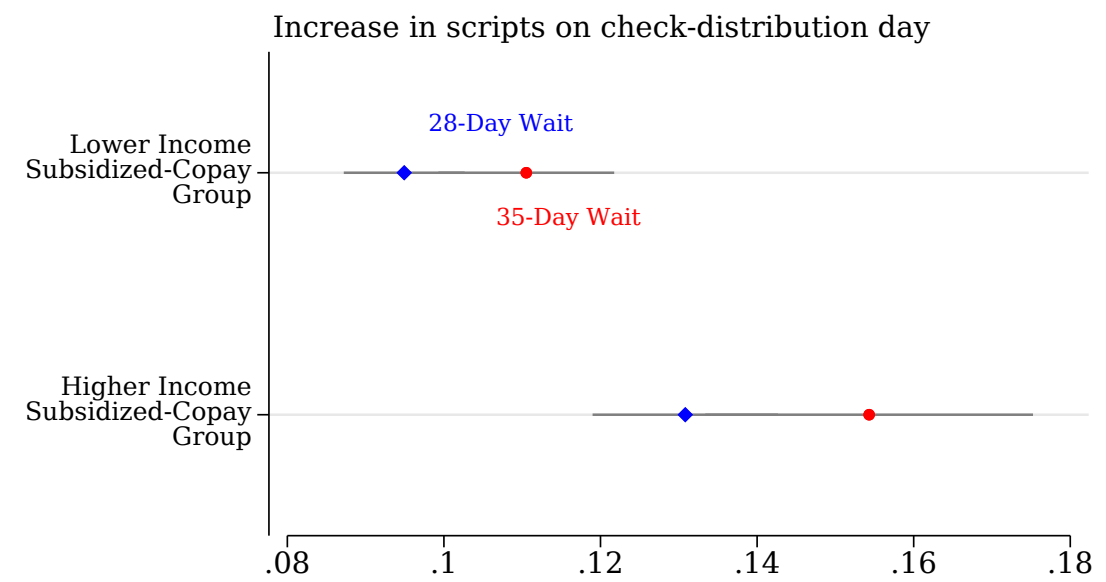

This figure presents the estimated event-study coefficient for check-distribution day when the outcome is the logarithm of the total scripts filled by the subsidized-copay group and by length of wait (28-day wait or 35-day wait). The horizontal lines along each marker plot 95-percent confidence intervals based on standard errors that are clustered at the level of the birthday group. These coefficients come from estimating equation (1). For more details, see Section 2.2. 


\section{Appendix: Robustness of Copayment Group Transition Results}

This section examines the robustness of the estimates from Section 3.1. The tables presented here offer alternate versions of Table 2 and alternative estimations of equation (2).

Table D1 extends our estimation sample to 24 months before and 24 months after transitions. As the top panel shows, the elasticity implied by transitions to the nocopayment group $(-0.067)$ is almost identical to the elasticity estimated with the narrower window presented in the main text $(-0.064)$. The bottom panel of Table D1 shows that the elasticity implied by transitions out of the no-copayment group with the longer time window $(-0.055)$ is also similar to the elasticity estimated with the narrower window $(-0.049)$. 
Appendix Table D1. Effect of Changes in Generosity of Coverage, 24 Months Before and After Transitions

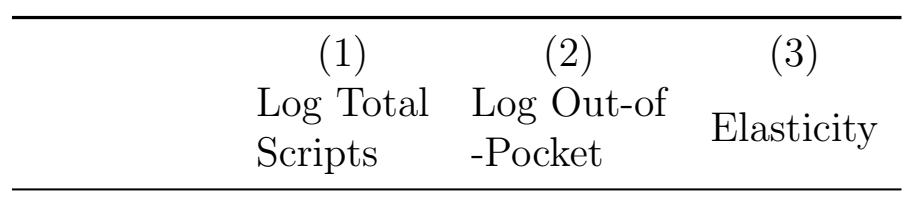

\begin{tabular}{|c|c|c|c|}
\hline \multicolumn{4}{|c|}{ A. Switch from Copay to No-Copay } \\
\hline $\begin{array}{l}\text { Post } \\
\text { Transition }\end{array}$ & $\begin{array}{c}0.0845^{* * *} \\
(0.0021)\end{array}$ & $\begin{array}{c}-1.2692^{\text {*** }} \\
(0.0079)\end{array}$ & $\begin{array}{c}-0.0666^{* * *} \\
(0.0018)\end{array}$ \\
\hline $\begin{array}{l}\text { Mean } \\
N\end{array}$ & $\begin{array}{c}2.97 \\
2,206,464\end{array}$ & $\begin{array}{c}6.76 \\
2,206,464\end{array}$ & $2,206,464$ \\
\hline \multicolumn{4}{|c|}{ B. Switch from No-Copay to Copay } \\
\hline $\begin{array}{l}\text { Post } \\
\text { Transition }\end{array}$ & $\begin{array}{c}-0.0723^{* * *} \\
(0.0030)\end{array}$ & $\begin{array}{c}1.3149^{* * *} \\
(0.0230)\end{array}$ & $\begin{array}{c}-0.0550^{* * *} \\
(0.0014)\end{array}$ \\
\hline $\begin{array}{l}\text { Mean } \\
N\end{array}$ & $\begin{array}{c}3.73 \\
1,158,528\end{array}$ & $\begin{array}{c}0.00 \\
1,158,528\end{array}$ & $1,158,528$ \\
\hline
\end{tabular}

This table presents estimates of the impact of switching to the no-copay group from the copay groups (top panel) and vice versa (bottom panel) on the outcomes listed. The data is limited to 24 months before and 24 months after the switch. Standard errors in parentheses clustered on cohort of recipients transitioning copay groups for the first two columns. Standard errors are based on the delta method for the elasticity estimation in the third column. Recipientspecific fixed effects and year-times-month-specific fixed effects not shown. These coefficients come from estimating equation (2). The means presented presented are the means of the given dependent variable one month before the transition across copayment groups. For more details, see Section 3.2. ${ }^{*} p<0.1,{ }^{* *} p<0.05,{ }^{* * *} p<0.01$

Table D2 adds a control group to the estimation. We expect recipients who never transition across copayment groups to be different from those who do. Thus, instead of using recipients who never transition as a control group, we use recipients who transition two years later. The top panel of the table suggests that this paper's main results are stable when a control group is introduced: the implied elasticity is -0.059 here versus -0.064 in Table 2 using full-to-subsidized transitions and -0.053 versus -0.049 in Table 2 using subsidized-to-full transitions. Results with a control group and with the longer time window around the transition are reported in Table D3. 
Appendix Table D2. Effect of Changes in Generosity of Coverage, 12 Months Before and After Transitions With Control Group

\begin{tabular}{|c|c|c|c|}
\hline & $\begin{array}{l}\quad(1) \\
\text { Log Total } \\
\text { Scripts }\end{array}$ & $\begin{array}{l}\quad(2) \\
\text { Log Out-of } \\
\text {-Pocket }\end{array}$ & $\begin{array}{c}\text { (3) } \\
\text { Elasticity }\end{array}$ \\
\hline \multicolumn{4}{|c|}{ A. Switch from Copay to No-Copay } \\
\hline $\begin{array}{l}\text { Post } \\
\text { Transition }\end{array}$ & $\begin{array}{c}0.0769^{* * *} \\
(0.0028)\end{array}$ & $\begin{array}{c}-1.2975^{* * *} \\
(0.0101)\end{array}$ & $\begin{array}{c}-0.0593^{* * *} \\
(0.0022))\end{array}$ \\
\hline $\begin{array}{l}\text { Mean } \\
N\end{array}$ & $\begin{array}{c}3.00 \\
1,911,063\end{array}$ & $\begin{array}{c}6.98 \\
1,911,063\end{array}$ & $1,911,063$ \\
\hline \multicolumn{4}{|c|}{ B. Switch from No-Copay to Copay } \\
\hline $\begin{array}{l}\text { Post } \\
\text { Transition }\end{array}$ & $\begin{array}{c}-0.0718^{* * *} \\
(0.0044)\end{array}$ & $\begin{array}{c}1.3409^{* * *} \\
(0.0260)\end{array}$ & $\begin{array}{c}-0.0536^{* * *} \\
(0.0028)\end{array}$ \\
\hline $\begin{array}{l}\text { Mean } \\
N\end{array}$ & $\begin{array}{c}3.74 \\
775,020\end{array}$ & $\begin{array}{c}0.00 \\
775,020\end{array}$ & 775,020 \\
\hline
\end{tabular}

This table presents estimates of the impact of switching from the subsidized-copay group or the full-copay group to the no-copay group (top panel) and vice versa (bottom panel) on the outcomes listed. The data includes a control group of switchers two-years before their switch.The data is limited to 12 months before and 12 months after the switch. Standard errors in parentheses clustered on cohort of recipients transitioning copay groups for the first two columns. Standard errors are based on the delta method for the elasticity estimation in the third column. Recipient-specific fixed effects and year-times-month-specific fixed effects not shown. These coefficients come from estimating Equation (2). The means presented presented are the means of the given dependent variable one month before the transition across copayment groups. For more details, see Section 3.2. ${ }^{*} p<0.1,{ }^{* *} p<0.05,{ }^{* * *} p<0.01$ 
Appendix Table D3. Effect of Changes in Generosity of Coverage, 24 Months Before and After Transitions with Control Group

\begin{tabular}{ccc}
\hline & $(1)$ & $(2)$ \\
Log Total & Log Out-of \\
Scripts & -Pocket & Elasticity \\
\hline
\end{tabular}

\begin{tabular}{|c|c|c|c|}
\hline \multicolumn{4}{|c|}{ A. Switch from Copay to No-Copay } \\
\hline $\begin{array}{l}\text { Post } \\
\text { Transition }\end{array}$ & $\begin{array}{c}0.0870^{* * *} \\
(0.0024)\end{array}$ & $\begin{array}{c}-1.2844^{* * *} \\
(0.0119)\end{array}$ & $\begin{array}{c}-0.0677^{* * *} \\
(0.0020)\end{array}$ \\
\hline $\begin{array}{l}\text { Mean } \\
N\end{array}$ & $\begin{array}{c}2.96 \\
2,813,598\end{array}$ & $\begin{array}{c}6.76 \\
2,813,598\end{array}$ & $2,813,598$ \\
\hline \multicolumn{4}{|c|}{ B. Switch from No-Copay to Copay } \\
\hline $\begin{array}{l}\text { Post } \\
\text { Transition }\end{array}$ & $\begin{array}{c}-0.0703^{* * *} \\
(0.0038)\end{array}$ & $\begin{array}{c}1.3437^{* * *} \\
(0.0207)\end{array}$ & $\begin{array}{c}-0.0523^{* * *} \\
(0.0023)\end{array}$ \\
\hline $\begin{array}{l}\text { Mean } \\
N\end{array}$ & $\begin{array}{c}3.74 \\
1,354,702\end{array}$ & $\begin{array}{c}0.00 \\
1,354,702\end{array}$ & $1,354,702$ \\
\hline
\end{tabular}

This table presents estimates of the impact of switching from the subsidized-copay group or the full-copay group to the no-copay group (top panel) and vice versa (bottom panel) on the outcomes listed. The data includes a control group of switchers two-years before their switch. The data is limited to 24 months before and 24 months after the switch. Standard errors in parentheses clustered on cohort of recipients transitioning copay groups for the first two columns. Standard errors are based on the delta method for the elasticity estimation in the third column. Recipient-specific fixed effects and year-times-month-specific fixed effects not shown. These coefficients come from estimating Equation (2). The means presented presented are the means of the given dependent variable one month before the transition across copayment groups. For more details, see Section 3.2. ${ }^{*} p<0.1,{ }^{* *} p<0.05,{ }^{* * *} p<0.01$

Finally, motivated by the trend observed in the second panel of Figure 7, Appendix Table D4 adds time trends with different slopes before and after the transitions. The top panel suggests that the implied elasticity is somewhat smaller, -0.033 versus -0.067 in Table 2 for transitions into the no-copayment group and somewhat larger, -0.077 versus -0.049 for transitions out of the no-copayment group. Table D5 presents results with a time trend but the larger window of 2 years before and after the transition, showing elasticities very close to those in the main text. 
Appendix Table D4. Effect of Changes in Generosity of Coverage, 12 Months Before and After Transitions With Time Trend

\begin{tabular}{llc}
\hline \multicolumn{1}{c}{$(1)$} & \multicolumn{1}{c}{$(2)$} & $(3)$ \\
Log Total & Log Out-of & Elasticity \\
Scripts & -Pocket & \\
\hline
\end{tabular}

\begin{tabular}{|c|c|c|c|}
\hline \multicolumn{4}{|c|}{ A. Switch from Copay to No-Copay } \\
\hline $\begin{array}{l}\text { Post } \\
\text { Transition }\end{array}$ & $\begin{array}{c}0.0407^{* * *} \\
(0.0023)\end{array}$ & $\begin{array}{c}-1.2520^{* * *} \\
(0.0081)\end{array}$ & $\begin{array}{c}-0.0325^{* * *} \\
(0.0019)\end{array}$ \\
\hline Mean & 2.97 & 6.76 & \\
\hline$N$ & $1,103,232$ & $1,103,232$ & $1,103,232$ \\
\hline \multicolumn{4}{|c|}{ B. Switch from No-Copay to Copay } \\
\hline $\begin{array}{l}\text { Post } \\
\text { Transition }\end{array}$ & $\begin{array}{c}-0.3236^{* * *} \\
(0.0531)\end{array}$ & $\begin{array}{c}4.1856^{* * *} \\
(0.0975)\end{array}$ & $\begin{array}{c}-0.0773^{* * *} \\
(0.0109)\end{array}$ \\
\hline Mea & 3.73 & 0.00 & \\
\hline & 579,264 & 579,264 & 579,264 \\
\hline
\end{tabular}

This table presents estimates of the impact of switching from the subsidized-copay group or the full-copay group to the no-copay group (top panel) and vice versa (bottom panel) on the outcomes listed. The data is limited to 12 months before and 12 months after the switch. Standard errors in parentheses clustered on cohort of recipients transitioning copay groups for the first two columns. Standard errors are based on the delta method for the elasticity estimation in the third column. Includes calendar time interacted with switcher cohort fixed effect controls. Recipient-specific fixed effects and year-times-month-specific fixed effects not shown. These coefficients come from estimating Equation (2). The means presented presented are the means of the given dependent variable one month before the transition across copayment groups. For more details, see Section 3.2. ${ }^{*} p<0.1,{ }^{* *} p<0.05,{ }^{* * *} p<0.01$ 
Appendix Table D5. Effect of Changes in Generosity of Coverage, 24 Months Before and After Transitions with Time Trend

\begin{tabular}{|c|c|c|c|}
\hline & $\begin{array}{l}\quad(1) \\
\text { Log Total } \\
\text { Scripts }\end{array}$ & $\begin{array}{l}\quad(2) \\
\text { Log Out-of } \\
\text {-Pocket }\end{array}$ & $\begin{array}{c}\text { (3) } \\
\text { Elasticity }\end{array}$ \\
\hline \multicolumn{4}{|c|}{ A. Switch from Copay to No-Copay } \\
\hline $\begin{array}{l}\text { Post } \\
\text { Transition }\end{array}$ & $\begin{array}{c}0.0605^{* * *} \\
(0.0019)\end{array}$ & $\begin{array}{c}-1.2631^{* * *} \\
(0.0079)\end{array}$ & $\begin{array}{c}-0.0479^{* * *} \\
(0.0016)\end{array}$ \\
\hline $\begin{array}{l}\text { Mean } \\
N\end{array}$ & $\begin{array}{c}2.97 \\
2,206,464\end{array}$ & $\begin{array}{c}6.76 \\
2,206,464\end{array}$ & $2,206,464$ \\
\hline \multicolumn{4}{|c|}{ B. Switch from No-Copay to Copay } \\
\hline $\begin{array}{l}\text { Post } \\
\text { Transition }\end{array}$ & $\begin{array}{c}-0.0802^{* * *} \\
(0.0033)\end{array}$ & $\begin{array}{c}1.3341^{* * *} \\
(0.0217)\end{array}$ & $\begin{array}{c}-0.0602^{* * *} \\
(0.0015)\end{array}$ \\
\hline $\begin{array}{l}\text { Mean } \\
N\end{array}$ & $\begin{array}{c}3.73 \\
1,158,528\end{array}$ & $\begin{array}{c}0.00 \\
1,158,528\end{array}$ & $1,158,528$ \\
\hline
\end{tabular}

This table presents estimates of the impact of switching from the subsidized-copay group or the full-copay group to the no-copay group (top panel) and vice versa (bottom panel) on the outcomes listed. The data is limited to 24 months before and 24 months after the switch.Standard errors in parentheses clustered on cohort of recipients transitioning copay groups for the first two columns. Standard errors are based on the delta method for the elasticity estimation in the third column. Includes calendar time interacted with switcher cohort fixed effect controls. Recipient-specific fixed effects and year-times-month-specific fixed effects not shown. These coefficients come from estimating Equation (2). The means presented presented are the means of the given dependent variable one month before the transition across copayment groups. For more details, see Section 3.2. ${ }^{*} p<0.1,{ }^{* *} p<0.05,{ }^{* * *} p<0.01$ 


\section{E Appendix: Share of Wednesday Fills on Paydays as Signal of Liquidity Sensitivity}

Sections 3.2 and 3.3 focus on one particular proxy for liquidity sensitivity: the share of each recipient's Wednesday fills that occur on their Social Security payday. This section provides evidence that that proxy is indeed correlated with liquidity sensitivity.

Appendix Figure E1 plots estimated effects of Social Security checks by deciles of this proxy. We calculate the proxy for all years other than the year that we calculate the effect of Social Security checks. That approach prevents this exercise from falling into a circular logic, testing for an effect of Social Security checks by decile of the effect of those checks.

The figure suggests a clear relationship between the share of Wednesday fills that occur on payday and liquidity sensitivity. There is a positive association between payday filling and the share of Wednesday fills that occur on payday. For the subsidizedcopay group, recipients in the tenth decile exhibit an increase in scripts on Social Security paydays that is greater than 100 percent. For the full-copay group, those in the tenth decile exhibit a nearly 50-percent increase in fills. That pattern motivates our focus in Section 3 on this top decile of recipients as the "constrained" group.

There also exists a positive association for the no-copay group, but the association is much smaller than for the other groups. Moreover, the positive association for the no-copay group may be somewhat spurious in that it reflects underlying autocorrelation in the tendency for a recipient to fill their scripts on a given Wednesday of the month over time.

Finally, Figure E2 offers a placebo test: we plot payday effects by decile of the share of Wednesday fills that occur on the Wednesday before payday. Unlike Figure E1, this false proxy is not associated with payday effects. 


\section{Appendix Figure E1. Heterogeneous Effects Across Share Filling Deciles}

(a) Subsidized-Copay Group

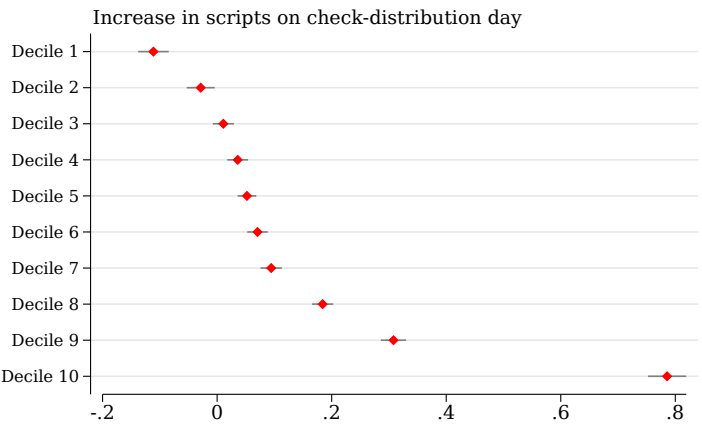

(b) Full-Copay Group

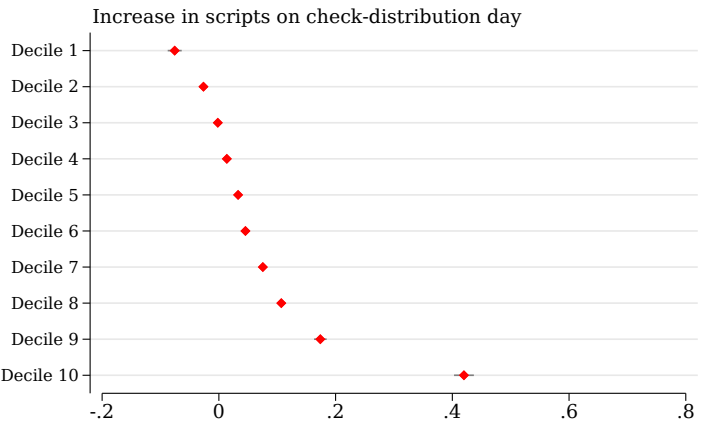

(c) No-Copay Group

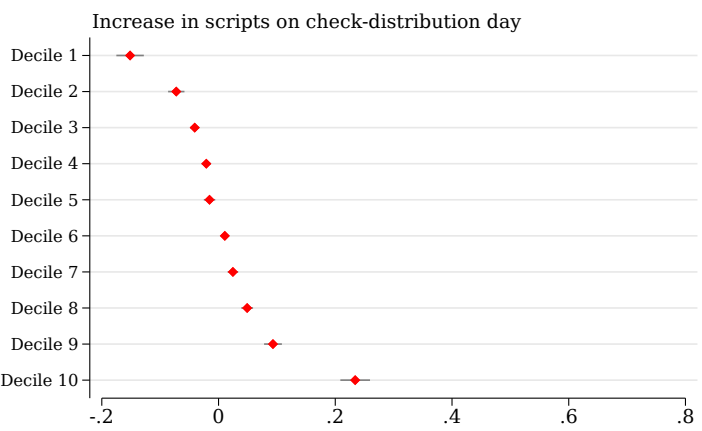

All panels plot estimated event-study coefficients on check-distribution day for the logarithm of total scripts filled by share of Wednesday fills that fall on payday. Panel (a) restricts to the subsidized-copay group. Panel (b) restricts to the full-copay group. Panel (c) restricts to the no-copay group. All coefficients come from estimating Equation (1). The horizontal lines through each marker plot 95-percent confidence intervals based on standard errors that are clustered at the level of the birthday group. For more details, see Section 2.2. 


\section{Appendix Figure E2. Falsification Test: Effects Across Psuedo-Share Filling Deciles}

(a) Subsidized-Copay Group

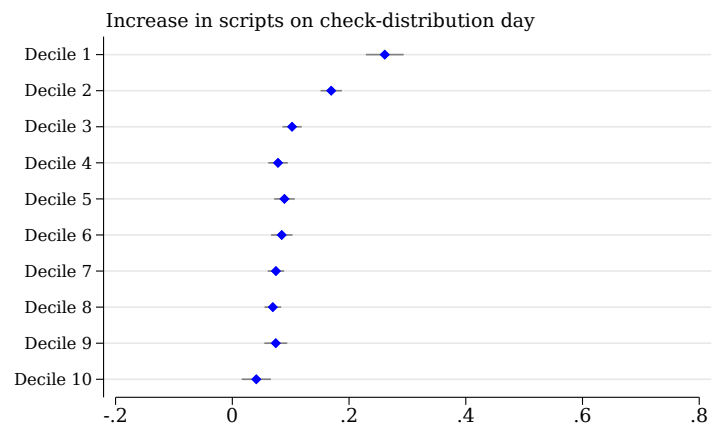

(b) Full-Copay Group

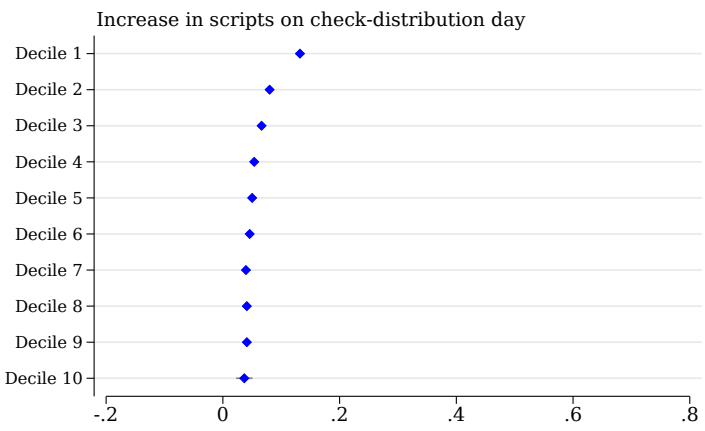

(c) No-Copay Group

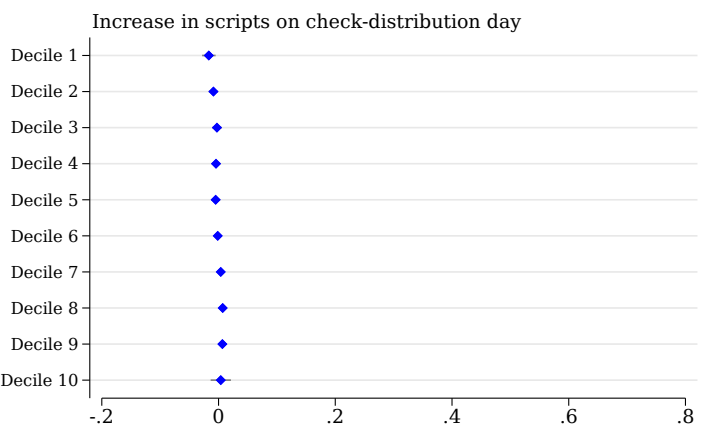

All panels plot estimated event-study coefficients on check-distribution day for the logarithm of total scripts filled by share of Wednesday fills that fall on Wednesday before payday. Panel (a) restricts to the subsidized-copay group. Panel (b) restricts to the full-copay group. Panel (c) restricts to the no-copay group. All coefficients come from estimating Equation (1). The horizontal lines through each marker plot 95-percent confidence intervals based on standard errors that are clustered at the level of the birthday group. For more details, see Section 2.2. 